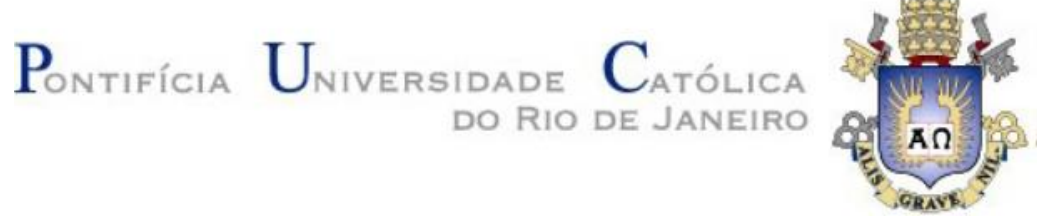

Rodrigo Neumann

Auto localização de robôs móveis por fusão
de sensores na presença de interferência
eletromagnética

Dissertação de Mestrado

Dissertação apresentada ao Programa de Pósgraduação em Engenharia Mecânica da PUC-Rio como requisito parcial para obtenção do grau de Mestre em Engenharia Mecânica.

Orientador: Prof. Marco Antonio Meggiolaro 
Rodrigo Neumann

\section{Auto localização de robôs móveis por fusão de sensores na presença de interferência eletromagnética}

Dissertação apresentada como requisito parcial para obtenção do grau de Mestre pelo Programa de Pósgraduação em Engenharia Mecânica do Centro Técnico Científico da PUC-Rio. Aprovada pela Comissão Examinadora abaixo assinada.

Prof. Marco Antonio Meggiolaro

Orientador

Departamento de Engenharia Mecânica - PUC-Rio

Prof. Mauro Speranza Neto Departamento de Engenharia Mecânica - PUC-Rio

Prof. Helon Vicente Hultmann Ayla Departamento de Engenharia Mecânica - PUC-Rio

Prof. Márcio da Silveira Carvalho Coordenador Setorial do Centro Técnico Científico - PUC-Rio

Rio de Janeiro 1 de outubro de 2018 
Todos os direitos reservados. É proibida a reprodução total ou parcial do trabalho sem autorização da universidade, do autor e do orientador.

\section{Rodrigo Neumann}

Graduou-se em Engenharia Mecânica na PUC-Rio (Pontifícia Universidade Católica do Rio de Janeiro) em 2015

Ficha Catalográfica

Neumann, Rodrigo
Auto localização de robôs móveis por fusão de
sensores na presença de interferência eletromagnética
Rodrigo Neumann ; orientador: Marco Antonio Meggiolaro.
2018.
103 f. ; 30 cm
Dissertação (mestrado)-Pontifícia Universidade
Católica do Rio de Janeiro, Departamento de Engenharia
Mecânica, 2018.
Inclui bibliografia
1. Engenharia Mecânica - Teses. 2. Robótica
móvel. 3. Auto-localização. 4. Fusão de sensores. 5. Rodas
magnéticas. 6. Robô de inspeção. I. Meggiolaro, Marco
Antonio. II. Pontifícia Universidade Católica do Rio de
Janeiro. Departamento de Engenharia Mecânica. Ill. Título.

CDD:621 


\section{Agradecimentos}

Primeiramente gostaria de agradecer a minha família por todo o suporte dado durante os anos de produção desta dissertação. Gostaria também de agradecer ao meu orientador, Marco Meggiolaro, pela orientação durante o desenvolvimento deste projeto. Aos amigos agradeço o apoio e paciência em momentos difíceis durante esse período e ao Laboratório de Robótica (LabRob) por disponibilizar o equipamento utilizado nos experimentos. O presente trabalho foi realizado com o apoio da Coordenação de Aperfeiçoamento Pessoal de Nível Superior (CAPES) - Código de Finaciamento 001. E ao programa de pósgraduação em Engenharia Mecânica da PUC-Rio pelo apoio institucional. 


\section{Resumo}

Neumann, Rodrigo; Meggiolaro, Marco Antonio. Auto localização de robôs móveis por fusão de sensores na presença de interferência eletromagnética. Rio de Janeiro, 2018. 103 p. Dissertação de Mestrado Departamento de Engenharia Mecânica. Pontifícia Universidade Católica do Rio de Janeiro.

A inspeção interna de tanques de armazenamento pode ser uma tarefa longa, custosa e até nociva à saúde do inspetor. Uma alternativa à inspeção humana é a utilização de sistemas robóticos. Esses sistemas podem ser teleoperados de fora dos tanques, permitindo realizar a inspeção de maneira mais segura, rápida, e em alguns casos, sem que seja necessário esvaziá-lo. Para poder fornecer a localização de eventuais defeitos no tanque, o robô móvel precisa ser capaz de conhecer sua posição relativa dentro dele. Auto-localização é de grande importância para a navegação de robôs móveis. Robôs de inspeção são, na sua maioria, veículos de rodas ou esteiras magnéticas fixas. Esta configuração adiciona duas dificuldades que precisam ser abordadas na tarefa de localização. Devido à sua configuração, neste tipo de veículo, deslizamento das rodas é intrínseco ao seu funcionamento, sendo essencial levar em conta seu efeito para modelar seu comportamento adequadamente. Outra dificuldade está no uso de rodas magnéticas, devido ao forte campo magnético gerado por estes elementos, que interferem nas medições de sensores magnéticos, como por exemplo bússolas. Neste trabalho, um filtro de Kalman foi desenvolvido e implementado para a localização de um robô de quatro rodas magnéticas fixas, a partir da fusão de sensores inerciais e odometria. $\mathrm{Na}$ modelagem do veículo, foi utilizado um modelo cinemático como base para um modelo dinâmico, o que permitiu considerar o deslizamento intrínseco do sistema. Na fusão de sensores, foram dispensadas as medições do magnetômetro embarcado, devido à grande interferência produzida pelas rodas e à grande distância que seria necessária entre eles para não ser afetado pelo ruído. Simulações e experimentos comprovaram a eficiência do filtro implementado.

\section{Palavras-chave}

Robótica móvel; auto-localização; fusão de sensores; rodas magnéticas; robô de inspeção. 


\section{Abstract}

Neumann, Rodrigo; Meggiolaro, Marco Antonio (Advisor). Self-localization of mobile robots through sensor fusion in the presence of electromagnetic interference. Rio de Janeiro, 2018. 103 p. Dissertação de Mestrado Departamento de Engenharia Mecânica. Pontifícia Universidade Católica do Rio de Janeiro.

Internal inspection of storage tanks can be long, costly and even detrimental to the health of the inspector. An alternative to human inspection is the use of robotic systems. These systems can be teleoperated from outside the tanks, making it possible to carry out the inspection more safely, quickly and in some cases without having to empty it. In order to provide the location of any defects in the tank, the mobile robot must be able to know its relative position within it. Selflocalization is of great importance for mobile robot navigation. Inspection robots are, for the most part, vehicles with wheels or tracks. This configuration adds two difficulties that need to be addressed in the localization task. Due to its configuration, in this type of vehicle, wheel slip is intrinsic to its operation, being essential to take into account its effect to model its behavior properly. Another difficulty is the use of magnetic wheels, due to the strong magnetic field generated by these elements, which interfere with the measurements of magnetic sensors, such as compasses. In this work, a Kalman filter was developed and implemented for the localization of a four-wheel fixed magnetic robot, from the fusion of inertial sensors and odometry. In the modeling of the vehicle, a kinematic model was used as the basis for a dynamic model, which allowed to consider the intrinsic slippage of the system. In the sensor fusion, measurements of the magnetometer on board were discarded, due to the great interference produced by the wheels and the great distance that would be necessary between them to be unaffected by noise. Simulations and experiments have proven the efficiency of the implemented filter.

\section{Keywords}

Mobile robotics; self-localization; sensor fusion; magnetic wheels; inspection robot. 


\section{Sumário}

1 Introdução 17

1.1. Robôs de Inspeção 21

1.2. Objetivo 26

1.3. Revisão bibliográfica 26

$\begin{array}{ll}\text { 1.4. Organização do Trabalho } & 27\end{array}$

2 Modelagem do Sistema $\quad 29$

2.1. Modelo cinemático 30

2.1.1. Cinemática Analítica 31

2.1.2. Cinemática pelo método do centro instantâneo de rotação-

(Experimental ICR kinematic method) 32

2.2. Modelo Dinâmico 35

3 Filtro de Kalman 38

3.1. Teoria do filtro de Kalman 38

3.2. Equacionamento sem bússola 41

3.3. Equacionamento com bússola 45

4 Sistema Experimental $\quad 49$

4.1. Veículo 49

4.2. Central Inercial 53

4.3. Calibração dos sensores

4.3.1. Encoders 55

4.3.2. IMU 56

4.3.3. Magnetômetro $\quad 59$

4.4. Redução da vibração na IMU 64

5 Simulações $\quad 71$

5.1. Parametrização do modelo do motor 71

5.2. Parametrização do modelo cinemático 75

5.3. Comparação com o modelo de acionamento diferencial 76

5.4. Simulação do sistema de localização 79 
6 Resultados experimentais $\quad 84$

6.1. Estrutura do sistema de localização 85

6.2. Testes em linha reta 86

6.3. Teste de manobra $\quad 87$

6.4. Testes com o sistema de bússola 91

7 Conclusões 98

7.1. Trabalhos Futuros 99

8 Referências Bibliográficas 101 


\section{Índice de Figuras}

Figura 1 - Tanque de Armazenamento (Sato, A. K., 2015)................................. 17

Figura 2 - Chaparia de fundo de tanque com problemas de corrosão .................... 18

Figura 3 - Robô GIRINO (Panta, P. E. G., 2005).............................................. 20

Figura 4 - Robô ambiental hibrido (Paranhos, P. M., 2009) ................................. 20

Figura 5 - Neptune (Schempf et al., 1995)..................................................... 21

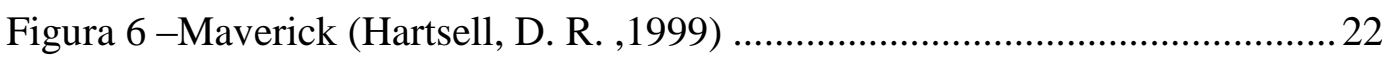

Figura 7 - Robô A.Hak Industrial Services’ InTank ............................................ 23

Figura 8 - Robô de inspeção (Sogi, T. ,2000) ...................................................... 24

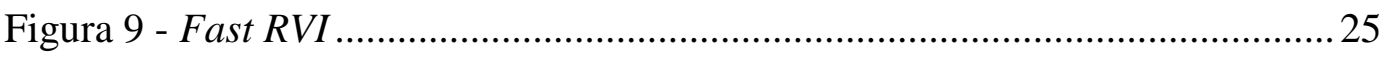

Figura 10 - Robô cedido para o trabalho (RITA) ……..........................................2 25

Figura 11 - Exemplos de veículos skid-steering ...............................................2 29

Figura 12 - Movimento de um veículo skid-steering, (Shamah, B. 1999).............. 30

Figura 13 - Velocidades nas rodas com/sem deslizamento .................................. 31

Figura 14 - Posições dos ICRs (Mandow, A. et al 2007) ..................................... 33

Figura 15- Diagrama do funcionamento do filtro de Kalman ............................... 41

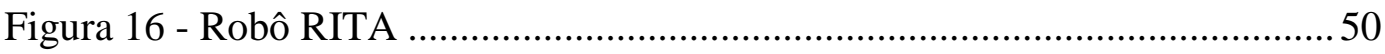

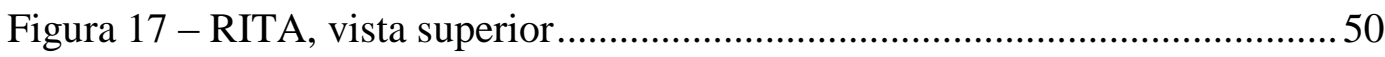

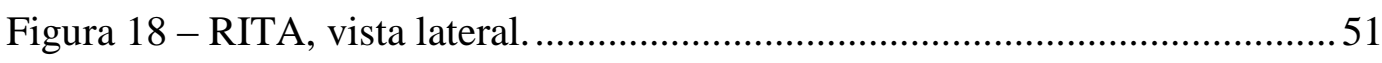

Figura 19 - Modelo em SolidWorks do robô RITA............................................. 52

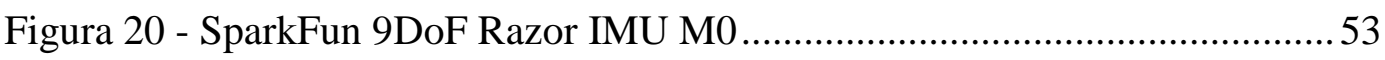

Figura 21 - Equipamento de Calibração IMU (Assad, M. M., 2018)..................... 56

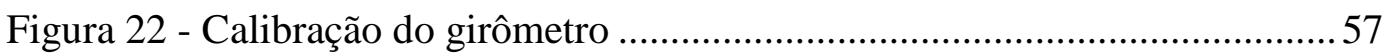

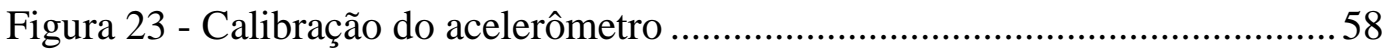

Figura 24 - Esquema de medições de intensidade de campo magnético sujeitas a distorção hard-iron

Figura 25 - Esquema de medições de intensidade de campo magnético sujeitas a

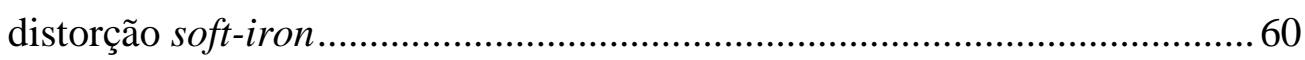

Figura 26 - Campo magnético não calibrado........................................................ 62

Figura 27 - Campo magnético calibrado e não calibrado ..................................... 63

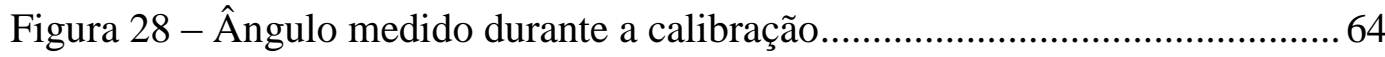

Figura 29 -- Medidas do acelerômetro sem vibração........................................... 65

Figura 30 - Medidas do acelerômetro com vibração .............................................. 66 
Figura 31 - Transformada de Fourier das medidas sem vibração.........................66

Figura 32 - Transformada de Fourier das medidas com vibração ........................ 67

Figura 33 - a) caixa de espuma (esquerda) b) IMU+base+pesos (direita) ............6 68

Figura 34 - Medidas do acelerômetro com sistema de atenuação ......................... 68

Figura 35 - Transformada de Fourier com sistema de atenuação ......................... 69

Figura 36 - Sinal do acelerômetro após filtragem................................................6 69

Figura 37 - Diagrama da simulação ................................................................ 72

Figura 38 - Comandos enviados aos motores esquerdo e direito........................... 73

Figura 39 - Estimativas a partir dos encoders esquerdo e direito ........................ 74

Figura 40 - Velocidade angular do modelo do motor ........................................... 75

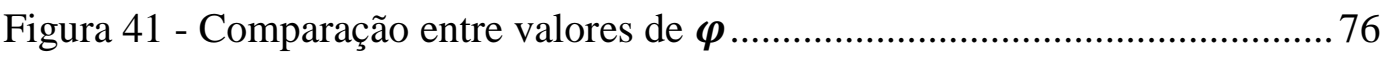

Figura 42 - Comparação entre as rotas previstas pelos modelos ......................... 77

Figura 43 - Comparação das velocidades angulares dos modelos e medida .......... 78

Figura 44 - Diagrama da simulação do sistema de localização ............................. 79

Figura 45 - Comandos utilizados na simulação do filtro de Kalman .................... 80

Figura 46 - Trajetória simulada e filtro de Kalman .............................................. 81

Figura 47 - Erro entre a simulação e o filtro de Kalman ....................................... 82

Figura 48 - Computador e o robô RITA conectados pelo umbilical ..................... 84

Figura 49 - Diagrama do sistema de localização ................................................... 86

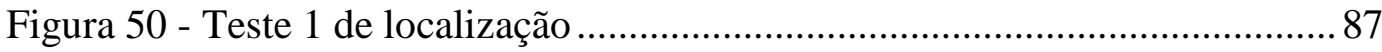

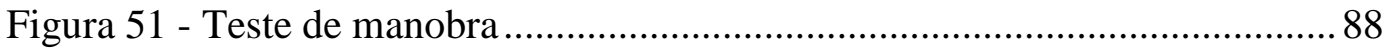

Figura 52 - Comparação entre trajetórias estimadas .............................................. 89

Figura 53 - Comparação entre posições finais estimadas ..................................... 90

Figura 54 - Caminho estimado com e sem magnetômetro ....................................92

Figura 55 - Ângulo medido pelo magnetômetro durante o teste ........................... 93

Figura 56 - Campo magnético com rodas magnéticas............................................94

Figura 57 - Campo magnético calibrado com rodas magnéticas..........................95

Figura 58 - Caminho estimados após a calibração ................................................ 96 


\section{Índice de Tabelas}

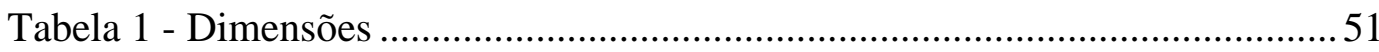

Tabela 2 - Dimensões utilizadas no modelo ........................................................5 52

Tabela 3 - Erro médio quadrático das distâncias medidas $\left(\mathrm{em}^{2}\right)$.......................56

Tabela 4 - Parâmetros da calibração do magnetômetro ........................................ 62

Tabela 5 - Variâncias dos sinais do acelerômetro para cada caso ........................ 70

Tabela 6 - Parâmetros do modelo do motor ......................................................... 74

Tabela 7- Erro quadrático médio entre modelos e girômetro ................................ 78

Tabela 8 - Variâncias utilizadas na simulação....................................................... 80

Tabela 9 - Erro quadrático médio da velocidade na simulação ............................. 83

Tabela 10 - Erro quadrático médio da velocidade angular na simulação ............... 83

Tabela 11- Variâncias utilizadas no filtro de Kalman ........................................... 86

Tabela 12 - Erro quadrático médio da posição final.............................................. 87

Tabela 13 - Posições inicias e finais dos testes de manobra ................................ 88

Tabela 14 - Erro entre a posição final e previsões ............................................... 91

Tabela 15 - Parametros para o sistema de localização com magnetômetro ...........91

Tabela 16 - Posições iniciais e finais para os testes com o magnetômetro ............92

Tabela 17 - Parâmetros de Calibração para as rodas magnéticas ......................... 94

Tabela 18 - Erros das posições finais e do sistema de localização........................ 96 


\section{Índice de Símbolos}

- $a$, aceleração do corpo rígido.

- $a_{c}$, aceleração centrípeta

- $a_{y}$, aceleração do veículo na direção y

- $\overline{a c}_{y_{k+1}}$, medida do acelerômetro prevista no instante $\mathrm{k}+1$;

- $\hat{a}_{y_{k}}$, estimativa da aceleração no instante $\mathrm{k}$

- $B$, distância entre centros das rodas

- $C$, matriz que representa a cinemática do veiculo

- $C_{1}, C_{2}$, constantes de calibração

- $C_{c}$, comprimento do corpo

- $C_{T}$, comprimento total

- $C_{x}$, offset para calibração do eixo X

- $C_{y}$, offset para calibração do eixo Y

- $d_{c}$, distância entre o centro do equipamento e a IMU

- $d t$, derivada do tempo

- $D$, distância percorrida

- $D_{k}$, matriz de entradas do modelo de medições do sistema;

- $D_{r}$, diâmetro das rodas

- $\bar{e}_{L_{k+1}}$, medida do encoder do motor esquerdo prevista;

- $\bar{e}_{R_{k+1}}$, medida do encoder do motor direito prevista.

- $f(x, u)$, modelo de previsão em função de $\mathrm{x}$ e u,

- $F$, forças aplicadas no corpo rígido

- $F_{k}$, matriz do modelo de dependência entre o estado previsto atual e o anterior

- $\quad \bar{g}_{z_{k+1}}$, medida do girômetro prevista no instante $\mathrm{k}+1$.

- $G_{k}$, matriz de efeito das entradas sobre o sistema

- $h$, modelo de medição em função de x

- $H_{c}$, altura do corpo

- $H_{c a}$, altura da câmera

- $H_{k}$, matriz de estado do modelo de medições do sistema;

- $H_{T}$, altura total

- $i_{L}$, deslizamento da roda esquerda 
- $i_{R}$, deslizamento da roda direita

- I, momento de inércia do eixo de rotação

- $I_{c}$, momento de inércia do corpo rígido

- $I_{m}$, corrente no motor;

- $I_{\text {no load }}$ corrente sem carga no motor, devido perdas mecânicas;

- $k$, constante de proporcionalidade entre u e $V_{i n}$

- $K_{k}$, ganho ótimo de Kalman no instante $\mathrm{k}$

- $K_{V}$, constante de tensão;

- $K_{t}$, constante de toruqe do motor;

- $K_{\omega}$, constante de rotação.

- $L_{c}$, largura do corpo

- $L_{D}$, largura da roda

- $L_{T}$, largura total

- $\quad m$, massa do veículo

- $m_{c}$, massa do corpo rígido

- $m_{x}$, sinal não calibrado da medição do magnetômetro no eixo $\mathrm{X}$

- $m_{y}$, sinal não calibrado da medição do magnetômetro no eixo Y

- $M$, momentos aplicados no corpo rígido

- $M_{x}$, sinal calibrado do magnetômetro no eixo X

- $\quad M_{y}$, sinal calibrado do magnetômetro no eixo $\mathrm{Y}$

- $\quad N$, relação de transmissão do sistema de engrenagens acopladas a cada motor

- $\widehat{P}_{k-1}$, matriz de covariância da estimativa do estado no instante anterior

- $\quad \bar{P}_{k}$, matriz de covariância da previsão do estado no instante k,

- $\widehat{P}_{k}$, matriz de covariância da estimativa do estado atual

- $Q_{k}$, matriz de covariância do ruído do processo

- $Q_{\text {mag }_{k}}$, matriz de covariância das previsões do sistema de localização com o magnetômetro

- $r$, raio das rodas

- $\quad R$, resistência do motor;

- $R_{k}$, matriz de covariância das medições

- $R_{\text {mag }_{k}}$, matriz de covariância das previsões do sistema de localização com o magnetômetro 
- $S_{k}$, covariância de $y_{k}$

- $S_{x}$, fator de escala para a calibração do eixo X

- $S_{y}$, fator de escala para a calibração do eixo Y

- $T_{m}$, torque exercido pelo motor

- $\mathrm{u}, \mathrm{comando}$ adimensional enviado ao motor

- $u_{k}$, entradas do sistema no instante $\mathrm{k}$

- $u_{L}$, comando enviado ao motor esquerdo;

- $u_{R}$, comando enviado ao motor direito;

- $u_{L_{k}}$ comando do motor esquerdo no instante $\mathrm{k}$

- $u_{R_{k}}$ comando do motor direito no instante $\mathrm{k}$

- $v_{x}$, velocidade do veículo na direção $\mathrm{x}$

- $v_{y}$, velocidade do veículo na direção y

- $\hat{v}_{y_{k}}$, estimativa da velociade no instante k;

- $\bar{v}_{y_{k+1}}$, previsão da velocidade no instante $\mathrm{k}+1$;

- $\quad V$, comando recebido pelo motor

- $V_{i n}$, tensão de entrada;

- $V_{L}$, comando enviado ao motor esquerdo

- $V_{R}$, comando enviado ao motor direito

- $V_{L_{k}}$, comando do motor esquerdo no instante $\mathrm{k}$

- $V_{R_{k}}$, comando do motor direito no instante $\mathrm{k}$

- $x_{\text {mag }}$, vetor de estado com magnetômetro

- $\hat{x}_{k}$, estimativa do estado atual

- $\hat{x}_{k-1}$, estimativa do estado no instante anterior do sistema (valor do filtro na etapa anterior)

- $\hat{x}_{m_{a g}-1}$, vetor de estado estimado para o filtro com magnetômetro, no instante $\mathrm{k}-1$

- $\bar{x}_{k}$, previsão do estado na etapa $\mathrm{k}$,

- $\bar{x}_{\text {mag }_{k}}$, vetor de estado previsto para o filtro com magnetômetro, no instante $\mathrm{k}$

- $\quad y_{k}$, resíduo entre as medições e a previsão do estado no instante $\mathrm{k}$

- $y_{\text {mag }_{k}}$, ruído entre as medições e as previsões para o filtro com o magnetômetro no instante $\mathrm{k}$. 
- $z_{k}$, medições realizadas no instante $\mathrm{k}$

- $z_{m a g}$, vetor de medições para o filtro com magnetômetro

- $\quad \alpha$, aceleração angular do corpo rígido

- $\quad \alpha_{L}$, aceleração angular da roda esquerda

- $\alpha_{R}$, aceleração angular da roda direita

- $\alpha_{z}$, aceleração angular do veículo.

- $\theta$, ângulo entre eixo longitudinal do veículo e o eixo fixo

- $\theta_{E}$, ângulo entre o eixo fixo e o norte magnético

- $\theta_{\text {mag }}$, ângulo de orientação medido pelo magnetômetro

- $\theta_{N}$, ângulo entre o norte magnético e o veículo.

- $\sigma_{a y}$, variância do acelerômetro;

- $\sigma_{e L}$, variância do encoder esquerdo;

- $\sigma_{e R}$, variância do encoder direito;

- $\sigma_{m a g}$, variância do ângulo medido pelo magnetômetro

- $\sigma_{v}$ variância da previsão da velocidade;

- $\sigma_{\theta}$, variância da previsão do ângulo de orientação $\theta$

- $\sigma_{\omega}$, variância da previsão da velocidade angular;

- $\sigma_{\omega z}$, variância do girômetro;

- $\Delta T$, variação do tempo

- $\tau$, torque exercido pelo motor;

- $\tau_{L}$, torque que as rodas esquerdas exercem no veículo

- $\tau_{R}$, torque que as rodas direitas exercem no veículo

- $\varphi$, fator de expansão

- $\omega$, velocidade angular do motor;

- $\omega_{c}$, velocidade angular da plataforma de teste

- $\omega_{L}$, velocidade angular da roda esquerda

- $\omega_{m}$, velocidade de rotação do motor

- $\omega_{R}$, velocidade angular da roda direita

- $\omega_{z}$, velocidade angular em torno do eixo z

- $\bar{\omega}_{L_{k+1}}$, previsão da velocidade angular da roda esquerda no instante k+1

- $\bar{\omega}_{R_{k+1}}$, previsão da velocidade angular da roda direita no instante k+1

- $\bar{\omega}_{z_{k+1}}$, previsão da velocidade angular no instante $\mathrm{k}+1$ 
- $\widehat{\omega}_{y_{k}}$, estimativa da velocidade angular no instante $\mathrm{k}$ 


\section{Introdução}

Tanques de armazenamento são equipamentos estáticos de caldeiraria pesada, sujeitos à pressão próxima à atmosférica e na maioria das vezes sendo de fundamental importância na produção, refino e distribuição de derivados de petróleo (Figura 1). Os tanques de armazenamento são um tipo de vaso de armazenamento, um recipiente destinado a armazenar fluídos sob a pressão atmosférica, ou seja, não está pressurizado. (Sato, A. K., 2015)

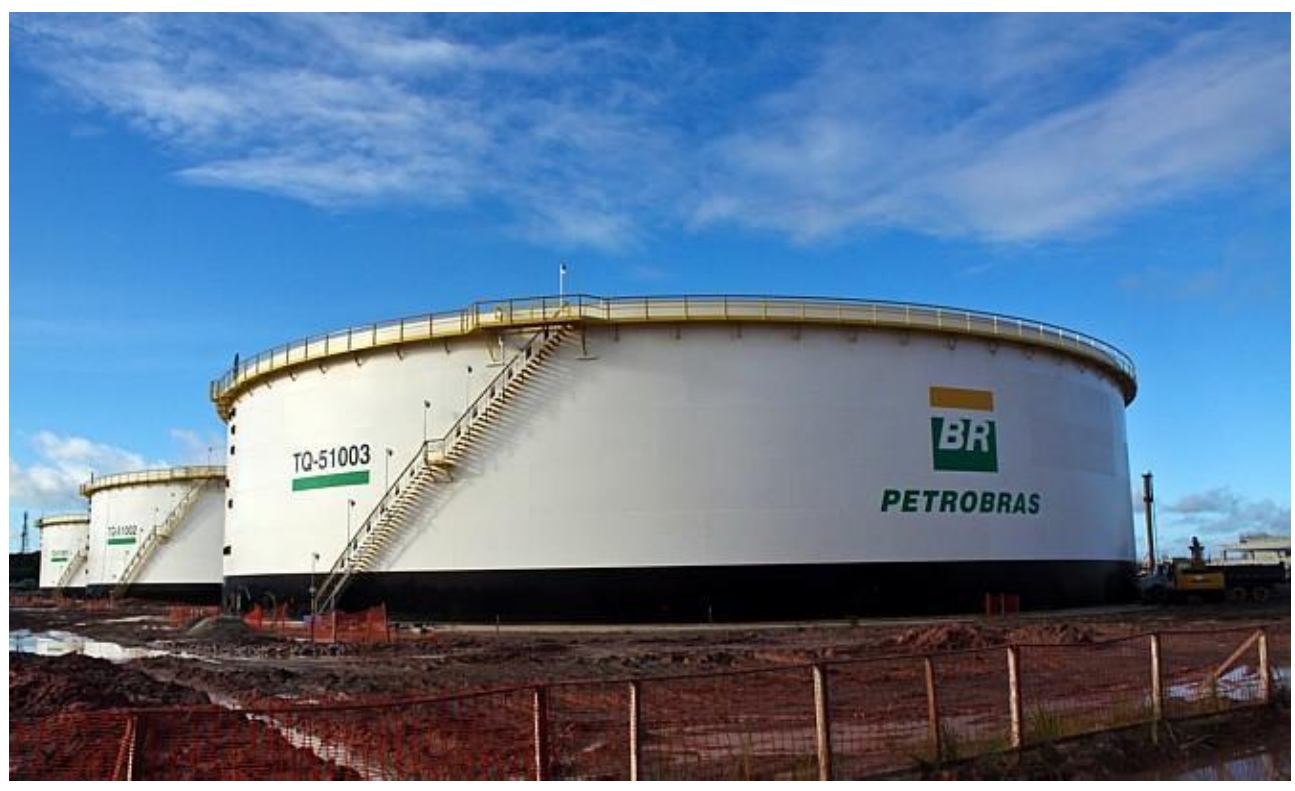

Figura 1 - Tanque de Armazenamento (Sato, A. K., 2015)

Os tanques de armazenamento podem ser construídos com teto fixo ou flutuante, interno ou externo, de acordo com as características e o tipo de produto que será armazenado, sendo classificados em tanque de armazenamento de baixa pressão, que são utilizados para fluidos mais voláteis como petróleo bruto leve, mistura para uso na gasolina e nafta leve, e o tanque atmosférico, que são usados para armazenar fluidos que possuam pressão de vapor substancialmente menor que a pressão atmosférica, como o petróleo bruto, o óleo pesado e a nafta. 
Diversos processos físicos e químicos como o trincamento, a erosão e a corrosão (Figura 2) levam à deterioração em tanques atmosféricos, os quais devem ser identificados através dos processos de inspeção.

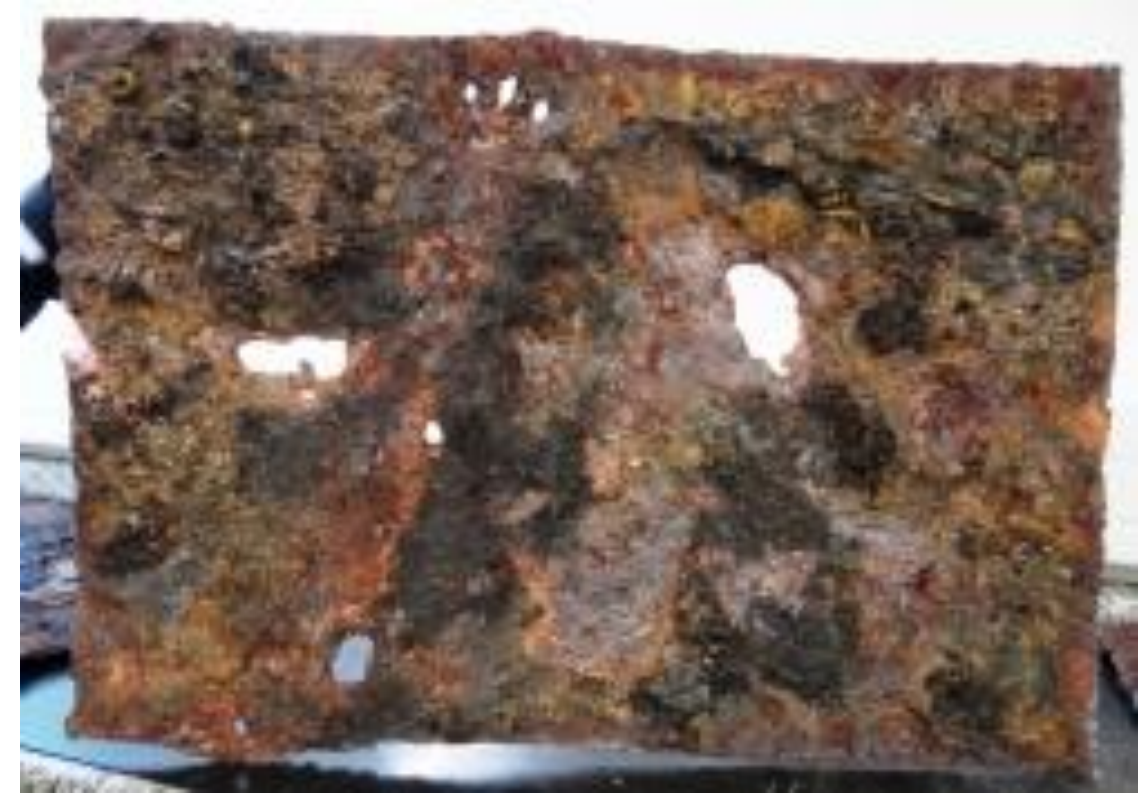

Fonte: <http://www.ipt.br/noticias_interna.php?id_noticia=1321>

Figura 2 - Chaparia de fundo de tanque com problemas de corrosão

A inspeção periódica durante a vida operacional dos tanques deve ser realizada com o objetivo de assegurar a integridade física e a segurança do tanque. A inspeção externa de rotina é realizada em todos os componentes possíveis de serem verificados com o tanque em operação, incluindo base, diques e bacia de contenção, buscando verificar e registrar evidências de vazamentos, deformações do costado, sinais de recalque, corrosão, condição da fundação, pintura, isolamento térmico, acessórios, etc. Outras atividades de inspeção interna são de fundamental importância, realizadas durante as paradas de operação, onde são verificados se o fundo não está corroído e com vazamento, são comparadas as espessuras mínimas do fundo e do costado com as espessuras reais medidas, além de serem identificados e avaliados quaisquer recalques de fundo do tanque e verificadas as condições de segurança.

A liberação de um tanque para inspeção e manutenção é complexa, pois além de reduzir a flexibilidade operacional e comprometer à logística que interliga todos os segmentos do setor, gera grande quantidade de resíduos, que se não forem 
adequadamente processados e tratados podem trazer sérias consequências para a segurança e o meio ambiente.

Embora estes equipamentos não trabalhem sob pressão, o grande volume de produtos armazenados e as baixas espessuras utilizadas em sua construção potencializam a gravidade de acidentes, e os tornam mais susceptíveis a falhas. Como os custos e dificuldades para liberação destes equipamentos são bastante elevados, as programações de manutenção/inspeção merecem especial atenção das empresas.

O avanço da tecnologia e a criação de robôs foi de fundamental importância para a otimização de processo produtivo, além de aumentar significativamente a segurança operacional. Estas máquinas são programadas para executar movimentos rápidos, padronizados e eficazes, e passaram a ser utilizadas para auxiliar a produção industrial, em geral em processos de automação programável, devido à facilidade de programação dos movimentos.

No início da automatização da indústria, a presença de robôs era uma exclusividade das linhas de montagem. Entretanto, atualmente é possível encontrálos em vários outros setores, incluindo em atividades exercidas por veículos.

A utilização de robôs na indústria de Petróleo e Gás é uma realidade em diversos segmentos, e.g. no segmento de upstream. Um exemplo é o projeto Girino (Figura 3) - Gabarito Interno Robotizado de Incidência Normal ao Oleoduto - que é responsável por um robô intrusivo que se movimenta por meios próprios, locomovendo-se por dentro dos dutos e rompendo bloqueios causados por parafina ou hidratos. (Panta, P. E. G., 2005)

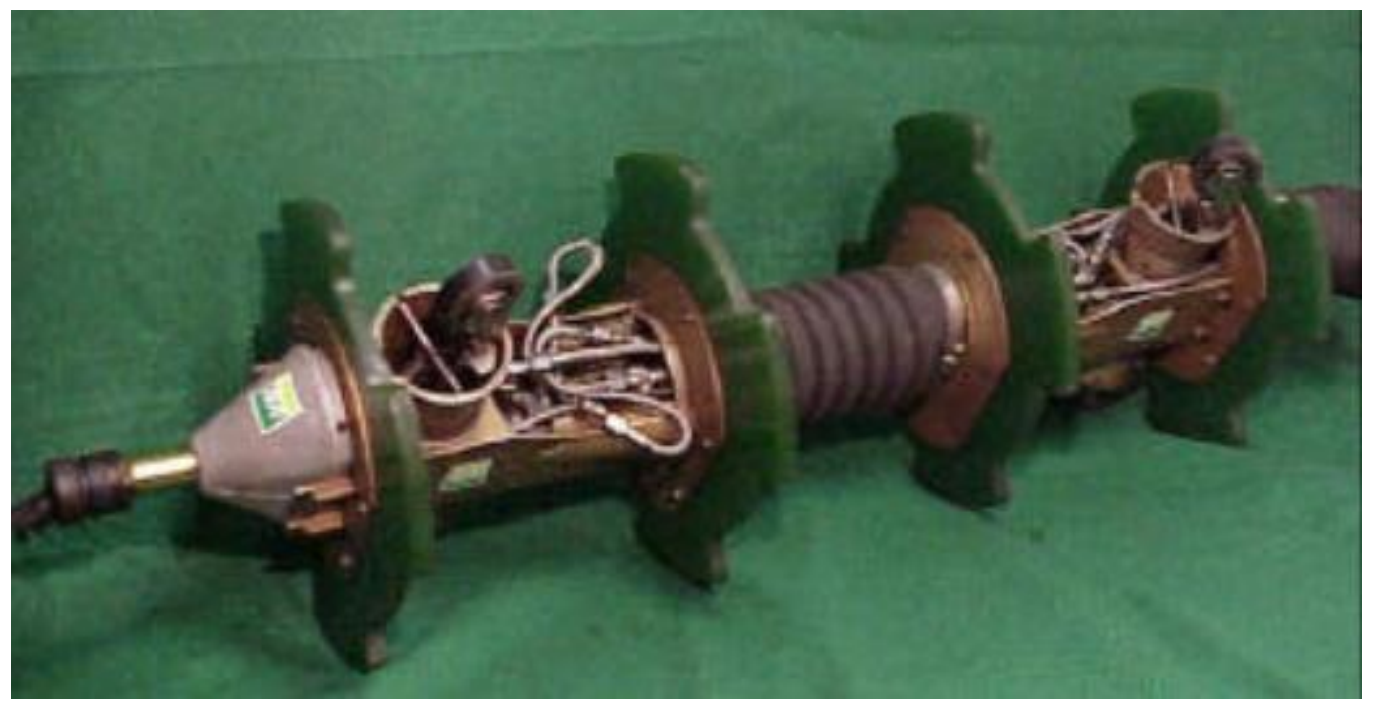


Figura 3 - Robô GIRINO (Panta, P. E. G., 2005)

Outro exemplo é o robô ambiental híbrido da Petrobras (Figura 4), integrante do projeto de monitoramento ambiental do gasoduto Coari-Manaus. A função do gasoduto é percorrer $420 \mathrm{~km}$ às margens do rio Solimões, passando por regiões de mata fechada ou alagada, inacessíveis ao homem. O robô foi desenvolvido para monitorar os trechos de difícil acesso e evitar desastres ambientais. (Paranhos, P. M., 2009)

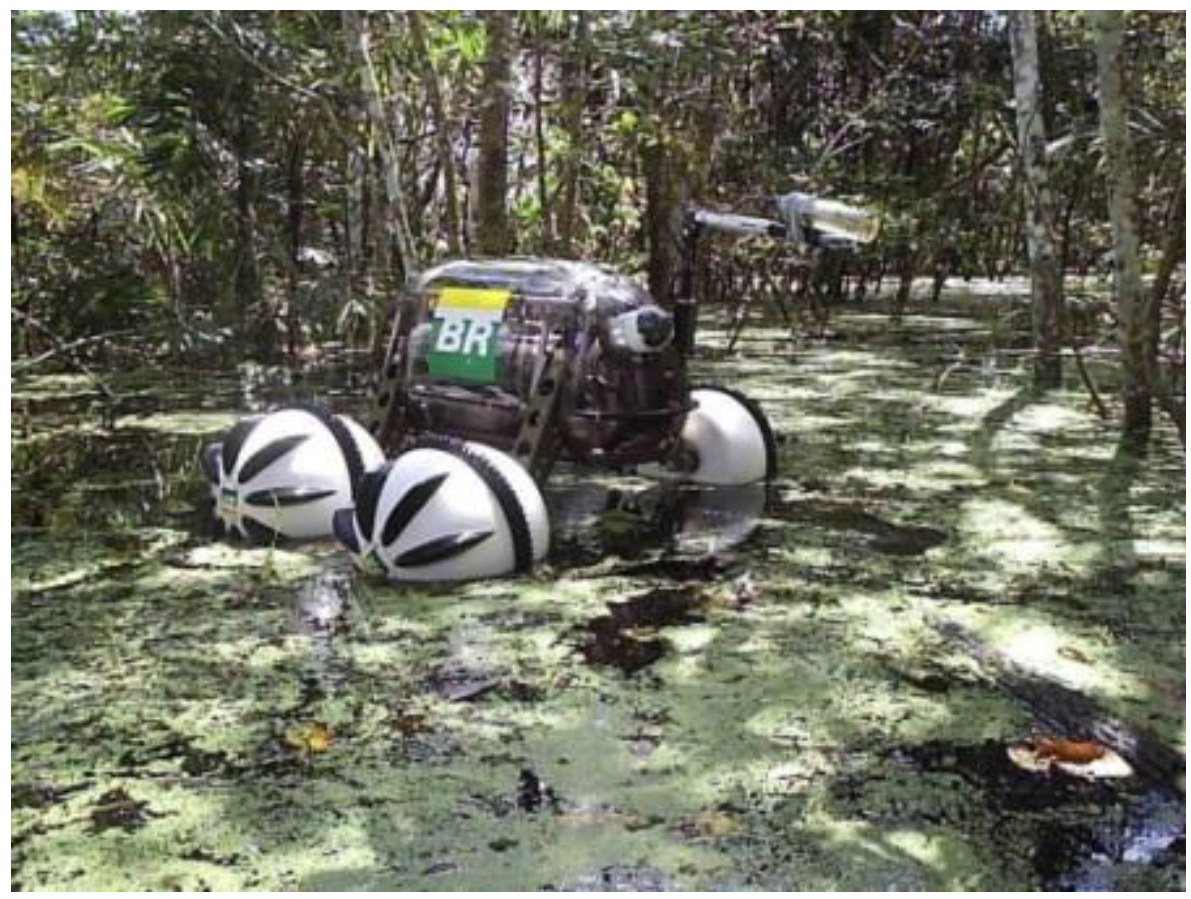

Figura 4 - Robô ambiental hibrido (Paranhos, P. M., 2009)

A utilização da robótica no segmento downstream da indústria do petróleo e gás também já se encontra bastante difundida. Na área de armazenagem, a automação destes processos é de fundamental importância, visto que a realização de inspeções em tanques de armazenamento oferece riscos de acidente aos envolvidos na operação, além do grande tempo despendido para a tarefa, aumentando custos de operação.

O uso de robôs de inspeção preventiva em tanques de armazenamento e a aplicação de tecnologias de ponta aumenta significativamente a confiabilidade operacional, além de reduzir o tempo das intervenções, minimizando o impacto na produtividade operacional. É possível encontrar múltiplas soluções robóticas para a realização de operações em tanques de inspeção disponíveis comercialmente. 
No entanto, nenhum sistema comercial de inspeção robótica interna é capaz de operar com o tanque cheio, sem o custoso processo de esvaziamento. Além disso, um dos desafios para essa operação é o processo de localização do robô dentro do tanque, como discutido adiante.

\subsection{Robôs de Inspeção}

Há múltiplas soluções robóticas para a realização de operações em tanques de inspeção. A maioria dos robôs se movimenta por meio de rodas ou esteiras magnéticas fixas, facilitando a movimentação em tanques de paredes feitas de material ferromagnético, e em alguns casos permitindo navegação pelas paredes do tanque.

O robô Neptune (Figura 5), desenvolvido pela universidade Carnegie Mellon, apesar de não ser capaz de realizar movimento ao longo das paredes dos tanques, utiliza rodas magnéticas. É utilizado um sistema de localização acústico na determinação da posição do veículo dentro do tanque. Múltiplos transdutores são posicionados no topo do tanque imersos no mesmo fluido que o veículo, permitindo a triangulação da sua posição. (Schempf et al., 1995)

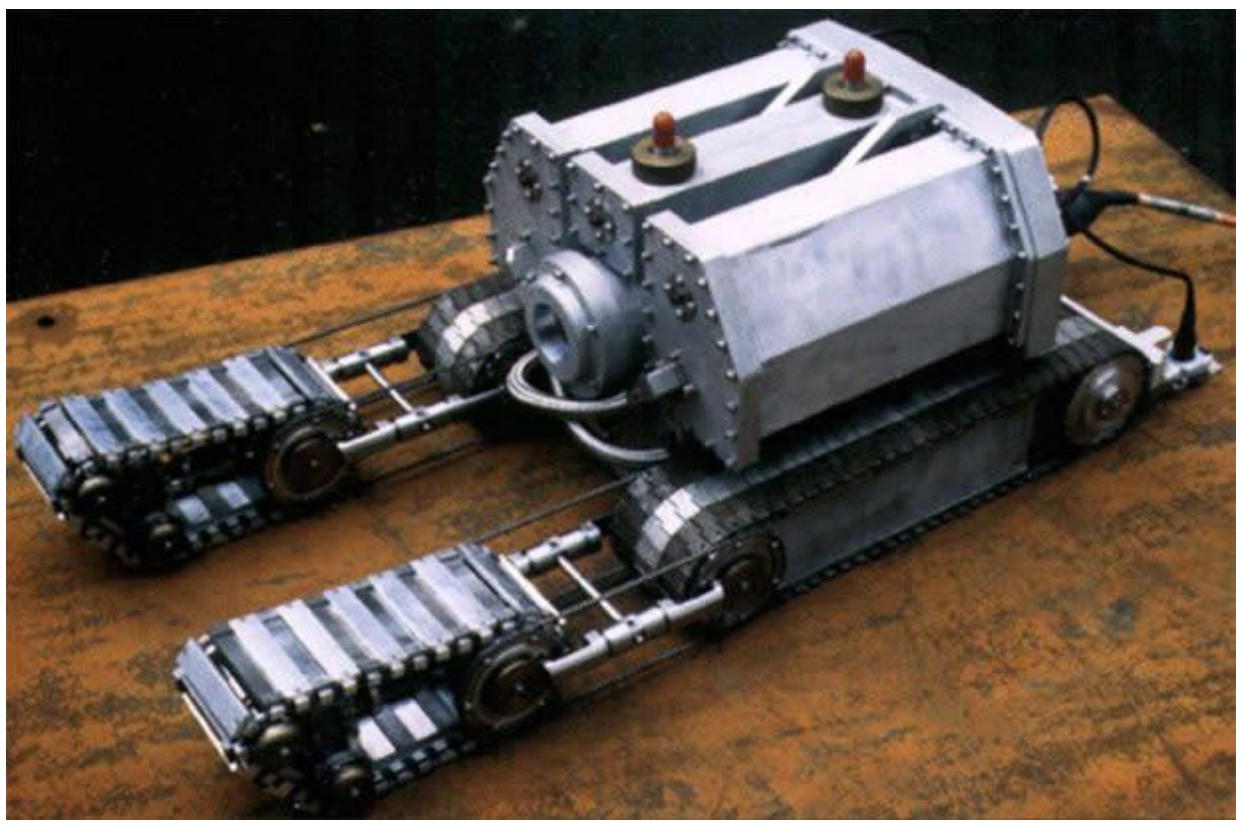

Figura 5 - Neptune (Schempf et al., 1995)

O robô Maverick (Figura 6), desenvolvido pela Solex Robótics, foi criado para a realização de inspeções no fundo de tanques, e utiliza um sistema de 
localização similar ao utilizado no Neptune. Testes realizados em tanques de armazenamento demonstraram dificuldades na utilização do sistema de autolocalização. Problemas com eco devido à curvatura das paredes do tanque foram citados como a causa do problema. (Hartsell, D. R. ,1999)

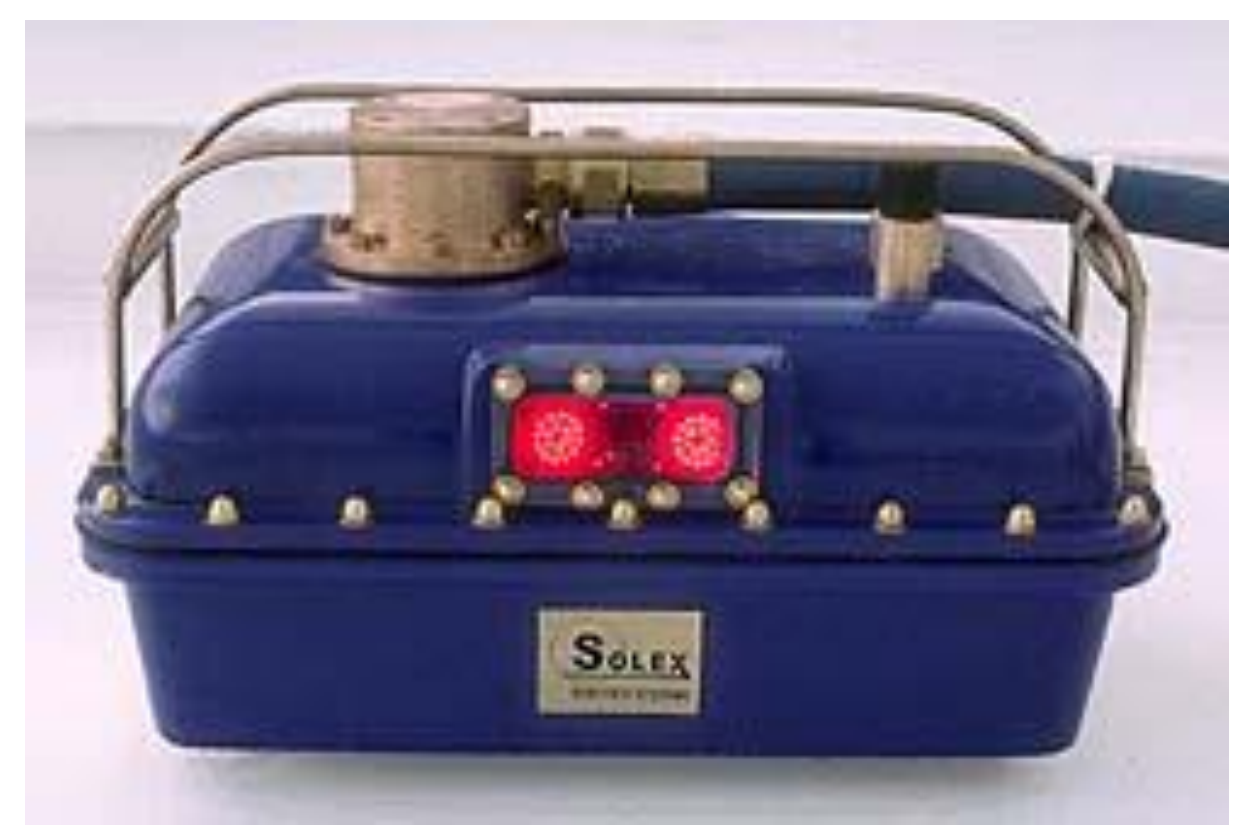

Figura 6 -Maverick (Hartsell, D. R. ,1999)

Um outro robô utilizado para inspeções internas de tanques é o A.Hak Industrial Services' InTank (Figura 7) que, igual ao Maverick, apenas faz inspeções no fundo do tanque. Assim como os outros dois robôs citados anteriormente, seu sistema de localização utiliza um sistema de navegação acústico, onde pingers localizados nos robôs se comunicam a transdutores na carcaça do tanque. 


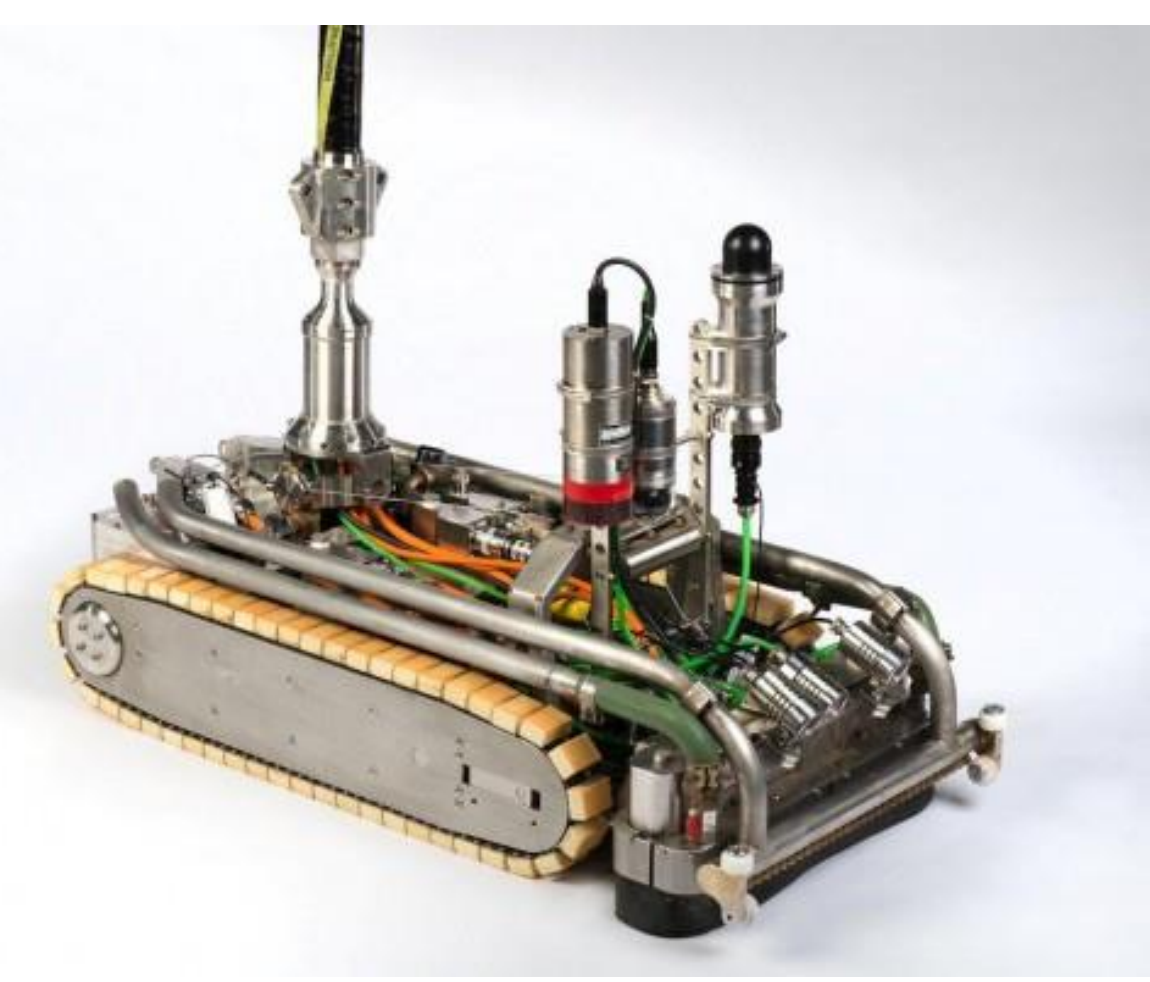

Fonte:<http://www.ahakis.com/en/home/what_we_do/markets/tank_storage/i ntegrated_tank_services/inspection/online_robotic_tank_bottom_inspection>

\section{Figura 7 - Robô A.Hak Industrial Services’ InTank}

Outro exemplo de robô de inspeção é o construído pela Osaka Gas Co.,Ltd. (Figura 8), utilizado em tanques esféricos, e que possuem rodas magnéticas para inspeção interna e externa desses tanques. Ele utiliza um método de detecção de falhas ultrassônico (TOFD method), porém este robô apenas tem seu movimento em linha reta e, devido a vibração no movimento, necessita de correção manual de sua posição (Sogi, T. ,2000). 


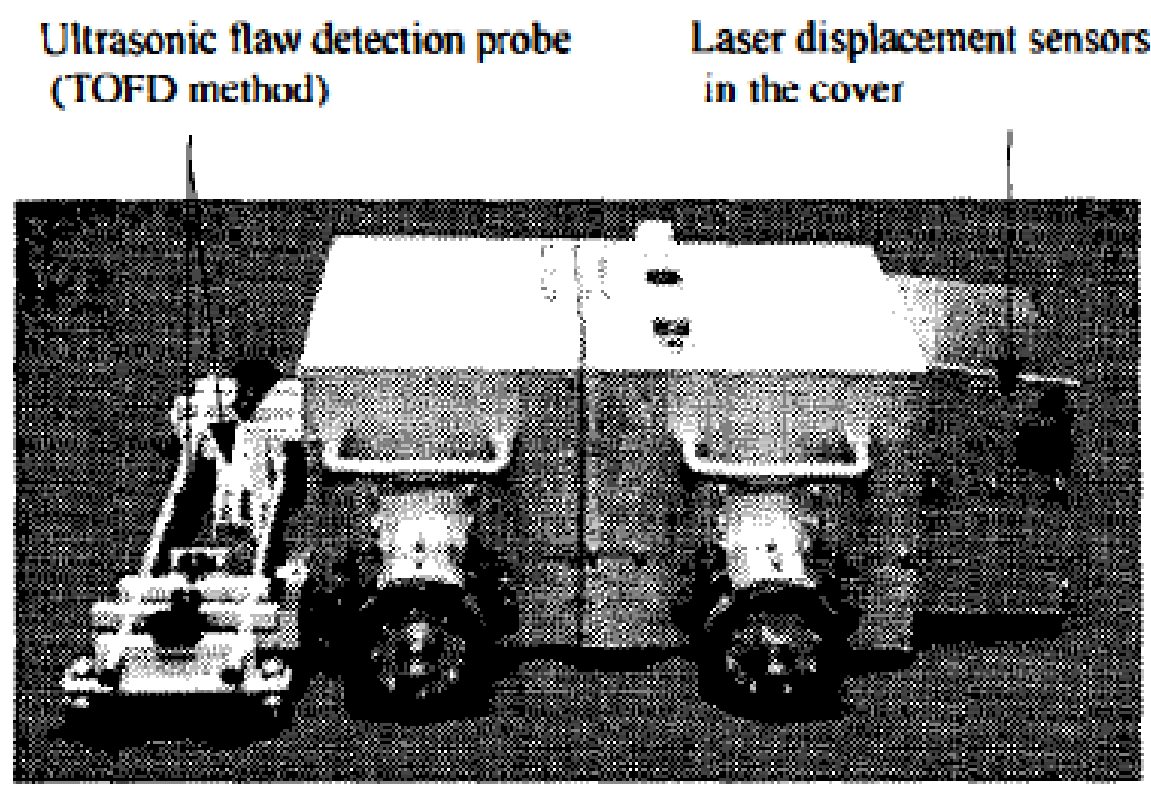

Figura 8 - Robô de inspeção (Sogi, T. ,2000)

Um robô mais recente no ramo de inspeção de tanques é o fast RVI (Figura 9) da General Eletrics (GE) que, assim como o Neptune e muitos outros, foi projetado com rodas magnéticas para possibilitar que ele se mova pelas paredes externas e internas dos tanques. O fast $R V I$ utiliza uma câmera de alta definição para captação de imagens, onde é possível detectar problemas nas paredes, como trincas. Para seu funcionamento, é utilizado um controle por joystick, onde o inspetor controla a posição do robô e, ao mesmo tempo, visualiza as imagens adquiridas pela câmera.

Para este trabalho, foi utilizado o robô RITA (Figura 10), desenvolvido pelo Laboratório de Robótica da PUC-Rio (LabRob) em parceria com a Petrobras. Este robô possui rodas magnéticas para inspeção de paredes internas e externas. Inspeção visual é realizada através da utilização de uma câmera embarcada. Um computador, conectado ao robô por um cabo umbilical, é utilizado para teleoperar o veículo através de joysticks, além de reproduzir as imagens da câmera, permitindo a visualização de trincas, borras e outros problemas. O robô é equipado com uma central inercial e encoders nos motores. Estes sensores são utilizados neste trabalho no desenvolvimento do sistema de localização para o veículo. 


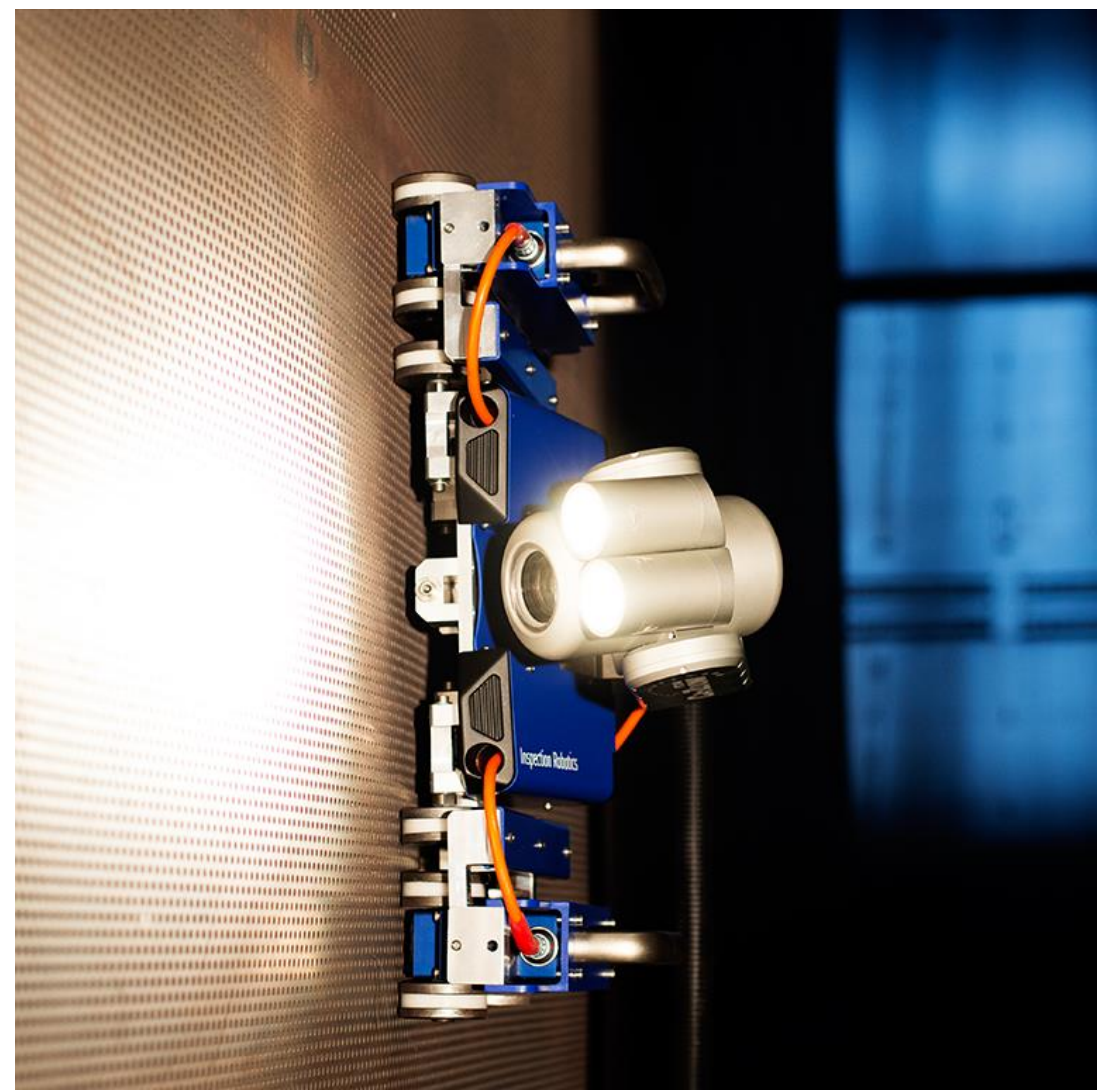

Fonte: <https://inspection-robotics.com/fast-rvi/>

Figura 9 - Fast RVI

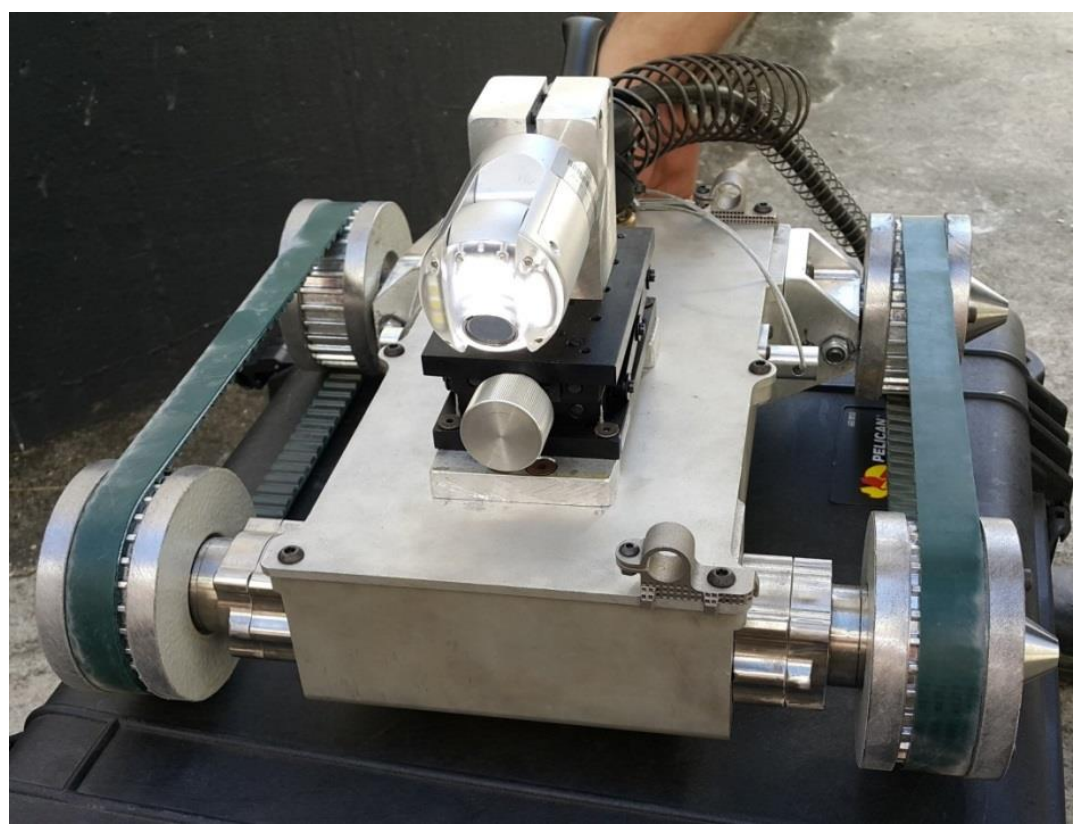

Figura 10 - Robô cedido para o trabalho (RITA) 


\subsection{Objetivo}

O objetivo deste trabalho é desenvolver um sistema de auto-localização para robôs móveis de rodas magnéticas fixas, para uso na inspeção de tanques de armazenamento. Para isso, será desenvolvido o modelo do veículo levando em conta os efeitos de deslizamento na roda, característicos desse tipo de locomoção. Simulações em Simulink serão desenvolvidas e ajustadas para representar o sistema real, e possibilitar o desenvolvimento das técnicas utilizadas neste trabalho. Finalmente, serão realizados testes para comprovar a validade e eficiência da abordagem selecionada.

\subsection{Revisão bibliográfica}

A indústria de óleo e gás utiliza tanques de armazenamento durante múltiplos estágios de produção. Estas estruturas precisam ser inspecionadas regularmente. Para realizar estas operações, pode ser necessário submeter o inspetor a condições potencialmente perigosas. Além disso, as inspeções podem ser custosas, necessitando em alguns casos a parada do funcionamento do tanque, tornando o uso de robôs que possam realizar estas tarefas uma área de pesquisa com grande interesse pela indústria. (Shukla e Karki, 2016)

Múltiplas estratégias podem ser utilizadas na localização de robôs, existindo inúmeras combinações de técnicas e sensores disponíveis para realizar esta tarefa. O filtro de Kalman é um dos métodos mais utilizados na fusão de sensores na robótica móvel (Malagon-Soldara, S. M., 2015). Este consiste em combinar as informações obtidas através de múltiplos sensores para estimar a posição real do robô, obtendo resultados com precisão melhor que os obtidos pela análise independente dos sensores. Em (Thrun et al, 2005) é apresentada uma revisão de técnicas probabilísticas, incluindo o filtro de Kalman. (Grewal, M. S. e Andrews, A. P., 2011) apresenta de maneira mais aprofundada o filtro e conceitos-base de sua formulação. $\mathrm{O}$ assunto é abordado de maneira mais direta e com foco em robótica móvel em (Jaulin, L., 2015).

Em (Kubelka, V. et al., 2015) é desenvolvido um sistema de fusão de sensores inerciais, câmera e um range-finder a laser com o filtro estendido de Kalman (EKF), para a localização de um veículo de resgate urbano. 
Em (Wong, J. Y., 2001) foi desenvolvida a teoria para movimento de veículos com tração tipo skid-steering em chão firme. Na elaboração de sua teoria, o autor considera a tensão gerada pelo deslizamento sendo dependente do movimento relativo entre a roda e o solo. Baseadas nas teorias de (Wong, J. Y., 2001), os autores de (Yu, W. et al., 2009) desenvolveram um modelo dinâmico para movimento geral, testando sua validade experimentalmente.

Em (Wang, T. et al., 2015) é abordado mais a fundo o conceito de cinemática experimental para veículos simulares ao utilizado neste trabalho; ao longo daquele trabalho, são desenvolvidas as equações por trás do modelo cinemático, e são realizados experimentos demonstrando melhorias na localização utilizando o modelo proposto. Em (Mandow, A. et al 2007), o modelo da cinemática experimental é utilizado para diminuir erros na localização por dead-reckoning. Em (Yi, J. et al, 2007) é realizada a localização de um veículo utilizando medidas de acelerômetros e odometria. Em (Klozlowsk, K. e Pazderski, D., 2004) é desenvolvida uma simulação para teste das estratégias de controle de trajetória, separando o funcionamento dos veículos em três subsistemas: dinâmica, cinemática e sistema de tração.

\subsection{Organização do Trabalho}

Este trabalho está dividido em oito capítulos. Neste capitulo está a introdução, onde é apresentado o problema e as motivações por trás da realização deste trabalho, além da revisão da bibliografia relevante.

No capítulo 2 são apresentadas as equações relacionadas ao movimento de veículos skid-steering. Nele são desenvolvidas as equações cinemáticas e dinâmicas utilizadas na implementação do filtro de Kalman e no desenvolvimento da simulação do sistema em Simulink.

O capítulo 3 apresenta o filtro de Kalman, explicando as equações por trás de seu funcionamento. As equações então são aplicadas ao sistema utilizado, baseadas nas equações desenvolvidas no capítulo 2 .

No capítulo 4, é descrito o sistema experimental utilizado. Neste capítulo também são discutidos detalhes de implementação, como calibração dos sensores, perturbações devido a vibração e o efeito das rodas magnéticas nas medidas do magnetômetro. 
O capítulo 5 descreve a simulação desenvolvida, que permitiu o ajuste do modelo utilizado no filtro de Kalman. Também foram descritos os métodos utilizados para ajustar a simulação ao sistema real utilizado.

No capítulo 6 são descritos os experimentos realizados no trabalho e são apresentados os resultados do sistema de localização proposto. Os resultados obtidos são comparados com os do modelo dinâmico desenvolvido e odometria. Neste capítulo também é comparada o desempenho do sistema com e sem o uso de magnetômetro.

O capítulo 7 finaliza o trabalho apresentando as conclusões obtidas e as sugestões para trabalhos futuros. 


\section{Modelagem do Sistema}

Neste capítulo é apresentada a cinemática analítica de um veículo skidsteering (Figura 11) de quatro rodas.. Apresenta-se um modelo simplificado da cinemática com calibração experimental, e são desenvolvidas as equações dinâmicas representativas do veículo.
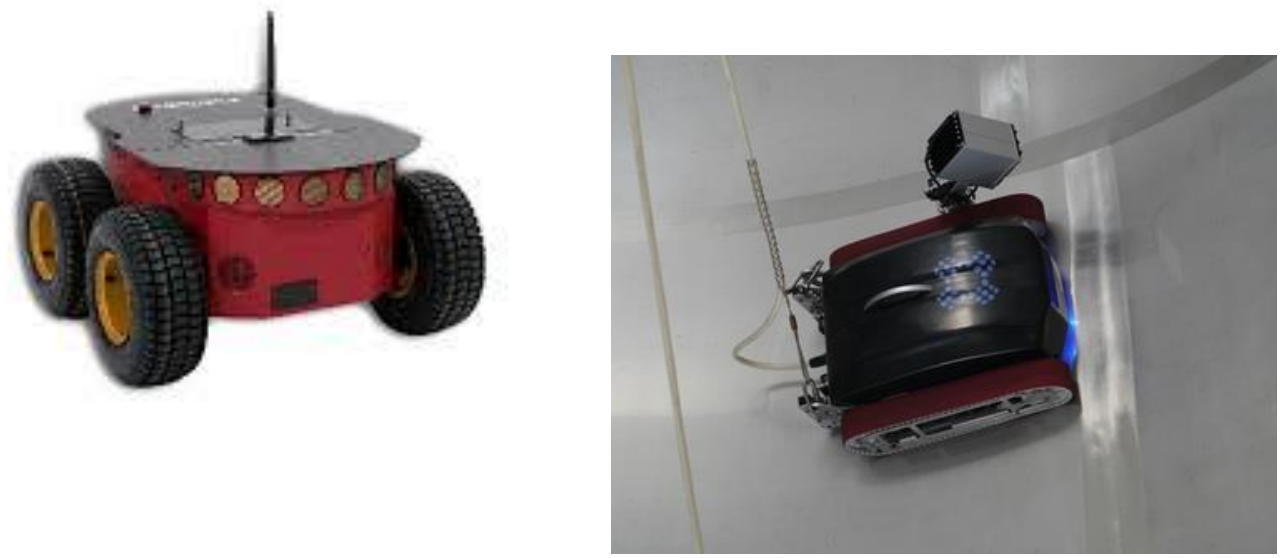

Fontes: <www.mobilerobots.com>, <http://furphyengineering.com.au/> Figura 11 - Exemplos de veículos skid-steering

Veículos do tipo skid-steering são veículos de rodas ou esteiras fixas, de modo que a velocidade do ponto de contato com o chão não está sempre alinhada com a direção da velocidade de rotação das rodas (Figura 12). Isto pode ser causado pelo uso de múltiplas rodas fixas com eixos desalinhados com o centro de rotação ou de esteiras, que devido a uma grande região de contato com o solo torna inevitável que haja pontos que não estão alinhados com o centro de rotação. 

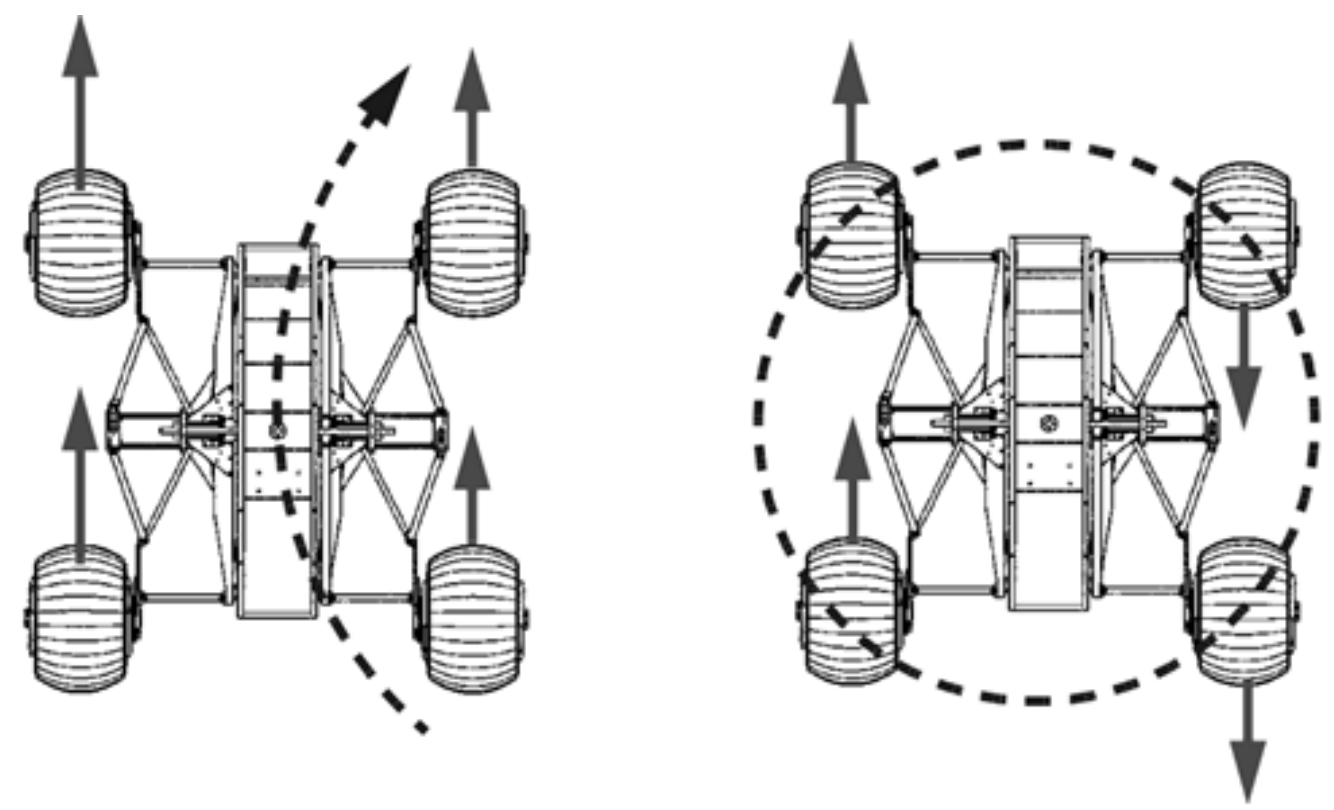

Figura 12 - Movimento de um veículo skid-steering, (Shamah, B. 1999)

As simplificações e hipóteses utilizadas na formulação do modelo são:

- Centro de massa coincidente com o centro geométrico do veículo;

- Inércia das rodas considerada desprezível;

- Não há efeitos de dissipação interna, como atrito no eixo das rodas;

- O veículo é considerado horizontalmente e verticalmente simétrico;

- As duas rodas direitas têm a mesma velocidade e são impulsionadas pelo mesmo motor, e analogamente para as esquerdas.

Diferentemente de veículos com sistema de direção diferencial ou Ackermann steering, veículos do tipo skid-steering possuem deslizamento das rodas como parte intrínseca de seu funcionamento. Assim a aproximação comumente utilizada nestes veículos, onde a velocidade entre a roda e o chão no ponto de contato é nula, não pode ser utilizada.

\subsection{Modelo cinemático}

A modelagem cinemática de um veículo consiste em estabelecer a relação entre as velocidades das rodas com as velocidades lineares e angulares do veículo. 
Para veículos onde o deslizamento é intrínseco para o seu funcionamento, ou seja, é necessário que ocorra deslizamento para sua movimentação, a velocidade entre a roda e o chão no ponto de contato não pode ser considerada nula (Figura 13), aumentando a dificuldade do desenvolvimento de modelos cinemáticos.

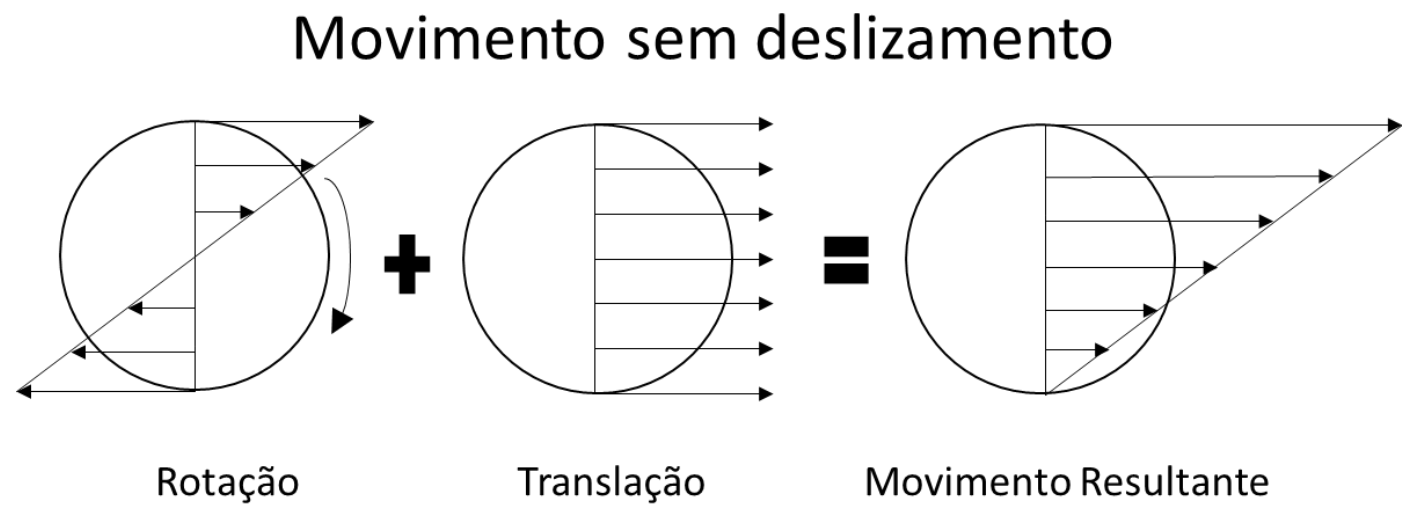

\section{Movimento com deslizamento}

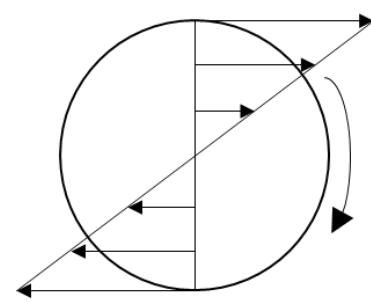

Rotação

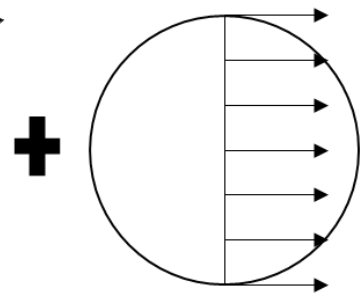

Translação

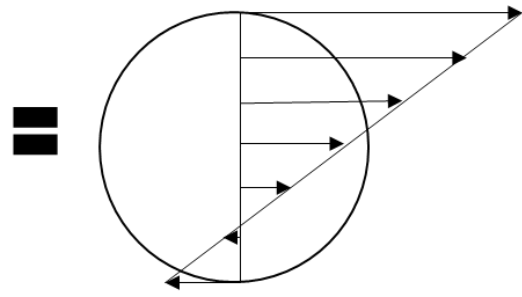

Movimento Resultante

Figura 13 - Velocidades nas rodas com/sem deslizamento

\subsubsection{Cinemática Analítica}

Para uma determinação rigorosa da cinemática deste tipo de veículo torna-se necessário introduzir as variáveis $i_{R}$ e $i_{L}$, que representam o deslizamento respectivamente das rodas direta e esquerda.

$$
\begin{aligned}
& i_{R}=\frac{v_{y}+\omega_{z} \frac{B}{2}-\omega_{R} r}{v_{y}+\omega_{z} \frac{B}{2}} \\
& i_{L}=\frac{v_{y}-\omega_{z} \frac{B}{2}-\omega_{L} r}{v_{y}-\omega_{z} \frac{B}{2}}
\end{aligned}
$$


onde:

- $i_{R}$, deslizamento da roda direita;

- $i_{L}$, deslizamento da roda esquerda;

- $v_{y}$, velocidade linear do veículo na direção y;

- $\omega_{z}$, velocidade angular em torno do eixo z;

- $\omega_{R}$, velocidade angular da roda direita;

- $\omega_{L}$, velocidade angular da roda esquerda;

- $r$, raio das rodas;

- $B$, largura do veículo.

Os numeradores das equações 1 e 2 representam a velocidade relativa entre o chão e o ponto de contato na roda. Observa-se que para caso de $i_{R}$ e $i_{L}$ sendo nulos são obtidas as equações cinemáticas para um veículo de acionamento diferencial, o que demonstra que o deslizamento é o principal diferenciador entre o funcionamento destes dois tipos de veículo.

Segundo Shamah, B. (1999), é possível escrever as velocidades lineares e angulares do robô em função das velocidades das rodas.

$$
\begin{aligned}
& v_{y}=\frac{r \omega_{R}\left(1-i_{R}\right)+r \omega_{L}\left(1-i_{L}\right)}{2} \\
& \omega_{z}=\frac{r \omega_{R}\left(1-i_{R}\right)-r \omega_{L}\left(1-i_{L}\right)}{B}
\end{aligned}
$$

O uso destas equações, porém, se torna uma tarefa complicada segundo Yu, W. et al (2009) pois os valores de $i_{R}$ e $i_{L}$ variam ao longo do movimento do robô e não podem ser calculados analiticamente.

Devido às similaridades no funcionamento de veículos skid-steering com os de acionamento diferencial, onde ambos realizam manobras devido à diferença das velocidades das rodas em cada lado do veículo, segundo Martínez, J. L. et al (2005), foram propostas várias maneiras de relacionar suas cinemáticas, discutidas a seguir.

\subsubsection{Cinemática pelo método do centro instantâneo de rotação- (Experimental ICR kinematic method)}

Considerando o veículo como um corpo rígido num plano, pode-se descrever seu movimento em função do seu centro instantâneo de rotação (ICR), que é 
definido como o ponto onde o movimento do corpo pode ser representado como uma rotação sem translação.

As posições dos centros instantâneos de rotação do corpo do veículo $\left(I C R_{v}\right)$, das rodas direitas $\left(I C R_{R}\right)$ e esquerdas $\left(I C R_{L}\right)$, podem ser representadas em relação ao eixo de variáveis do veículo na forma:

$$
\begin{aligned}
& I C R_{v}=\left(X_{I C R_{v}}, Y_{I C R_{v}}\right) \\
& I C R_{R}=\left(X_{I C R_{R}}, Y_{I C R_{R}}\right) \\
& I C R_{L}=\left(X_{I C R_{L}}, Y_{I C R_{L}}\right)
\end{aligned}
$$

É conhecido que $I C R_{v}, I C R_{R}$ e $I C R_{L}$ se encontram sobre um eixo paralelo ao eixo x do veículo. Além disto, as velocidades angulares das rodas em relação ao eixo z $\left(\omega_{z}\right)$ devem ser a mesma do veículo, pois estas não podem girar em relação ao corpo do veículo (Figura 14) (Martínez, J. L. et al 2005).

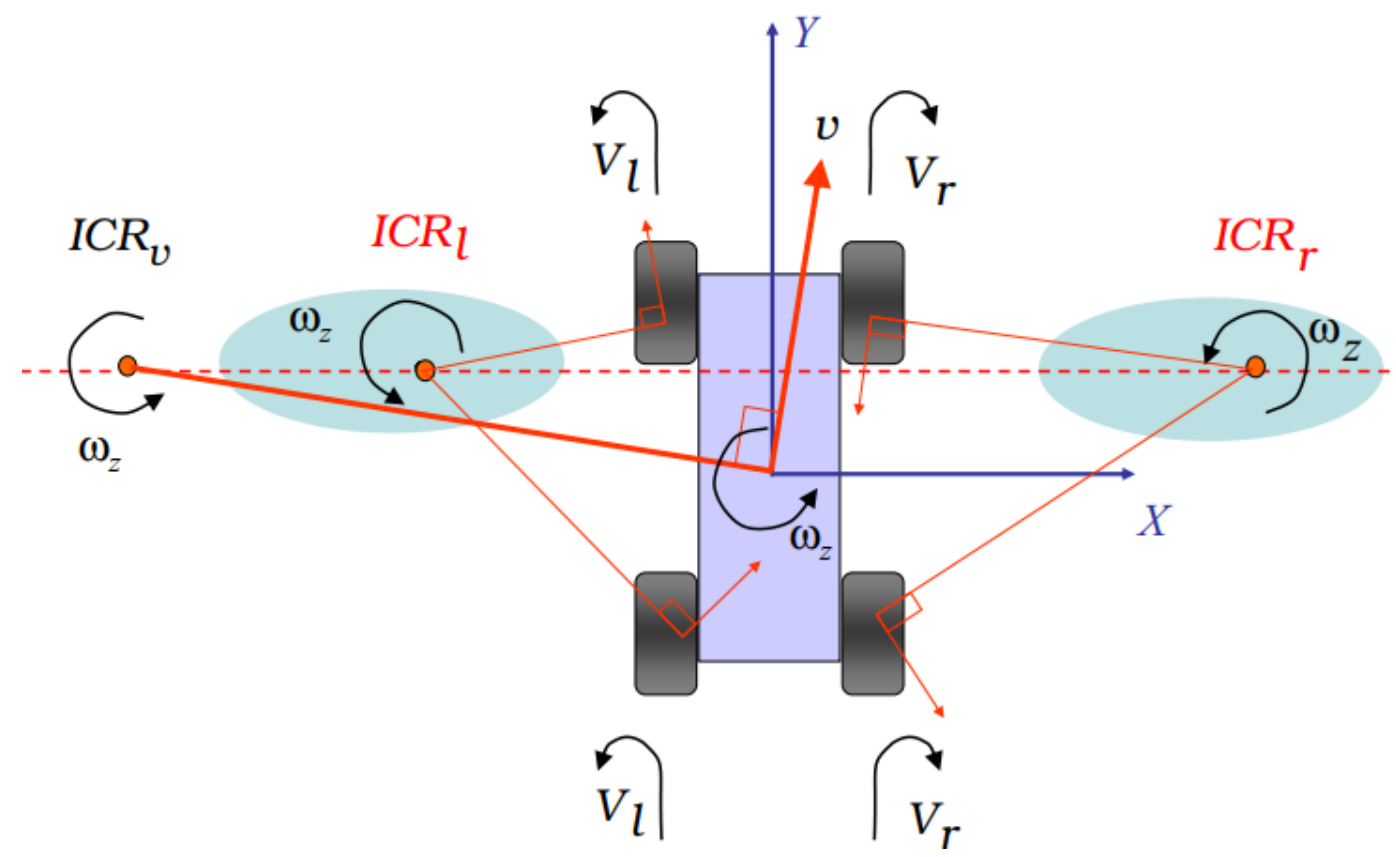

Figura 14 - Posições dos ICRs (Mandow, A. et al 2007)

Definido as posições dos centros instantâneos de rotação, é possível escrevêlas em função das velocidades das rodas e das velocidades do corpo do veículo, como é descrito nas equações 8 a 11 .

$$
X_{I C R_{v}}=-\frac{v_{y}}{\omega_{z}}
$$




$$
\begin{gathered}
X_{I C R_{L}}=\frac{r \omega_{L}-v_{y}}{\omega_{z}} \\
X_{I C R_{R}}=\frac{r \omega_{R}-v_{y}}{\omega_{z}} \\
Y_{I C R_{v}}=Y_{I C R_{R}}=Y_{I C R_{L}}=\frac{v_{x}}{\omega_{z}}
\end{gathered}
$$

onde

- $v_{x}$, velocidade do veículo na direção $\mathrm{x}$.

Para facilitar o entendimento da cinemática do veículo, foram representadas as equações 8 a 11 na sua forma matricial:

$$
\left(\begin{array}{l}
v_{x} \\
v_{y} \\
\omega_{z}
\end{array}\right)=C\left(\begin{array}{l}
\omega_{L} \\
\omega_{R}
\end{array}\right)
$$

onde

- $\quad C$, é a matriz que representa a cinemática do veículo.

Obtém-se:

$$
\left(\begin{array}{c}
v_{x} \\
v_{y} \\
\omega_{z}
\end{array}\right)=\frac{r}{X_{I C R_{R}}-X_{I C R_{L}}}\left(\begin{array}{cc}
-Y_{I C R_{v}} & Y_{I C R_{v}} \\
X_{I C R_{R}} & X_{I C R_{L}} \\
-1 & 1
\end{array}\right)\left(\begin{array}{c}
\omega_{L} \\
\omega_{R}
\end{array}\right)
$$

Usando a hipótese de um veículo simétrico, pode-se considerar que:

$$
\begin{gathered}
X_{I C R_{R}}=-X_{I C R_{L}}=\varphi B \\
Y_{I C R_{v}}=0
\end{gathered}
$$

onde $\varphi$ é o fator de expansão.

Substituindo as equações 14 e 15 na equação 13, é obtida a equação cinemática:

$$
\left(\begin{array}{l}
v_{x} \\
v_{y} \\
\omega_{z}
\end{array}\right)=\left(\begin{array}{cc}
0 & 0 \\
\frac{r}{2} & \frac{r}{2} \\
-\frac{r}{\varphi B} & \frac{r}{\varphi B}
\end{array}\right)\left(\begin{array}{l}
\omega_{L} \\
\omega_{R}
\end{array}\right)
$$


Nota-se que, utilizando a hipótese de veículo simétrico, a velocidade $v_{x}$ se torna nula, sendo assim não existe velocidade lateral no caso de um veículo perfeitamente simétrico.

Deve-se ressaltar que nada na dedução realizada define $\varphi$ como uma constante, e considerar este valor variável resulta no mesmo problema obtido na seção 2.1.1.

Múltiplos trabalhos realizados na área, porém, se utilizaram deste modelo supondo esta variável constante como em (Yu, W. et al, 2009), (Mandow, A. et al 2007) e (Wang, T. et al 2015), que demonstraram resultados positivos para valores de $\varphi$ calibrados experimentalmente.

\subsection{Modelo Dinâmico}

As equações que descrevem o movimento de um corpo rígido no espaço são derivadas diretamente da segunda lei de Newton:

$$
\begin{aligned}
& m_{c} a=\sum_{i} F_{i} \\
& I_{c} \alpha=\sum_{j} M_{j}
\end{aligned}
$$

onde:

- $m_{c}$, massa do corpo rígido;

- $\quad a$, aceleração do corpo rígido;

- $I_{c}$, momento de inércia do corpo rígido;

- $\quad \alpha$, aceleração angular do corpo rígido;

- $F$, forças aplicadas no corpo rígido;

- $M$, momentos aplicados no corpo rígido.

No sistema sendo modelado, as forças mais importantes aplicadas são as forças no contato entra as rodas e o chão, resultando em

$$
\begin{gathered}
m a_{y}=N \frac{\tau_{R}+\tau_{L}}{r} \\
I \alpha_{z}=\frac{B}{2} N \frac{\tau_{R}-\tau_{L}}{r}
\end{gathered}
$$

onde:

- m, massa do veículo; 
- $a_{y}$, aceleração do veículo na direção y;

- $\quad N$, relação de transmissão do sistema de engrenagens acopladas a cada motor;

- $\tau_{R}$, torque que as rodas direitas exercem no veículo;

- $\tau_{L}$, torque que as rodas esquerdas exercem no veículo;

- $\quad I$, momento de inércia do veículo;

- $\alpha_{z}$, aceleração angular do veículo.

Utilizando a cinemática desenvolvida na seção 2.1 .2 é possível escrever as equações dinâmicas em função das acelerações angulares das rodas:

$$
\begin{gathered}
m a_{y}=\frac{m r}{2}\left(\alpha_{L}+\alpha_{R}\right)=N \frac{\tau_{R}+\tau_{L}}{r} \\
I \alpha_{z}=\frac{I r}{\varphi B}\left(-\alpha_{L}+\alpha_{R}\right)=\frac{B}{2} N \frac{\tau_{R}-\tau_{L}}{r}
\end{gathered}
$$

onde:

- $\alpha_{R}$, aceleração angular da roda direita;

- $\alpha_{L}$, aceleração angular da roda esquerda.

Apesar dos motores do veículo serem tipo brushless os torques dos motores foram modelados apartir das equações do motor de corrente continua desprezando a indutância:

$$
\begin{gathered}
\tau=K_{t}\left(I_{m}-I_{\text {no load }}\right) \\
\omega=\frac{1}{K_{t}}\left(V_{\text {in }}-R I_{m}\right)
\end{gathered}
$$

Onde:

- $\tau$, torque exercido pelo motor

- $K_{t}$, constante de toruqe do motor

- $I_{m}$, corrente no motor

- $I_{\text {no load }}$ corrente sem carga no motor, devido perdas mecânicas

- $\omega$, velocidade angular do motor

- $V_{i n}$, tensão de entrada

- $R$, resistência do motor

Desconsiderando as perdas mecânicas a equação de torque do motor de ser escrita da seguinte maneira: 


$$
\tau=\frac{K_{t}}{R} V_{i n}-\frac{\omega}{R}
$$

A tensão de entrada pode ser considerada proporcional ao comando adimensional enviado ao motor:

$$
\tau=\frac{K_{t}}{R} k u-\frac{\omega}{R}
$$

onde:

- $\mathrm{u}$, comando adimensional enviado ao motor

- $k$, constante de proporcionalidade entre u e $V_{i n}$

Por simplicidade os termos $\frac{K_{t}}{R} k$ e $\frac{1}{R}$ podem ser substituídos pelas constantes $K_{V}$ e $K_{\omega}$, respectivamente.

$$
\begin{aligned}
& \tau_{R}=K_{V} u_{R}-K_{\omega} N \omega_{R} \\
& \tau_{L}=K_{V} u_{L}-K_{\omega} N \omega_{L}
\end{aligned}
$$

onde:

- $u_{R}$, comando enviado ao motor direito;

- $u_{L}$, comando enviado ao motor esquerdo;

- $K_{V}$, constante de tensão;

- $K_{\omega}$, constante de rotação.

Embora existam modelos mais sofisticados capazes de modelar de maneira mais próxima a dinâmica de um motor elétrico, foi utilizado o modelo apresentado nas equações 27 e 26, devido à sua simplicidade.

Utilizando as equações apresentadas e a cnimatica desenvolvida anteriormente é possível escrever as equações dinâmicas em função das velocaides do veículo e das entradas nos motores

$$
\begin{gathered}
a_{y}=-\frac{2 K_{\omega} v_{y}}{r^{2} N m}+\frac{K_{V} u_{L}}{m r}+\frac{K_{V} u_{R}}{m r} \\
\omega_{z}=-\frac{B^{2} K_{\omega} \phi \omega}{r^{2} N I}-\frac{K_{V} B u_{L}}{I r}+\frac{K_{V} B u_{R}}{I r}
\end{gathered}
$$

Utilizando-se as equações apresentadas neste capitulo, foi desenvolvida uma simulação em Simulink, descrita no capitulo 5, e o modelo de previsão utilizado no filtro de Kalman, descrito no capítulo a seguir. 


\section{Filtro de Kalman}

Com origem na década de 1960, o filtro de Kalman é um conjunto de equações matemáticas que tem como objetivo, a partir de um processo recursivo, estimar eficientemente os estados de um sistema dinâmico na presença de ruídos. Foi baseado no artigo "A New Approach to Linear Filtering and Prediction Problems”, criado por Rudolf Kalman, onde descreve a resolução de problemas lineares através da observação e estimação de estados (Kalman R. E. 1960).

Inicialmente, o filtro de Kalman apenas era utilizado para tempos discretos. Em março de 1961, com a parceria de Richard Bucy, foi desenvolvido um artigo chamado "New Results in Linear Filtering and Prediction Theory", onde foi criada uma variante para tempos contínuos.

O filtro de Kalman é aplicável na robótica, em sistemas de localização como GPS (Global Positioning System), em telecomunicação, em estimações de cursos de rios, e em muitas outras aplicações.

\subsection{Teoria do filtro de Kalman}

Nesta seção é apresentada uma revisão sobre o funcionamento do filtro. É abordado somente o funcionamento do filtro para o caso discreto, uma vez que todas as medidas e previsões são realizadas discretamente no sistema utilizado. Em (Thrun, S., Burgard, W., Fox, D., 2005), (Grewal, M. S., Andrews, A. P.,2011) e (Negenborn, R., 2003) é possível encontrar uma análise mais profunda das equações descritas aqui.

Central ao conceito de robótica probabilística está a representação de incertezas de forma explícita, utilizando a teoria da probabilidade como background para os cálculos realizados. Sendo possível representar informações, não como um único número, mas como uma distribuição de probabilidade ao longo de vários valores possíveis. 
O filtro de Kalman é definido na literatura como um filtro Gaussiano. Este tipo de filtro considera a distribuição de probabilidades das incertezas por distribuições normais multivariadas.

O método consiste em duas etapas principais: de previsão e de correção, que funcionam de forma recursiva (Figura 15) de modo a minimizar o erro quadrático entre os valores previstos e os medidos. Na primeira etapa, também conhecida como estimativa a priori, o filtro estima utilizando um modelo linear o estado atual a partir dos dados obtidos do estado anterior e das entradas do sistema no estado atual. A matriz de covariância da previsão realizada é calculada a partir da covariância do estado anterior, do modelo de previsão utilizado e da matriz de covariância associada ao modelo utilizado. A equação a seguir representa de forma matemática a etapa de previsão.

$$
\left\{\begin{array}{l}
\bar{x}_{k}=F_{k} \hat{x}_{k-1}+G_{k} u_{k} \\
\bar{P}_{k}=F_{k} \hat{P}_{k-1} F_{k}^{T}+Q_{k}
\end{array}\right.
$$

onde:

- $\bar{x}_{k}$, previsão do estado no instante k;

- $\quad F_{k}$, matriz do modelo de dependência entre o estado previsto atual e o anterior;

- $\hat{x}_{k-1}$, estimativa do estado no instante anterior do sistema (valor do filtro na etapa anterior);

- $G_{k}$, matriz de efeito das entradas sobre o sistema;

- $u_{k}$, entrada do sistema no instante k;

- $\bar{P}_{k}$, matriz de covariância da previsão do estado no instante k;

- $\hat{P}_{k-1}$, matriz de covariância da estimativa do estado no instante anterior;

- $Q_{k}$, matriz de covariância do ruído do processo.

Na segunda etapa do filtro, são realizados os cálculos de correção:

$$
\left\{\begin{array}{l}
y_{k}=z_{k}-H_{k} \bar{x}_{k}+D_{k} u_{k} \\
S_{k}=H_{k} \bar{P}_{k} H_{k}^{T}+R_{k} \\
K_{k}=\bar{P}_{k} H_{k}^{T} S_{k}^{-1} \\
\hat{x}_{k}=\bar{x}_{k}+K_{k} y_{k} \\
\hat{P}_{k}=\bar{P}_{k}-K_{k} H_{k} \bar{P}_{k}
\end{array}\right.
$$


- $y_{k}$, resíduo entre as medições e a previsão do estado no instante k;

- $z_{k}$, medições realizadas no instante $\mathrm{k}$;

- $H_{k}$, matriz de estado do modelo de medições do sistema;

- $\quad D_{k}$, matriz de entradas do modelo de medições do sistema;

- $S_{k}$, covariância de $y_{k}$;

- $R_{k}$, matriz de covariância das medições;

- $K_{k}$, ganho ótimo de Kalman no instante k;

- $\hat{x}_{k}$, estimativa do estado atual;

- $\hat{P}_{k}$, covariância da estimativa do estado atual.

Inicialmente é calculado o resíduo entre as medições realizadas pelos sensores no instante atual e o valor previsto. Para que seja possível realizar a comparação, é necessário um modelo de medições que transforma o vetor de estado obtido pela previsão para um vetor de medidas previstas, sendo possível então realizar a comparação com as medidas realizadas pelos sensores. No passo seguinte é calculada a matriz de covariância do resíduo, utilizando a matriz de covariância das medições. Em seguida é calculado o ganho ótimo de Kalman, que é um peso obtido de forma a minimizar o erro quadrático entre a estimativa do estado e as informações disponíveis (previsão e medição).

O ganho de Kalman pode ser visto como um grau de confiabilidade das medições em um dado instante. Quanto maior o valor, considera-se que a medição está mais próxima da realidade que a previsão. Com este valor, é calculado uma estimativa do estado real no instante atual. E, finalmente, é calculada a matriz de covariância da estimativa fornecida pelo filtro.

Analisando o valor da covariância da estimativa do estado atual, pode-se saber quanto o valor estimado está próximo da realidade. Sendo assim, quanto menor o valor da covariância, mais próximo da realidade é o valor estimado. 


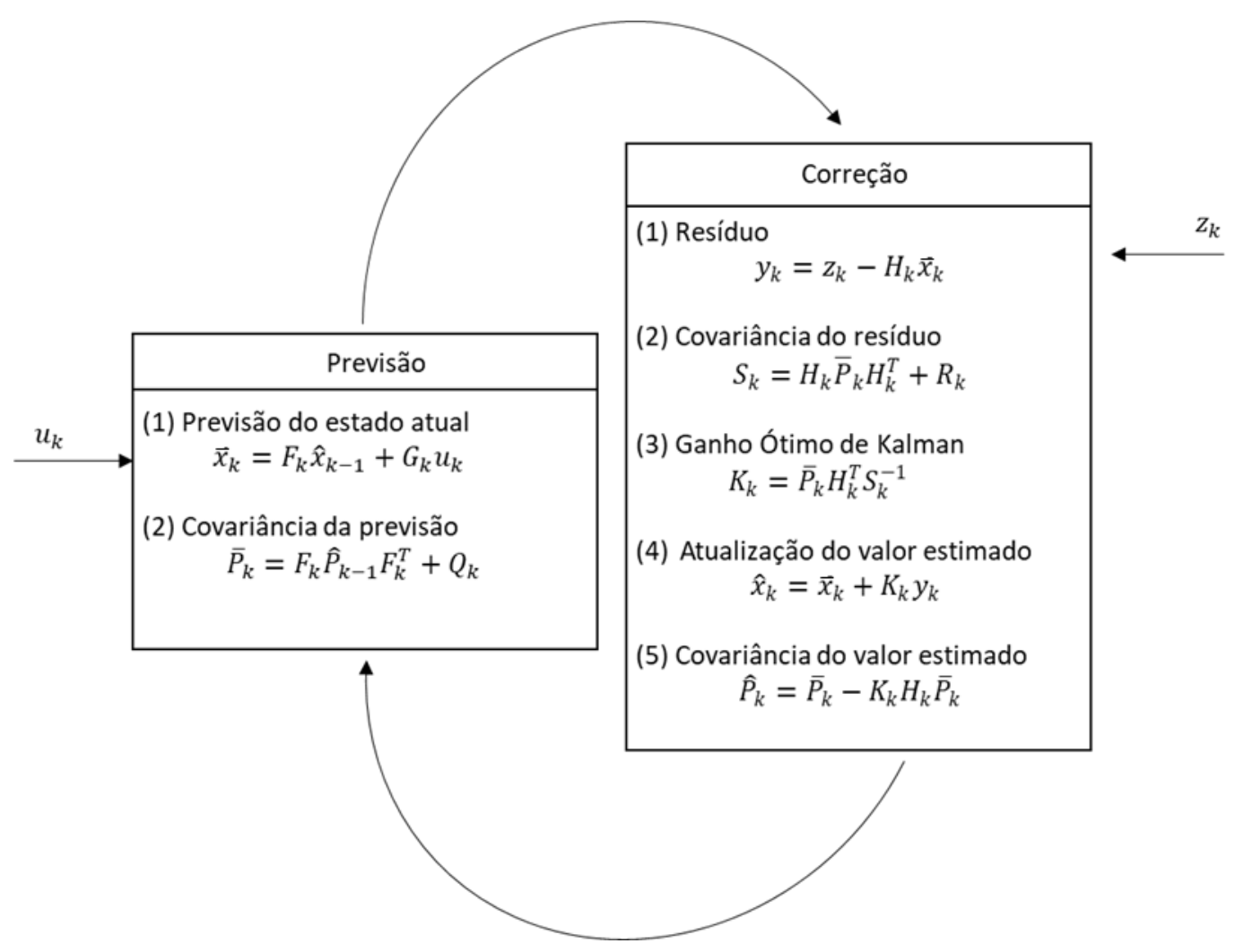

Figura 15- Diagrama do funcionamento do filtro de Kalman

\subsection{Equacionamento sem bússola}

Para implementar as equações do modelo desenvolvido no capitulo 2, devese definir primeiramente quais são as variáveis de estado. Neste trabalho, as variáveis de estado utilizadas serão a velocidade e a velocidade angular do veículo testado. Também é necessário definir as entradas do sistema, que no caso do robô RITA (Robô de Inspeção de Tanques de Armazenamento) utilizado são os comandos enviados aos motores:

$$
\begin{aligned}
& x=\left(\begin{array}{l}
v_{y} \\
\omega_{z}
\end{array}\right) \\
& u=\left(\begin{array}{l}
u_{L} \\
u_{R}
\end{array}\right)
\end{aligned}
$$

onde:

- $x$, vetor de estado;

- $u$, vetor de entradas. 
Para que seja possível trabalhar com o filtro de Kalman, é preciso descrever o modelo de previsão do sistema da forma:

$$
\bar{x}_{k}=F_{k} \hat{x}_{k-1}+G_{k} u_{k-1}
$$

Tendo definido as variáveis de estado e as entradas, é preciso definir as matrizes $F_{k}$ e $G_{k}$. No cpitulo 2 foram desenvolvidas as equações de aceleração ( $\mathrm{XX}$ ) e aceleração angular (XX) do veículo, a velocidade e velocidade angular do veiculo pode ser calculada apartir da integração destas variáveis

$$
\begin{aligned}
& v_{y}=\int a_{y} d t \\
& \omega_{z}=\int \alpha_{z} d t
\end{aligned}
$$

Para que seja possível trabalhar com o filtro de Kalman, deve-se simplificar a integração para um sistema linear da forma:

$$
\begin{aligned}
& \bar{v}_{y_{k+1}}=\hat{v}_{y_{k}}+\Delta T \hat{a}_{y_{k}} \\
& \widehat{\omega}_{z_{k+1}}=\widehat{\omega}_{y_{k}}+\Delta T \hat{\alpha}_{z_{k}}
\end{aligned}
$$

onde:

- $\bar{v}_{y_{k+1}}$, previsão da velocidade no instante $\mathrm{k}+1$;

- $\hat{v}_{y_{k}}$, estimativa da velociade no instante $\mathrm{k}$;

- $\Delta T$, variação do tempo

- $\hat{a}_{y_{k}}$, estimativa da aceleração no instante $\mathrm{k}$

- $\widehat{\omega}_{z_{k+1}}$, previsão da velocidade angular no instante $k+1$

- $\widehat{\omega}_{y_{k}}$, estimativa da velocidade angular no instante $\mathrm{k}$

- $\hat{\alpha}_{z_{k}}$, estimativa da aceleração angular no instante $\mathrm{k}$

Utilizandos as equações 29 e 30 é possivel reescrever as equações 38 e 39 em função das variáveis de estado e das esntradas. 


$$
\begin{aligned}
\left(\begin{array}{c}
v_{y_{k+1}} \\
\omega_{z_{k+1}}
\end{array}\right)= & \left(\begin{array}{cc}
-\frac{2 K_{\omega} \Delta T}{r^{2} N m}+1 & 0 \\
0 & -\frac{B^{2} K_{\omega} \phi \Delta T}{r^{2} N I}+1
\end{array}\right)\left(\begin{array}{l}
v_{y_{k}} \\
\omega_{z_{k}}
\end{array}\right) \\
& +\left(\begin{array}{cc}
\frac{K_{V} \Delta T}{m r} & \frac{K_{V} \Delta T}{m r} \\
-\frac{K_{V} B \Delta T}{I r} & \frac{K_{V} B \Delta T}{I r}
\end{array}\right)\left(\begin{array}{l}
u_{L_{k}} \\
u_{R_{k}}
\end{array}\right)
\end{aligned}
$$

Assim, as matrizes $F_{k}$ e $G_{k}$ são definidas como:

$$
\begin{gathered}
F_{k}=\left(\begin{array}{cc}
-\frac{2 K_{\omega} \Delta T}{r^{2} N m}+1 & 0 \\
0 & -\frac{B^{2} K_{\omega} \phi \Delta T}{r^{2} N I}+1
\end{array}\right) \\
G_{k}=\left(\begin{array}{cc}
\frac{K_{V} \Delta T}{m r} & \frac{K_{V} \Delta T}{m r} \\
-\frac{K_{V} B \Delta T}{I r} & \frac{K_{V} B \Delta T}{I r}
\end{array}\right)
\end{gathered}
$$

A matriz $H_{k}$ realiza a simulação das medidas que seriam obtidas no estado previsto, permitindo a comparação com as medidas obtidas pelos sensores naquele instante. As medidas dos encoders pode ser obitadas atravé da equação 16 descrita no cápitulo 2

$$
\begin{gathered}
\bar{e}_{L_{k+1}}=-\left(\frac{B \phi \bar{\omega}_{z_{k+1}}-2 v_{y_{k+1}}}{2 r}\right) \\
\bar{e}_{R_{k+1}}=\left(\frac{B \phi \bar{\omega}_{z_{k+1}}+2 v_{y_{k+1}}}{2 r}\right)
\end{gathered}
$$

onde:

- $\bar{e}_{L_{k+1}}$, medida do encoder do motor esquerdo prevista;

- $\bar{e}_{R_{k+1}}$, medida do encoder do motor direito prevista.

A aceleração prevista pode ser calculada apartir da equação 29 desenvolvida no cpitulo 2

$$
\overline{a c}_{y_{k+1}}=-\frac{2 K_{\omega} v_{y_{k+1}}}{r^{2} N m}+\frac{\left.K_{V(} u_{R_{k+1}}+u_{L_{k+1}}\right)}{m r}
$$


onde:

- $\overline{a c}_{y_{k+1}}$, medida do acelerômetro prevista no instante $\mathrm{k}+1$;

A velocidade angular prevista é obtida diretamente, pois a velocidade angular é uma das variáveis de estado do sitema:

$$
\begin{gathered}
\bar{g}_{z_{k+1}}=\omega_{z_{k+1}} \\
\bar{\omega}_{z_{k+1}}=\frac{r}{\varphi B} N\left(-\bar{\omega}_{L_{k+1}}+\bar{\omega}_{R_{k+1}}\right)
\end{gathered}
$$

onde:

- $\bar{g}_{z_{k+1}}$, medida do girômetro prevista no instante $\mathrm{k}+1$.

As matrizes $H_{k}$ e $D_{k}$ resultantes destas equações são:

$$
\begin{aligned}
H_{k} & =\left(\begin{array}{cc}
-\frac{2 K_{\omega}}{r^{2} N m} & 0 \\
0 & 1 \\
\frac{1}{r} & \frac{B \phi}{2 r} \\
\frac{1}{r} & \frac{B \phi}{2 r}
\end{array}\right) \\
D_{k} & =\left(\begin{array}{cc}
\frac{K_{V}}{m r} & \frac{K_{V}}{m r} \\
0 & 0 \\
0 & 0 \\
0 & 0
\end{array}\right)
\end{aligned}
$$

As matrizes $R_{k}$ e $Q_{k}$ foram consideradas matrizes diagonais constantes, onde os valores nas suas diagonais são as variâncias dos sensores utilizados e das previsões realizadas pelo modelo, respectivamente:

$$
\begin{gathered}
R_{k}=\left(\begin{array}{cccc}
\sigma_{a y} & 0 & 0 & 0 \\
0 & \sigma_{\omega z} & 0 & 0 \\
0 & 0 & \sigma_{e L} & 0 \\
0 & 0 & 0 & \sigma_{e R}
\end{array}\right) \\
Q_{k}=\left(\begin{array}{cc}
\sigma_{v} & 0 \\
0 & \sigma_{\omega}
\end{array}\right)
\end{gathered}
$$

onde:

- $\sigma_{a y}$, variância do acelerômetro;

- $\sigma_{\omega z}$, variância do girômetro;

- $\sigma_{e L}$, variância do encoder esquerdo;

- $\sigma_{e R}$, variância do encoder direito;

- $\sigma_{v}$ variância da previsão da velocidade;

- $\sigma_{\omega}$, variância da previsão da velocidade angular; 


\subsection{Equacionamento com bússola}

O sistema proposto neste trabalho não utiliza as medições ruidosas da bússola, porém, para permitir uma comparação dos resultados com e sem o sensor, foram desenvolvidas as equações necessárias para implementar o uso do magnetômetro no filtro de Kalman.

Para introduzir as medições do magnetômetro no sistema de localização proposto, é necessário reescrever as equações do filtro. Para localização $2 \mathrm{D}$, as medidas do magnetômetro podem ser utilizadas para calcular diretamente o ângulo entre o veículo e o norte magnético:

$$
\theta_{N}=\arctan \left(\frac{M_{y}}{M_{x}}\right)
$$

onde:

- $\theta_{N}$, o ângulo entre o norte magnético e o veículo.

- $M_{x}$, sinal do magnetômetro no eixo X;

- $M_{y}$, sinal do magnetômetro no eixo Y.

O ângulo do veículo em relação a um eixo fixo de coordenadas pode ser obtido se o ângulo entre o eixo de coordenadas e o norte magnético é conhecido:

$$
\theta=\theta_{N}-\theta_{E}
$$

onde:

- $\theta$, ângulo entre o eixo longitudinal do veículo e o eixo fixo;

- $\theta_{E}$, ângulo entre o eixo fixo e o norte magnético.

Para facilidade de integração com o filtro desenvolvido, os cálculos descritos acima são realizados fora do filtro de Kalman, permitindo continuar utilizando o filtro linear para o sistema.

Para introduzir as medições do magnetômetro no filtro de Kalman, é necessário alterar o vetor de estado de forma a incluir o ângulo de orientação $\theta$. Sendo assim, o vetor de estados $x_{m a g}$ é: 


$$
x_{m a g}=\left(\begin{array}{c}
v_{y} \\
\omega_{z} \\
\theta
\end{array}\right)
$$

onde

- $x_{\text {mag }}$, vetor de estado do filtro de Kalman com o magnetômetro.

A adição de $\theta$ no vetor de estados do sistema requer que seja determinada uma nova matriz para o passo de previsão. Para isso, é necessário relacionar $\theta$ com as outras variáveis do estado. $\theta$ pode ser calculado a partir da integração da velocidade angular do veículo $\left(\omega_{z}\right)$ :

$$
\theta=\int \omega_{z} d t
$$

Como feito anteriormente para as variáveis $v_{y}$ e $\omega_{z}$, é possível escrever a equação 48 como um sistema linear, resultado em:

$$
\bar{\theta}_{k}=\hat{\theta}_{k-1}+\widehat{\omega}_{z_{k-1}} \Delta t
$$

onde:

- $\bar{\theta}_{k}$, ângulo de orientação previsto, no instante k;

- $\hat{\theta}_{k-1}$, ângulo de orientação estimado, no instante k-1;

- $\widehat{\omega}_{z_{k-1}}$, velocidade angular estimada, no instante $\mathrm{k}-1$.

A partir destas equações, é possível escrever a etapa de previsão deste sistema de localização como:

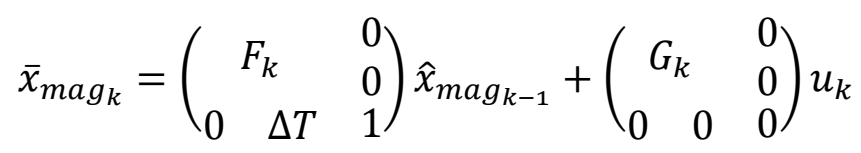

onde:

- $\bar{x}_{\text {mag }_{k}}$, vetor de estado previsto para o filtro com magnetômetro, no instante $\mathrm{k}$;

- $\hat{x}_{m_{a g} g_{k-1}}$, vetor de estado estimado para o filtro com magnetômetro, no instante k-1.

Sendo introduzida uma nova medição no filtro, o vetor de medições deve ser alterado de acordo:

$$
z_{m a g}=\left(\begin{array}{c}
a_{y} \\
\omega_{z} \\
e_{L} \\
e_{R} \\
\theta_{m a g}
\end{array}\right)
$$


onde:

- $z_{\text {mag }}$, vetor de medições para o filtro com magnetômetro.

Como o filtro de Kalman recebe diretamente o ângulo de orientação medido através do magnetômetro, a equação relacionando a medição $\theta_{\text {mag }}$, num instante $\mathrm{k}$ com o ângulo de orientação $\theta$ é:

$$
\theta_{\text {mag }_{k}}=\theta_{k}
$$

Desta maneira, a equação para o cálculo do ruído entre as medições e as previsões pode ser escrita como:

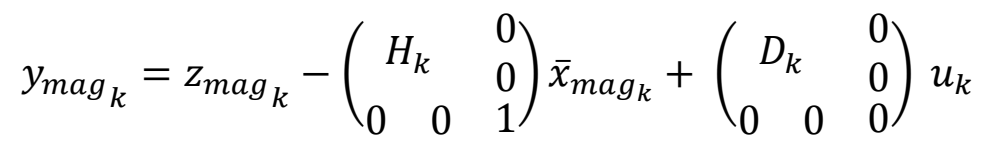

onde

- $y_{\text {mag }_{k}}$, ruído entre as medições e as previsões para o filtro com o magnetômetro no instante $\mathrm{k}$.

A última alteração necessária para o uso do filtro é incluir a variância da previsão de $\theta$ na matriz de covariância das previsões, incluindo também a variância da medição do ângulo de orientação $\theta_{\text {mag }}$ na matriz de covariância das medições.

$$
\begin{gathered}
R_{\text {mag }_{k}}=\left(\begin{array}{ccc}
R_{k} & & 0 \\
0 & 0 & \sigma_{\theta}
\end{array}\right) \\
Q_{\text {mag }_{k}}=\left(\begin{array}{ccccc} 
& & & 0 \\
& Q_{k} & & 0 \\
& & & 0 \\
0 & 0 & 0 & 0 & \sigma_{m a g}
\end{array}\right)
\end{gathered}
$$

onde:

- $R_{m a g_{k}}$, matriz de covariância das previsões do sistema de localização com o magnetômetro;

- $Q_{m a g_{k}}$, matriz de covariância das previsões do sistema de localização com o magnetômetro;

- $\sigma_{\theta}$, variância da previsão do ângulo de orientação $\theta$;

- $\sigma_{\text {mag }}$, variância do ângulo medido pelo magnetômetro. 
As equações desenvolvidas neste capitulo serão utilizadas no capitulo 5, onde são realizadas simulações do funcionamento do filtro proposto (sem o uso da bússola), e no capítulo 6, onde estão descritos os experimentos realizados para analisar o desempenho do método desenvolvido. Para que seja possível realizar testes práticos das técnicas desenvolvidas neste capítulo, é necessário determinar os parâmetros do veículo utilizado. Estes valores e os métodos utilizados para determiná-los são apresentados no capítulo seguinte. 


\section{Sistema Experimental}

Neste capítulo são descritos os equipamentos utilizados na realização dos testes experimentais descritos no capítulo 6. Também são descritas as calibrações dos sensores utilizados, e os problemas encontrados na utilização da central inercial (IMU) e as soluções adotadas neste trabalho.

Com o objetivo de testar o sistema de localização desenvolvido, foi utilizado o robô RITA, mostrado na Figura 16, um protótipo desenvolvido pelo Laboratório de Robótica da PUC-Rio (LabRob) em parceria com a Petrobras, para a inspeção interna dos seus tanques de armazenamento.

\subsection{Veículo}

O sistema de tração do veículo consiste de rodas magnéticas tracionadas por dois motores tipo brushless, equipados com encoders para medição das velocidades de rotação. Cada um destes está conectado a uma caixa de transmissão planetária de relação de transmissão $N=113$.

Como pode ser observado na Figura 16, as rodas de cada lado do veículo estão conectadas por fitas dentadas, isto permite que a tração seja transmitida das rodas atuadas para as rodas passivas do veículo. Este acoplamento também garante que a velocidade das rodas de um mesmo lado seja a mesma, sendo esta uma das hipóteses utilizadas no desenvolvimento do modelo do veículo realizado no capítulo 2.

Representado no esquema da Figura 17 estão as dimensões do veículo; todas as medidas foram obtidas através de medição direta no laboratório realizadas pelo autor, a partir das dimensões do protótipo usinado.

A largura total $\left(L_{T}\right)$ do veículo é $0,375 \mathrm{~m}$, com os pontos extremos sendo as faces externas das rodas direita e esquerda. O comprimento total $\left(C_{T}\right)$ do veículo é $0,368 \mathrm{~m}$, sendo os pontos extremos nesta direção as rodas dianteiras e traseiras. As dimensões do paralelepípedo que forma o corpo do veículo (chassis) possuem largura $\left(L_{C}\right) 0,175 \mathrm{~m}$ e comprimento $\left(C_{C}\right) 0,33 \mathrm{~m}$. As rodas do veículo têm largura 
$\left(L_{R}\right)$ 0,055m e diâmetro $\left(D_{R}\right)$ 0,1m. Na Figura 17 está ilustrado um desenho esquemático das dimensões descritas.

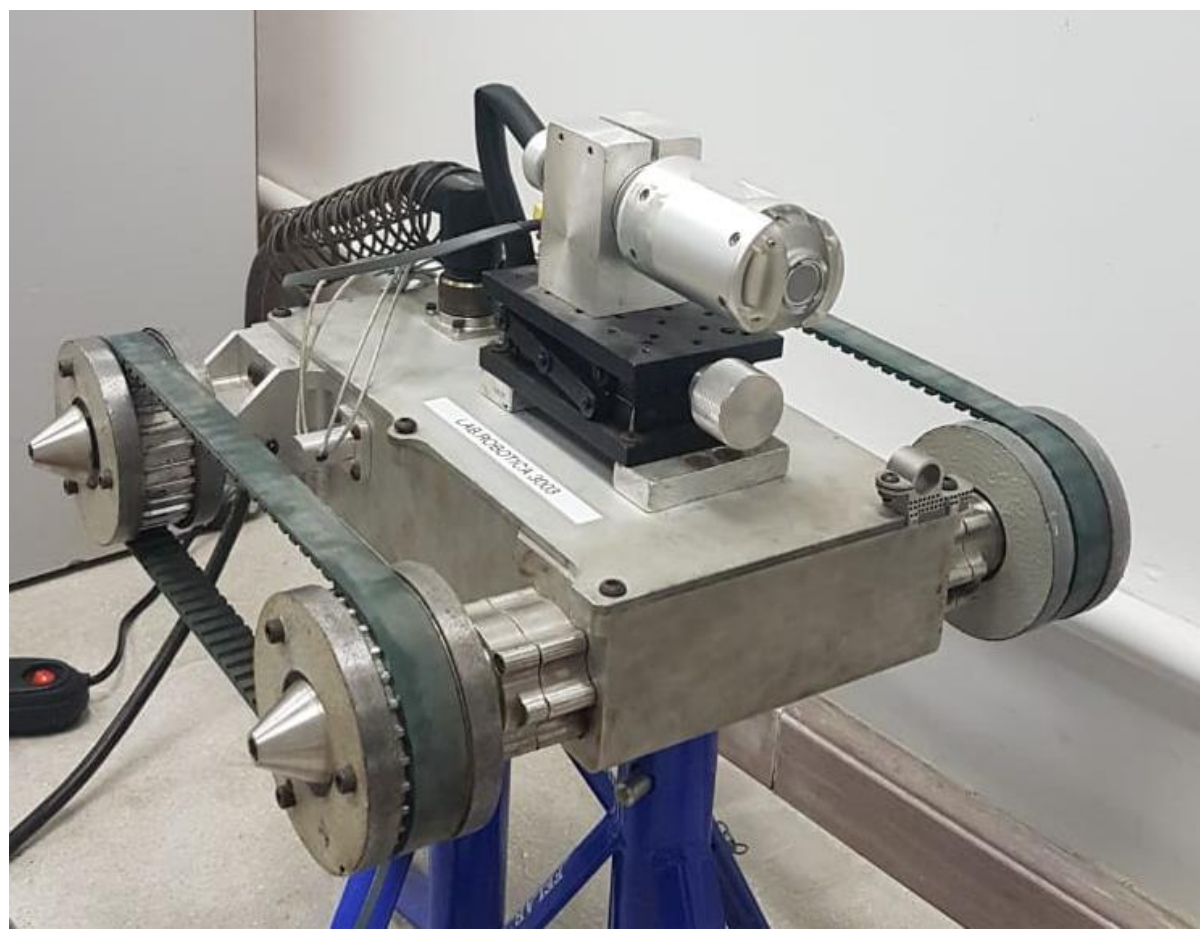

Figura 16 - Robô RITA

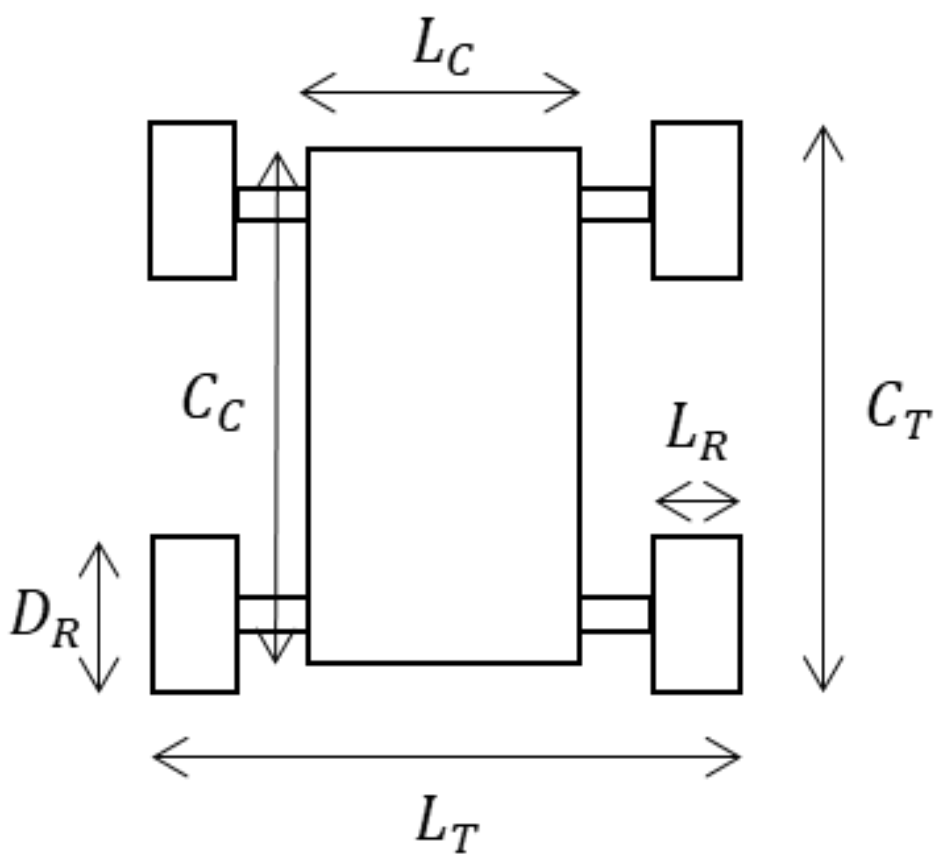

Figura 17 - RITA, vista superior 
As dimensões no mesmo eixo da altura do veículo, o eixo z, também foram medidas. A altura total do veículo $\left(H_{T}\right)$ é $0,225 \mathrm{~m}$, sendo esta medida do chão ao ponto mais alto do veículo, localizado na parte superior do suporte da câmera utilizada em tarefas de inspeção. A altura $\left(H_{C}\right)$ do paralelepípedo que compõe o corpo do veículo mede $0,077 \mathrm{~m}$, e a altura $\left(H_{c a}\right)$ do topo do corpo do veículo até o ponto mais alto do veículo vale $0,13 \mathrm{~m}$. A Figura 18 representa esquematicamente a vista lateral do veículo, e nela estão representadas as dimensões citadas anteriormente.

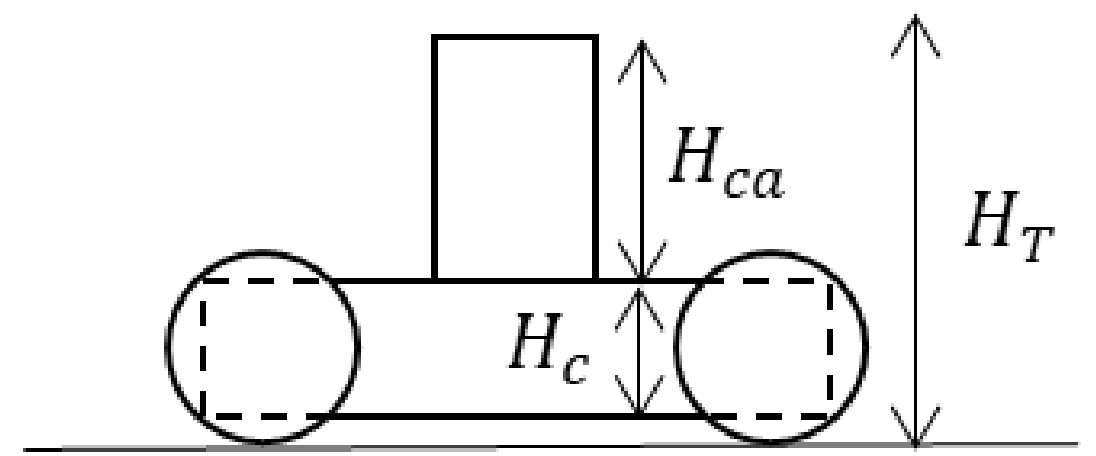

Figura 18 - RITA, vista lateral.

Para melhor acesso aos dados foi feita uma tabela - Tabela 1 - com todos os dados de dimensão do robô RITA.

Tabela 1 - Dimensões

\begin{tabular}{|l|c|}
\hline Altura da câmera $\left(H_{c a}\right)$ & $0,13 \mathrm{~m}$ \\
\hline Altura do corpo $\left(H_{c}\right)$ & $0,077 \mathrm{~m}$ \\
\hline Altura total $\left(H_{T}\right)$ & $0,225 \mathrm{~m}$ \\
\hline Comprimento do corpo $\left(C_{c}\right)$ & $0,33 \mathrm{~m}$ \\
\hline Comprimento total $\left(C_{T}\right)$ & $0,368 \mathrm{~m}$ \\
\hline Diâmetro das rodas $\left(D_{R}\right)$ & $0,1 \mathrm{~m}$ \\
\hline Largura da roda $\left(L_{R}\right)$ & $0,055 \mathrm{~m}$ \\
\hline Largura do corpo $\left(L_{C}\right)$ & $0,175 \mathrm{~m}$ \\
\hline Largura total $\left(L_{T}\right)$ & $0,378 \mathrm{~m}$ \\
\hline
\end{tabular}

Para a utilização do modelo desenvolvido no capitulo 2, é necessário a determinação de alguns parâmetros físicos do veículo utilizado. Estes parâmetros 
são a distância entre as rodas (B), o raio das rodas (r), a massa do veículo (m), e o momento de inércia no eixo de rotação do veículo $\left(I_{z}\right)$.

A distância entre as rodas e o raio das rodas podem ser obtidos diretamente através das medidas na Tabela 1 . O raio da roda é simplesmente a metade do diâmetro da roda. A distância entre as rodas (B) é comumente definida como a distância entre os centros das rodas, podendo ser obtida facilmente sabendo a largura total do veículo e a largura das rodas.

Os parâmetros restantes foram determinados utilizando o modelo de 3D desenvolvido no SolidWorks, ilustrado na Figura 19. Apesar de existirem diferenças entre o modelo 3D inicial e o protótipo final, foi considerado que os dados extraídos representavam satisfatoriamente o veículo sendo utilizado.

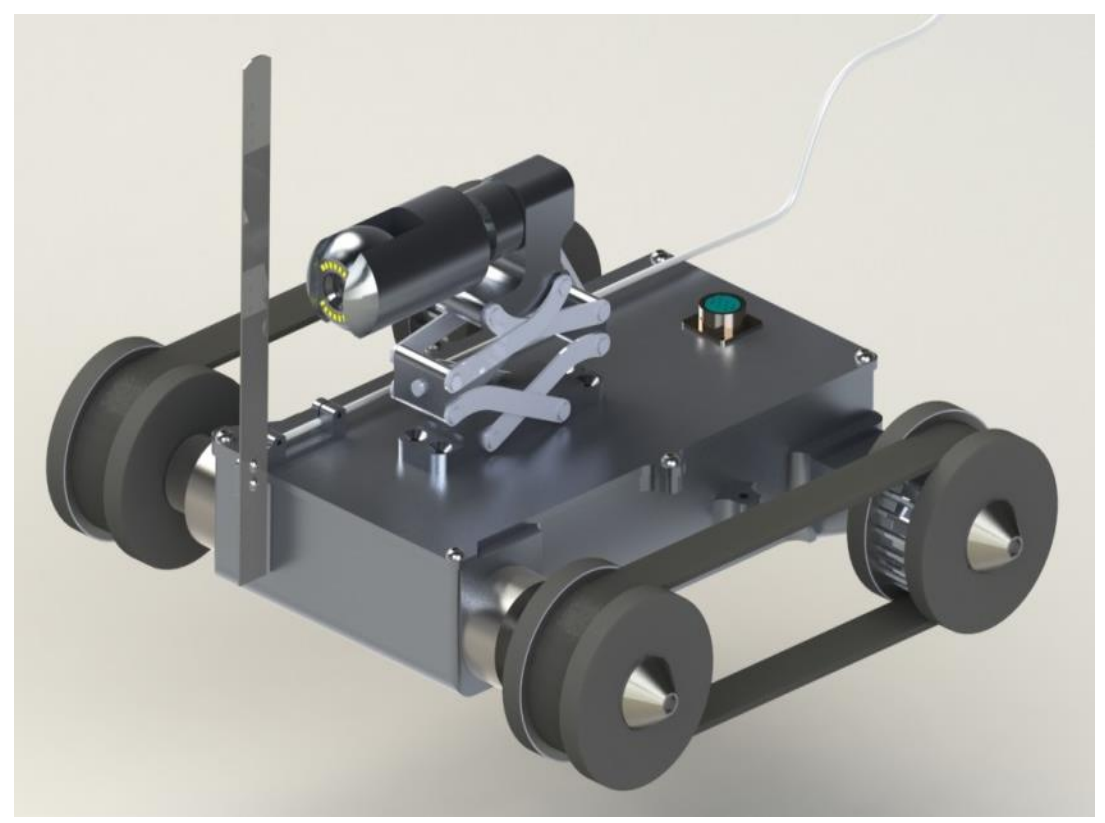

Figura 19 - Modelo em SolidWorks do robô RITA

Para fácil consulta ao longo deste trabalho, os parâmetros físicos utilizados no modelo estão relacionados na Tabela 2 .

Tabela 2 - Dimensões utilizadas no modelo

\begin{tabular}{|c|c|}
\hline Distância entre rodas- B $(\mathrm{m})$ & 0,323 \\
\hline Raio das rodas $-\mathrm{r}(\mathrm{m})$ & 0,05 \\
\hline Massa do veículo $(\mathrm{Kg})$ & 26,5 \\
\hline Momento de inércia no eixo $\mathrm{z}-I_{z}\left(\mathrm{Kg} \mathrm{m}^{2}\right)$ & 0,9835 \\
\hline
\end{tabular}




\subsection{Central Inercial}

Para a ajudar na localização do veículo, foi instalada no robô uma central inercial (Figura 20), ou Inertial Mesurement Unit (IMU). O modelo utilizado foi a SparkFun 9DoF Razor IMU M0. Este modelo contém três tipos de sensores diferentes, um acelerômetro MEMS de três eixos, um girômetro MEMS de três eixos e um magnetômetro MEMS de três eixos, permitindo medir acelerações, velocidades angulares e intensidade do campo magnético nas três diferentes direções.

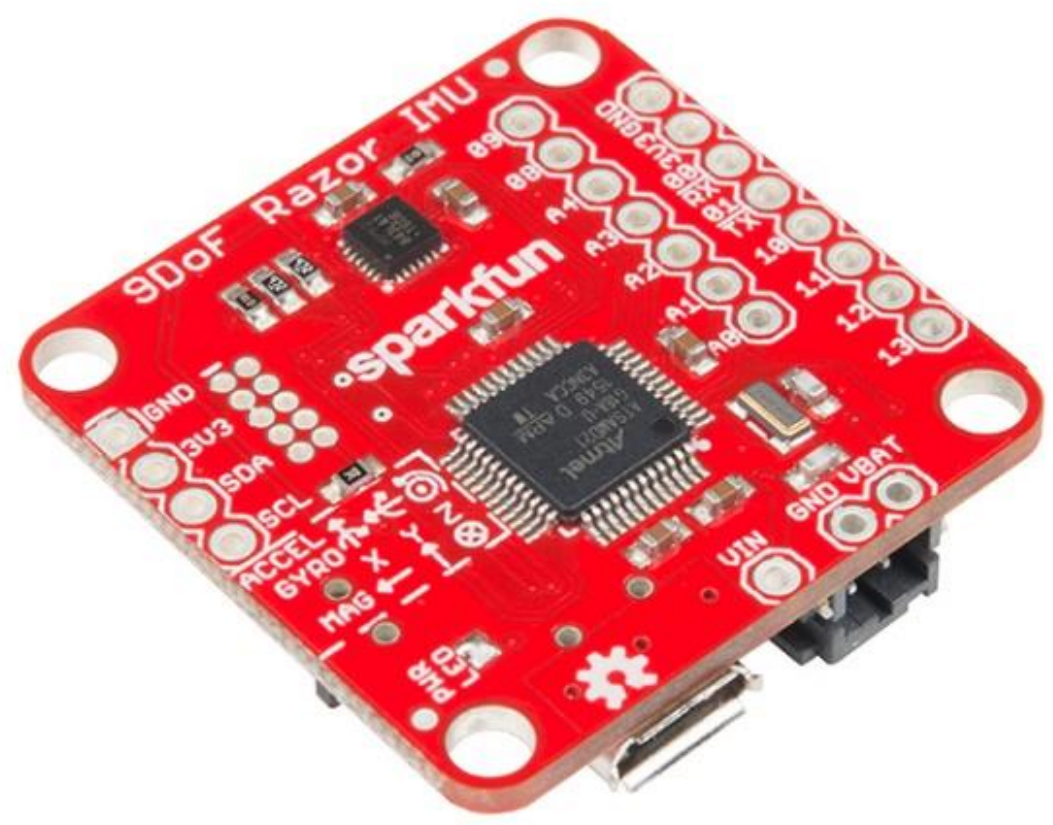

Fonte: <https://www.sparkfun.com/products/14001> Figura 20 - SparkFun 9DoF Razor IMU M0

A IMU é capaz de medir acelerações lineares e velocidades angulares, a partir dos acelerômetros e girômetros respectivamente. Desta forma, é possível estimar os seis graus de liberdade de um corpo rígido no espaço 3D, o que deveria permitir determinar a posição da IMU em relação a um ponto inicial conhecido. Este processo, porém, está sujeito ao grande efeito de drift. 
Em sistemas equipados com magnetômetros, o efeito de drift pode ser reduzido utilizando estes sensores para identificar a direção do campo magnético da Terra oferecendo, em tese, medições absolutas sobre a orientação dos sensores.

Os magnetômetros utilizados em IMUs, devido ao seu principal uso ser a medição do campo eletromagnético da Terra, são sensores de alta sensibilidade, o que os torna vulneráveis a interferência de outros campos eletromagnéticos.

O robô utilizado, assim como a maioria dos robôs de inspeção de tanques de armazenamento, utiliza rodas magnéticas, sendo estas essenciais para que o robô seja capaz de realizar a inspeção em todo o tanque. O campo produzido pelas rodas devido à sua proximidade com o sensor tem uma intensidade muito maior que a do campo da Terra, interferindo de maneira aguda nas medições produzidas por ele. Além disso, a distância necessária para afastar o magnetômetro das rodas para evitar os ruídos seria muito elevada, e sua implementação inviável em um robô compacto que precisa ser inserido por uma estreita entrada de serviço do tanque de armazenamento inspecionado. Por esta razão, o magnetômetro não foi utilizado para o sensoriamento do veículo.

Originalmente, a IMU foi posicionada dentro do veículo, sendo integrada aos sistemas do robô por meio de comunicação serial. As medidas então eram extraídas pelo computador de controle, de maneira idêntica ao que é feito para o registro das medidas dos encoders e dos comandos enviados pelos joysticks.

Este método, porém, ofereceu uma baixa frequência de aquisição para as medidas da IMU, na ordem de $2 \mathrm{~Hz}$. Com o objetivo de aumentar a frequência de aquisição, foi utilizado um segundo computador exclusivamente para a realização e registro das medições realizadas pela IMU.

Para os testes, foi utilizado um laptop comum, devido à necessidade de este acompanhar o veículo ao longo dos testes. Os equipamentos foram conectados por meio de um cabo microUSB, utilizado para alimentação e extração de dados. A frequência de aquisição dos dados com esta alteração foi $83 \mathrm{~Hz}$.

Para garantir a melhor taxa de aquisição possível, foi desenvolvido um firmware personalizado em Arduino utilizando as bibliotecas fornecidas pelo fabricante do sensor. Com estas alterações, foi possível atingir uma frequência de aquisição de $250 \mathrm{~Hz}$. Esta frequência foi considerada satisfatória e foi utilizada ao longo deste trabalho. 


\subsection{Calibração dos sensores}

A precisão e a acurácia das medições realizadas pelos sensores são limitadas pela quantidade de erro presente. Erros sistemáticos podem ser previsto e eliminados pelo processo de calibração dos sensores (Paranhos, P. M., 2009). Desta forma, todos os sensores utilizados foram devidamente calibrados, como descrito a seguir.

\subsubsection{Encoders}

Para a calibração dos encoders nos motores das rodas, foram utilizados principalmente os dados de testes em linha reta, que serão descritos em maior detalhe no capitulo 6.

A velocidade de rotação dos motores é correlacionada linearmente com a velocidade de rotação das rodas utilizando a relação de transmissão do sistema de transmissão utilizado:

$$
\omega_{m_{L}}=N \omega_{L} \text { e } \omega_{m_{R}}=N \omega_{R}
$$

Utilizando as equações cinemáticas, descritas na Seção 2.1.2, é possível escrever a velocidade frontal do veículo em função das velocidades dos motores:

$$
v_{y}=\frac{r}{2}\left(\omega_{L}+\omega_{R}\right)=\frac{r}{2 N}\left(\omega_{m_{L}}+\omega_{m_{R}}\right)
$$

A distância percorrida pelo veículo pode ser obtida pela simples integração de equação acima, resultando em

$$
D=\int v_{y} d t=\frac{r}{2 N} \int\left(\omega_{m_{L}}+\omega_{m_{R}}\right) d t
$$

onde

- $\quad D$, distância percorrida.

Assim, é possível utilizar distâncias medidas durante a realização dos testes para a calibração dos encoders. A integração do sinal enviado pelos encoders foi realizada utilizando o ambiente computacional MATLAB.

Com o objetivo de quantificar a qualidade da calibração obtida, foi calculado o erro quadrático médio entre os valores medidos da distância percorrida com os obtidos através da integração dos valores calibrados dos encoders. Os resultados estão ilustrados na Tabela 3. 
Tabela 3 - Erro médio quadrático das distâncias medidas $\left(\mathbf{e m ~ m}^{2}\right)$

\begin{tabular}{|l|c|c|c|c|c|}
\hline & Teste 1 & Teste 2 & Teste 3 & Teste 4 & Média \\
\hline EMQ $\left(m^{2}\right)$ & 0,0311 & 0,0240 & 0,0200 & 0,0049 & 0,0200 \\
\hline
\end{tabular}

Finalmente, é determinada a variância das medidas dos encoders, sendo esta necessária para o uso do filtro de Kalman. O valor da variância medido é de $\sigma_{e L}=$ $\sigma_{e R}=0,0426\left(\frac{m^{2}}{s^{2}}\right)$.

\subsubsection{IMU}

Para a calibração dos sensores da IMU, foi necessária a utilização de um equipamento construído pelo Laboratório de Desenvolvimento de Sistemas Mecatrônicos (LDSM) da PUC-Rio, mostrado na Figura 21. O funcionamento do equipamento é baseado em uma plataforma conectada a um motor elétrico de corrente continua, de forma a realizar rotação pura. A velocidade de rotação pode ser controlada a partir da corrente fornecida ao motor elétrico. A velocidade de rotação é medida por um encoder conectado ao eixo de rotação do sistema. Uma rotina no software Labview é utilizada para salvar as informações dos testes (Assad, M. M., 2018).

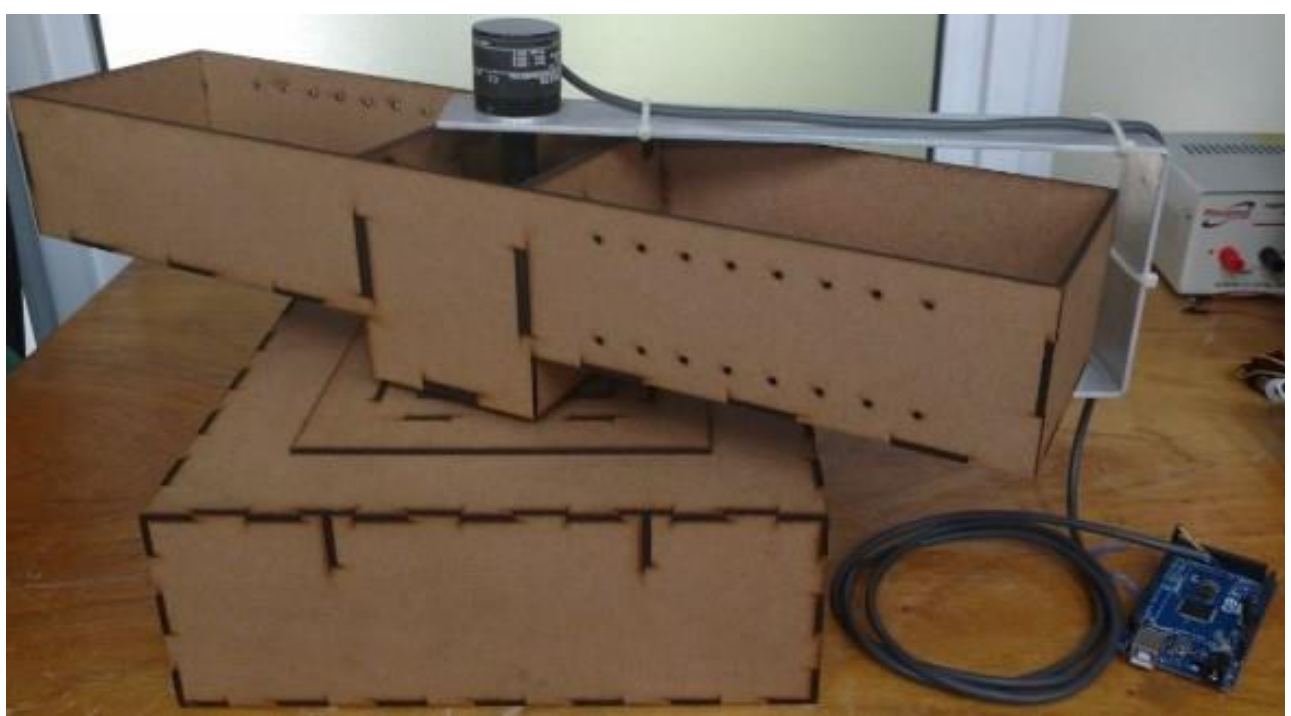

Figura 21 - Equipamento de Calibração IMU (Assad, M. M., 2018)

Durante o teste, a IMU é presa à plataforma de forma a alinhar um de seus eixos com o eixo de rotação do sistema, e outro alinhado com a aceleração 
centrípeta, permitindo assim uma fácil interpretação dos dados. Este processo é repetido, de forma a calibrar os três eixos do acelerômetro e do girômetro. Devido ao funcionamento do sistema, não é possível conectar a IMU diretamente a um computador, por isso os dados são salvos em cartões SD e a alimentação é realizada via uma bateria presa também na plataforma.

Na calibração do girômetro, são definidos três níveis de tensão diferentes. Entre cada nível foi dado tempo suficiente para a estabilização da velocidade de rotação do motor. Os resultados das medições do girômetro são comparados com as medidas realizadas pelo encoder (Figura 22).

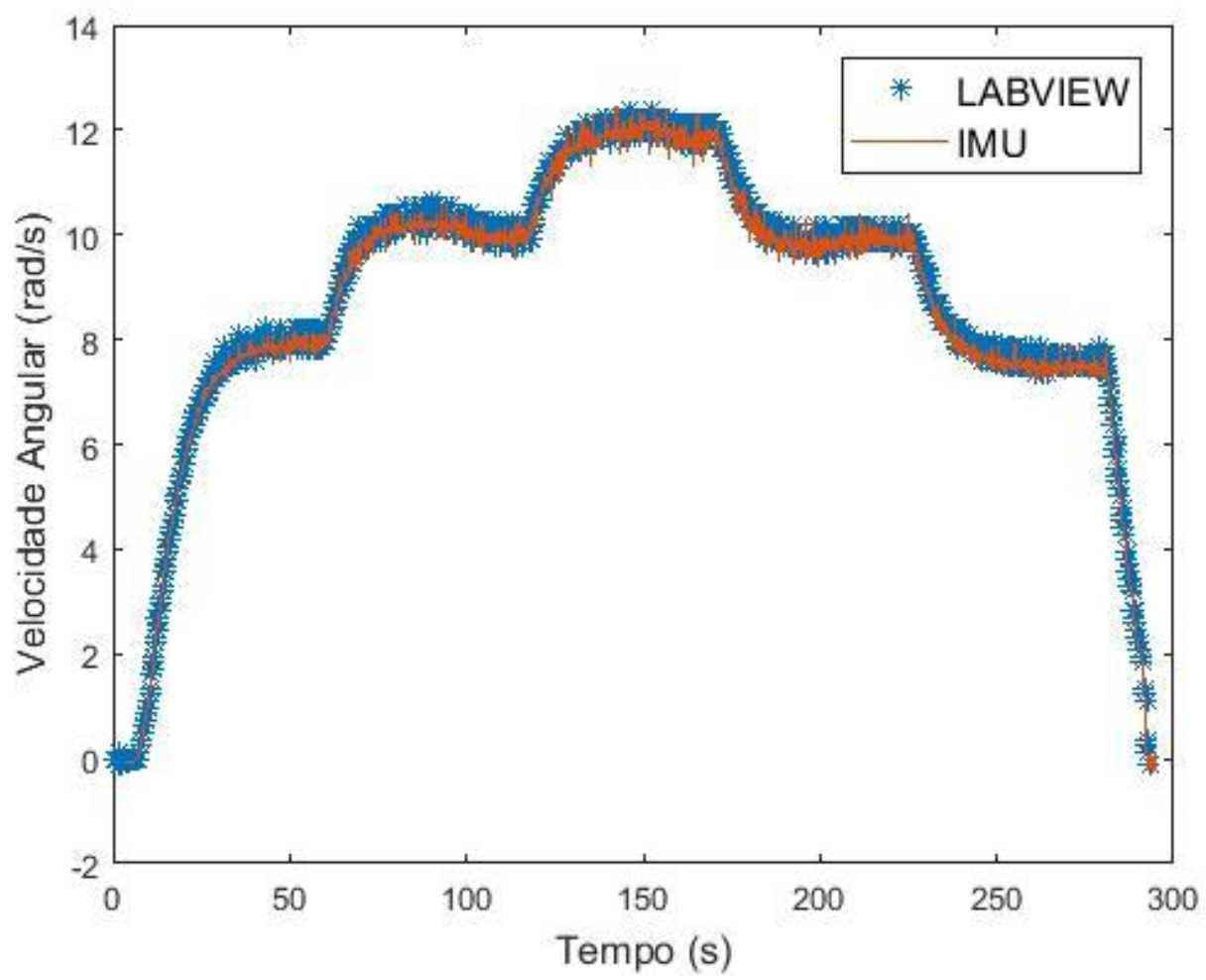

Figura 22 - Calibração do girômetro

O método descrito anteriormente é repetido para os três eixos do girômetro, realizando-se assim a calibração do sensor. Para a calibração do acelerômetro, é enviado um único nível de tensão. A aceleração na direção radial sofrida na IMU é a aceleração centrípeta devida ao movimento rotacional da plataforma. A aceleração centrípeta pode ser calculada por

$$
a_{c}=\omega_{c}^{2} d_{c}
$$

onde: 
- $a_{c}$, aceleração centrípeta;

- $\omega_{c}$, velocidade de rotação da plataforma de teste;

- $d_{c}$, distância entre o centro do equipamento e a IMU.

A distância entre a IMU e o eixo do motor deste aparato de calibração é medida para cada posição utilizada. Assim, são utilizadas as medições realizadas pelo encoder para determinar a velocidade de rotação do sistema, e com isso é possível estimar a aceleração sofrida pelo sensor. Estes resultados são utilizados para calibrar o acelerômetro da IMU, como ilustrado na Figura 23.

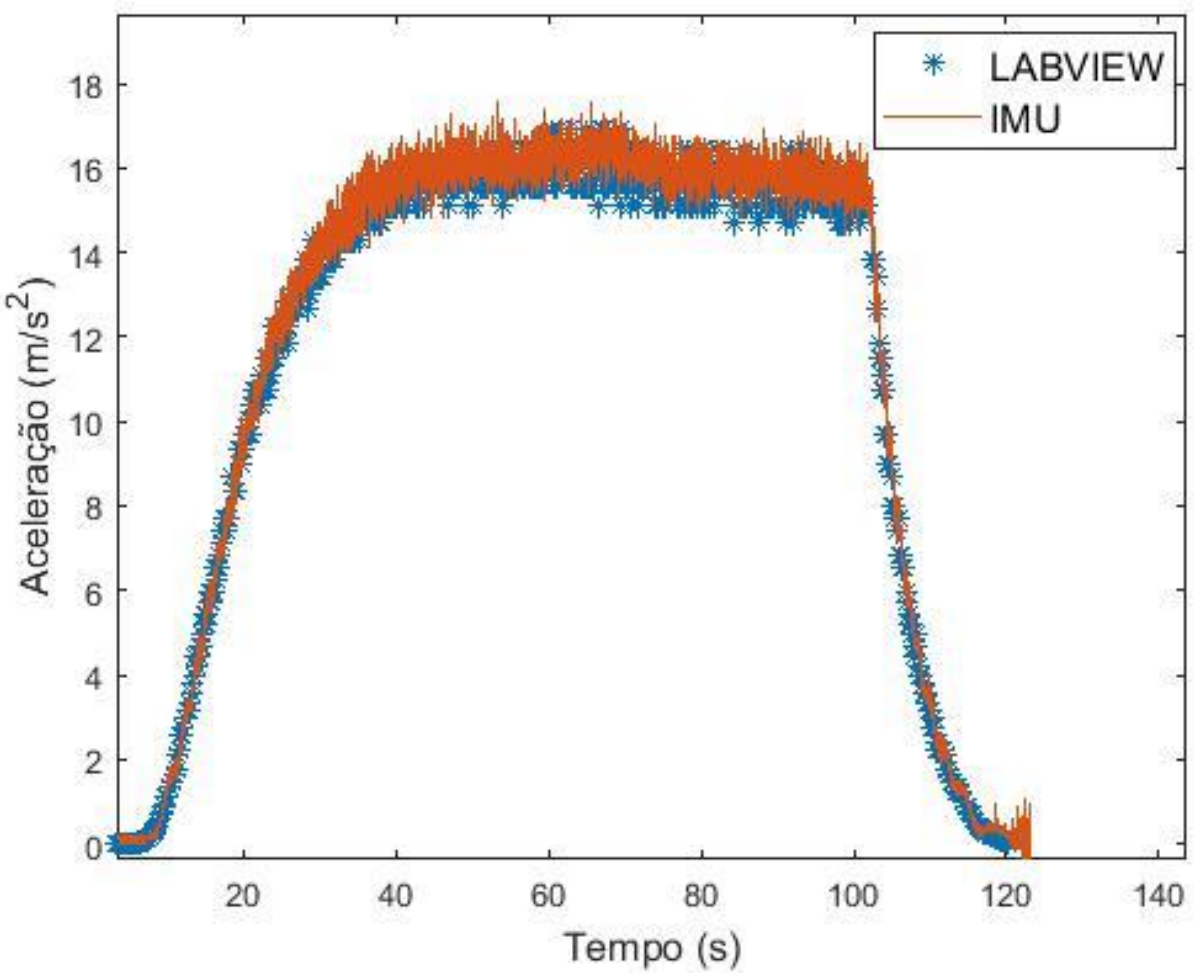

Figura 23 - Calibração do acelerômetro

Ao fim da realização dos processos descritos para todos os eixos dos sensores, a IMU é considerada calibrada. Nestas condições serão realizadas todas a medições com o robô RITA utilizadas ao longo deste trabalho.

Com ambos os sensores calibrados, são calculadas as variâncias dos sensores, necessárias para a utilização no filtro de Kalman. A variância encontrada para o acelerômetro é $\sigma_{a y}=0,0348\left(\frac{m^{2}}{s^{4}}\right)$ e o valor encontrado para o girômetro é $\sigma_{\omega_{z}}=$ $0,000162\left(\frac{r^{2} d^{2}}{s^{2}}\right)$ 


\subsubsection{Magnetômetro}

Embora não seja parte do sistema de localização proposto, o magnetômetro é utilizado na realização de testes comparativos, portanto deve ser calibrado devidamente.

Os principais efeitos de distorção na medida de magnetômetros são os efeitos de hard-iron e soft-iron. Distorções do tipo hard-iron são campos constantes gerados por materiais ferromagnéticos na proximidade do sensor. Este fenômeno gera um desvio (bias) nas medições do campo magnético da Terra (Won, D et al., 2015), vide Figura 24.

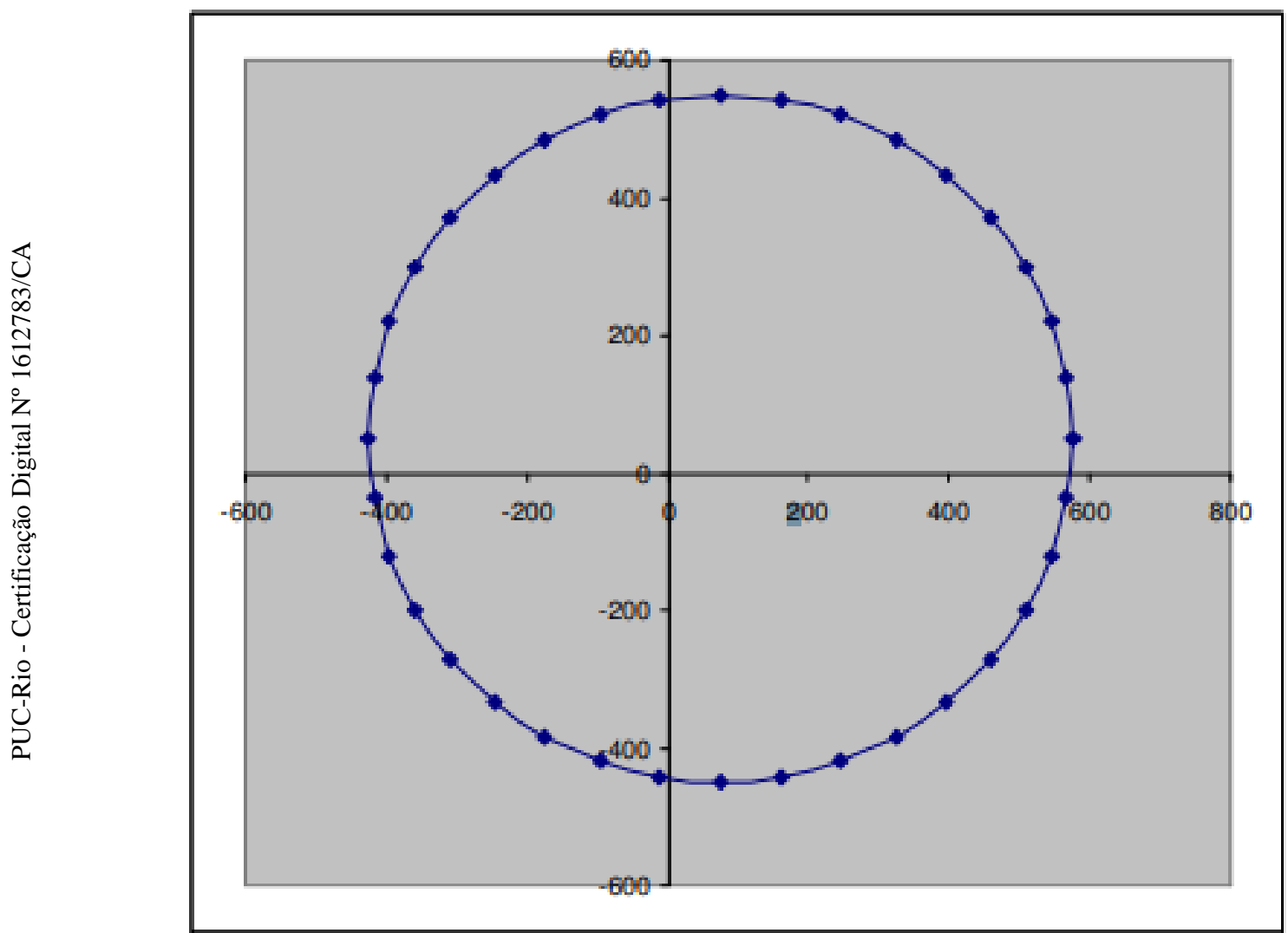

Fonte: 〈www.novatronic.de>

Figura 24 - Esquema de medições de intensidade de campo magnético sujeitas a distorção hard-iron

Distorções Soft-iron são causadas pela presença de materiais magneticamente permeáveis nas proximidades do sensor, gerando distorção no campo magnético 
local. Este tipo de distorção é dependente da orientação do sensor em relação ao campo magnético da Terra. Na Figura 25 está exemplificado este tipo de distorção.

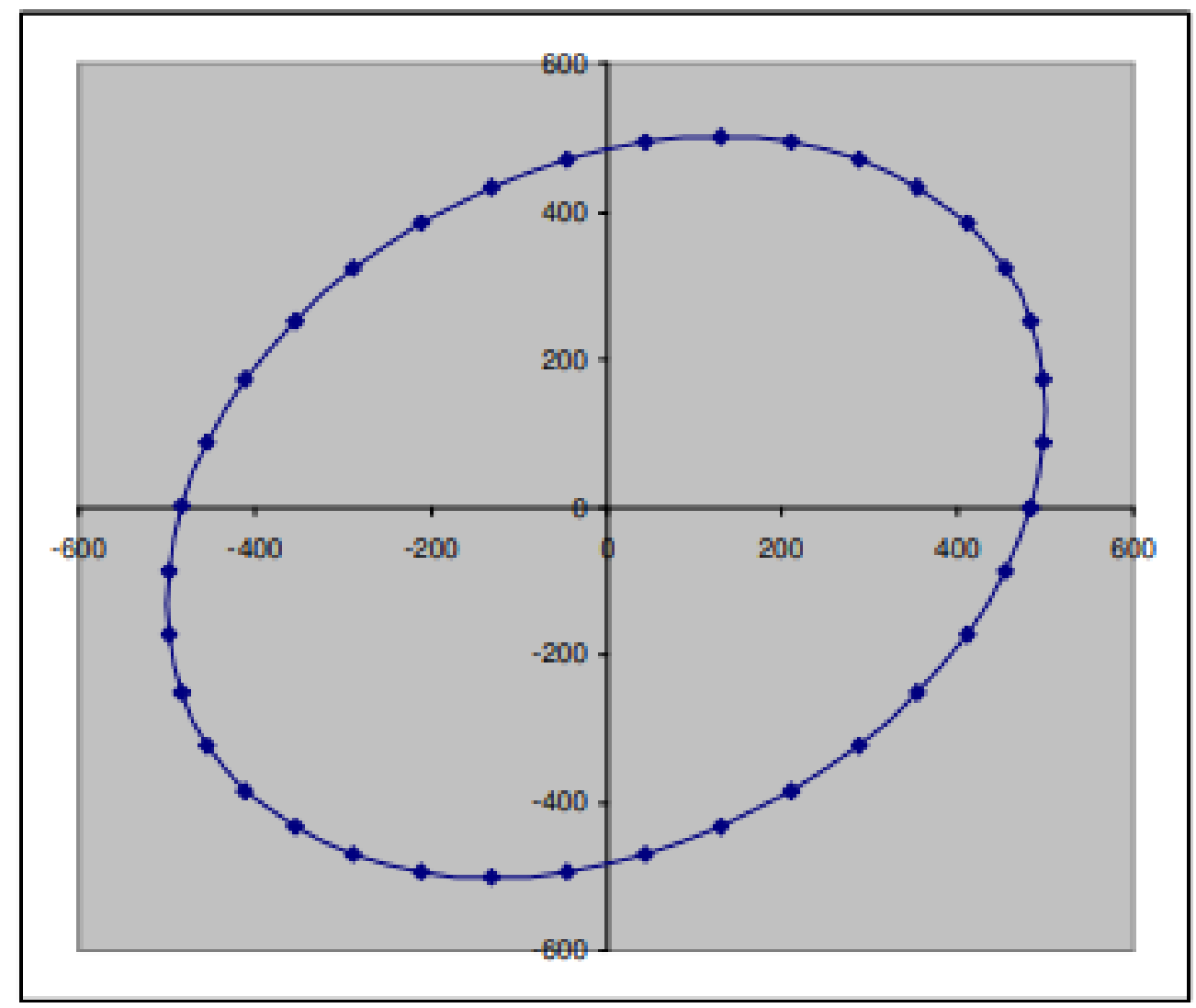

Fonte: <www.novatronic.de>

Figura 25 - Esquema de medições de intensidade de campo magnético sujeitas a distorção soft-iron

A maneira mais simples de calibrar um magnetômetro contra os efeitos das distorções citadas anteriormente é o método de ajuste do elipsoide (Kluga, J et al, 2016). Para a calibração, é realizada a medição do campo magnético durante uma rotação de no mínimo $360^{\circ}$. Para compensar os erros causados pelos efeitos de softiron, são introduzidos dois fatores de escala: um para o eixo $\mathrm{X}\left(S_{x}\right)$ e outro para o eixo $\mathrm{Y}\left(S_{y}\right)$. Estes fatores podem ser determinados pelas equações:

$$
\begin{aligned}
& S_{y}=\max \left(1, \frac{\max \left(m_{x}\right)-\min \left(m_{x}\right)}{\max \left(m_{y}\right)-\min \left(m_{y}\right)}\right) \\
& S_{x}=\max \left(1, \frac{\max \left(m_{y}\right)-\min \left(m_{y}\right)}{\max \left(m_{x}\right)-\min \left(m_{x}\right)}\right)
\end{aligned}
$$


onde:

- $m_{x}$, sinal não calibrado da medição do magnetômetro no eixo X;

- $m_{y}$, sinal não calibrado da medição do magnetômetro no eixo Y;

- $S_{y}$, fator de escala para a calibração do eixo Y;

- $S_{x}$, fator de escala para a calibração do eixo X.

Para compensar os bias introduzidos pelo efeito de hard-iron, devem ser determinados os deslocamentos (offsets) no eixo X $\left(C_{x}\right)$ e no eixo Y $\left(C_{y}\right)$. Estes podem ser determinados pelas equações:

$$
\begin{aligned}
C_{x} & =\frac{\max \left(m_{x}\right)-\min \left(m_{x}\right)}{2}-\max \left(m_{x}\right) \\
C_{y} & =\frac{\max \left(m_{y}\right)-\min \left(m_{y}\right)}{2}-\max \left(m_{y}\right)
\end{aligned}
$$

onde:

- $C_{x}$, offset para calibração do eixo $\mathrm{X}$;

- $C_{y}$, offset para calibração do eixo Y.

Tendo determinados os offsets e os fatores de escala para cada eixo, é possível escrever valores das medições calibradas $M_{x}$ e $M_{y}$ como:

$$
\begin{aligned}
& M_{x}=S_{x} m_{x}+C_{x} \\
& M_{y}=S_{y} m_{y}+C_{y}
\end{aligned}
$$

onde:

- $M_{x}$, sinal calibrado do magnetômetro no eixo X;

- $\quad M_{y}$, sinal calibrado do magnetômetro no eixo $\mathrm{Y}$.

Para a realização das medições, a IMU é posicionada numa superfície horizontal, de modo que o eixo $\mathrm{Z}$ do magnetômetro esteja perpendicular à superfície de apoio. O sensor é rotacionado, mantendo contato com a superfície de apoio, desta forma mantendo alinhado o eixo de rotação com a vertical. São realizadas duas rotações, de forma a garantir que o campo é medido em todas as direções. Os resultados não calibrados obtidos estão ilustrados na Figura 26. 


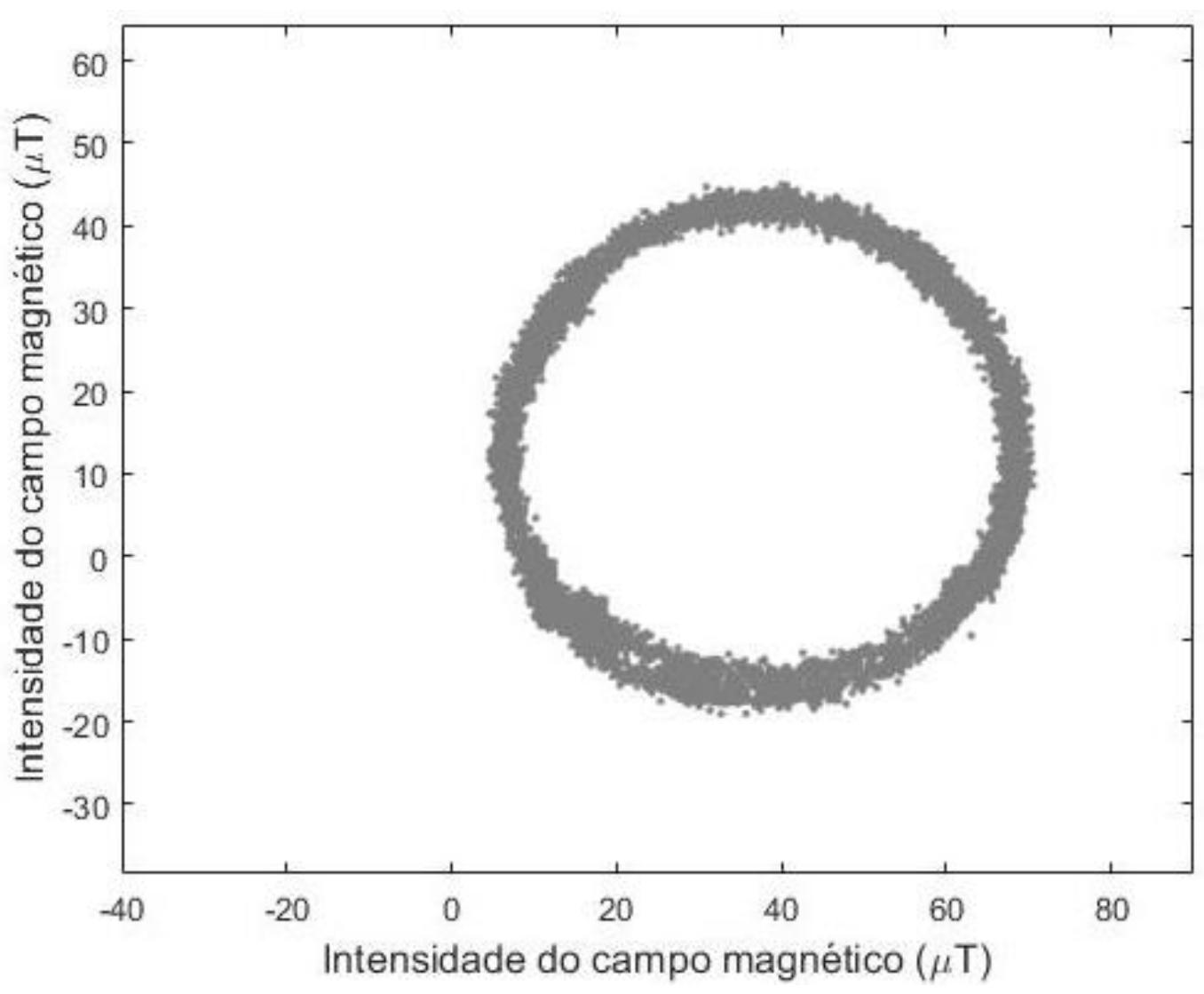

Figura 26 - Campo magnético não calibrado

Na Figura 26 é visível que a maior parte dos erros são causados por perturbações hard-iron, existindo grande deslocamento do centro do elipsoide do ponto $(0,0)$. Apesar de menos visível, os testes realizados para calibração também demonstraram uma pequena distorção devido ao efeito soft-iron. Os parâmetros obtidos na calibração estão apresentados na Tabela 4.

Tabela 4 - Parâmetros da calibração do magnetômetro

\begin{tabular}{|c|c|}
\hline$S_{x}$ & 1 \\
\hline$S_{y}$ & 1,05 \\
\hline$C_{x}$ & $-37,5$ \\
\hline$C_{y}$ & $-13,5$ \\
\hline
\end{tabular}

Os sinais calibrados podem ser vistos na Figura 27, onde estão comparados junto com sinais obtidos diretamente do sensor ilustrados na Figura 26. 


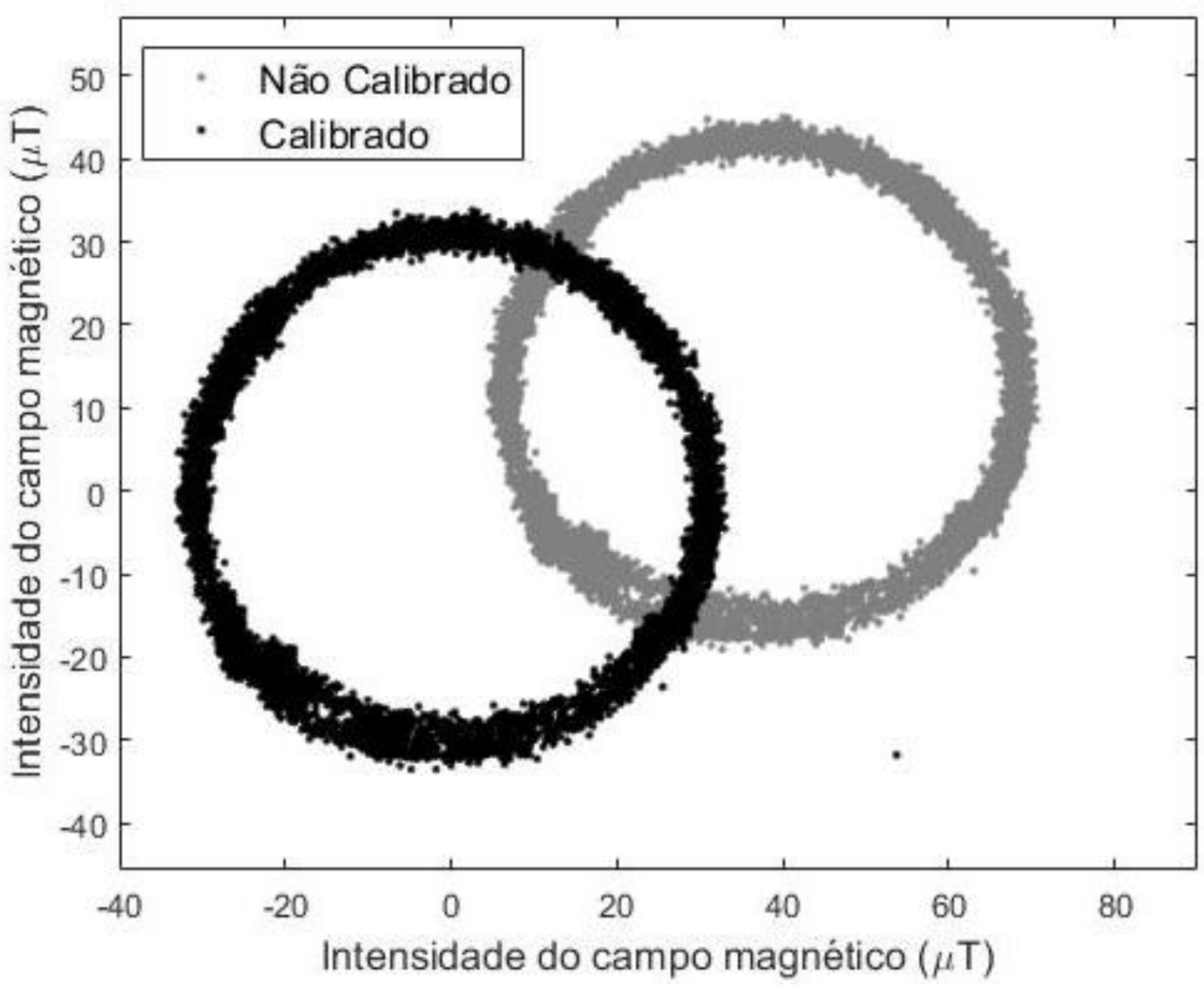

Figura 27 - Campo magnético calibrado e não calibrado

Para testar a calibração, é calculado o ângulo de orientação da central inercial durante os testes realizados, utilizando as medições calibradas do magnetômetro. A direção do campo magnético da Terra, no plano horizontal, pode ser calculada por:

$$
\theta_{\text {mag }}=\arctan \left(\frac{M_{y}}{M_{x}}\right)
$$

onde

- $\theta_{\text {mag }}$, ângulo de orientação medido pelo magnetômetro.

O cálculo numérico do ângulo foi realizado em MATLAB, utilizando a função “atan2', que permite o cálculo de ângulos no intervalo $-\pi$ a $\pi$. Os resultados obtidos estão ilustrados na Figura 28. 


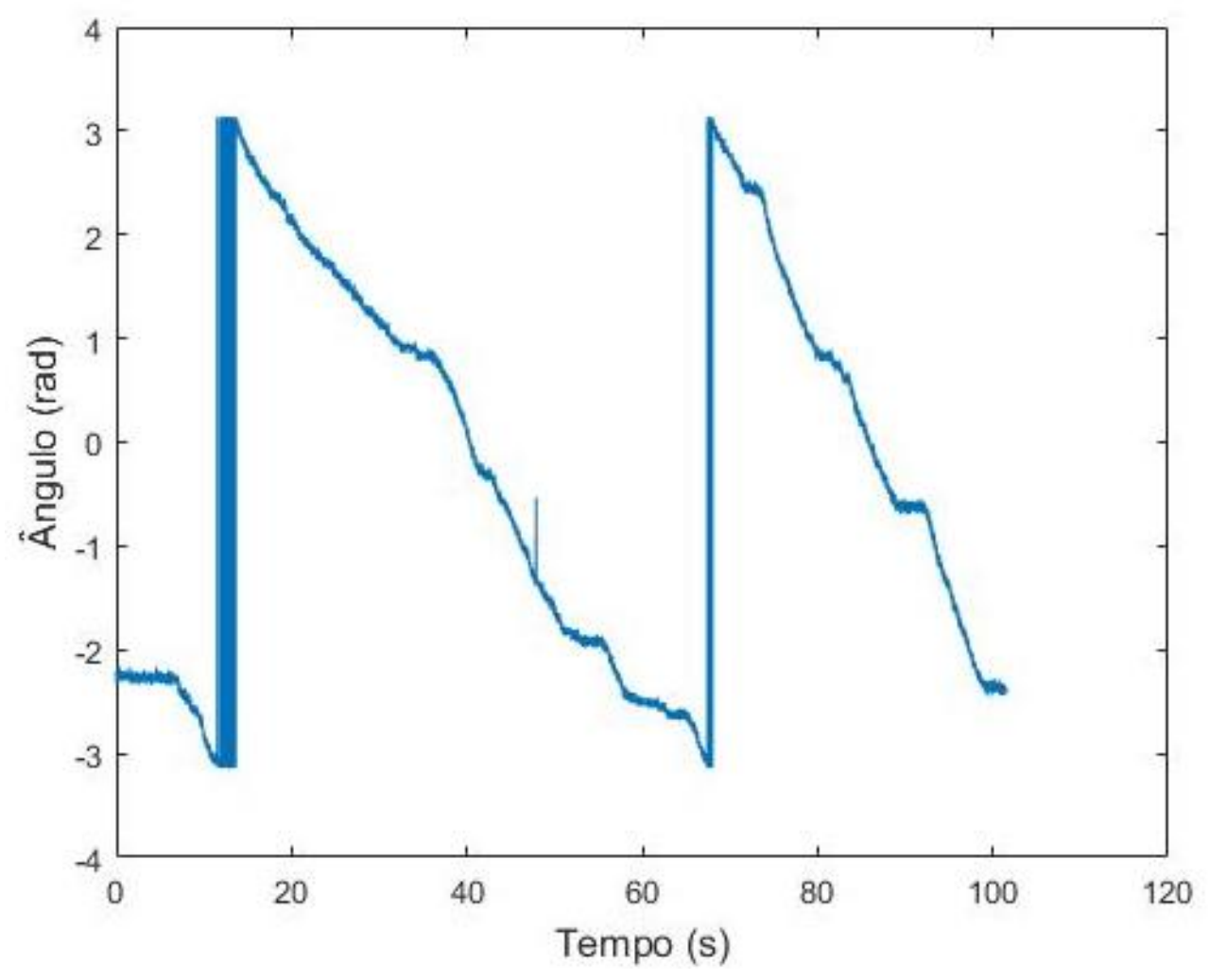

Figura 28 - Ângulo medido durante a calibração

Os resultados ilustrados na Figura 28 demonstram um movimento de rotação no sentido horário por duas rotações, parando aproximadamente na mesma posição que a inicial. Os dados reproduzem com qualidade o teste realizado para calibração, descrito no início desta seção. Desta forma, é considerado que as medições representam adequadamente os valores esperados, e o sensor é considerado calibrado.

Finalmente, é calculada a variância do ângulo de orientação medido pelo magnetômetro, para utilização no filtro de Kalman. O valor obtido é de $\sigma_{\text {mag }}=$ $0,0016 \mathrm{rad}^{2}$.

\subsection{Redução da vibração na IMU}

Ao longo do trabalho, foi identificado a presença de perturbações de alta frequência e grande amplitude nas medidas realizadas tanto pelo acelerômetro quanto pelo girômetro. É determinado que, quando há rotação nos motores, e consequentemente nas rodas, perturbações interferem com as medidas realizadas pelos sensores na IMU. Para verificar isto, o veículo foi posicionado sobre dois pedestais de modo que suas rodas não tocassem no chão, e em seguida foram 
realizadas medições com a IMU com os motores parados e depois com os motores na velocidade próxima à máxima. A Figura 29 ilustra os resultados obtidos para o acelerômetro com os motores parados e a Figura 30 demonstra o resultado com os motores em movimento.

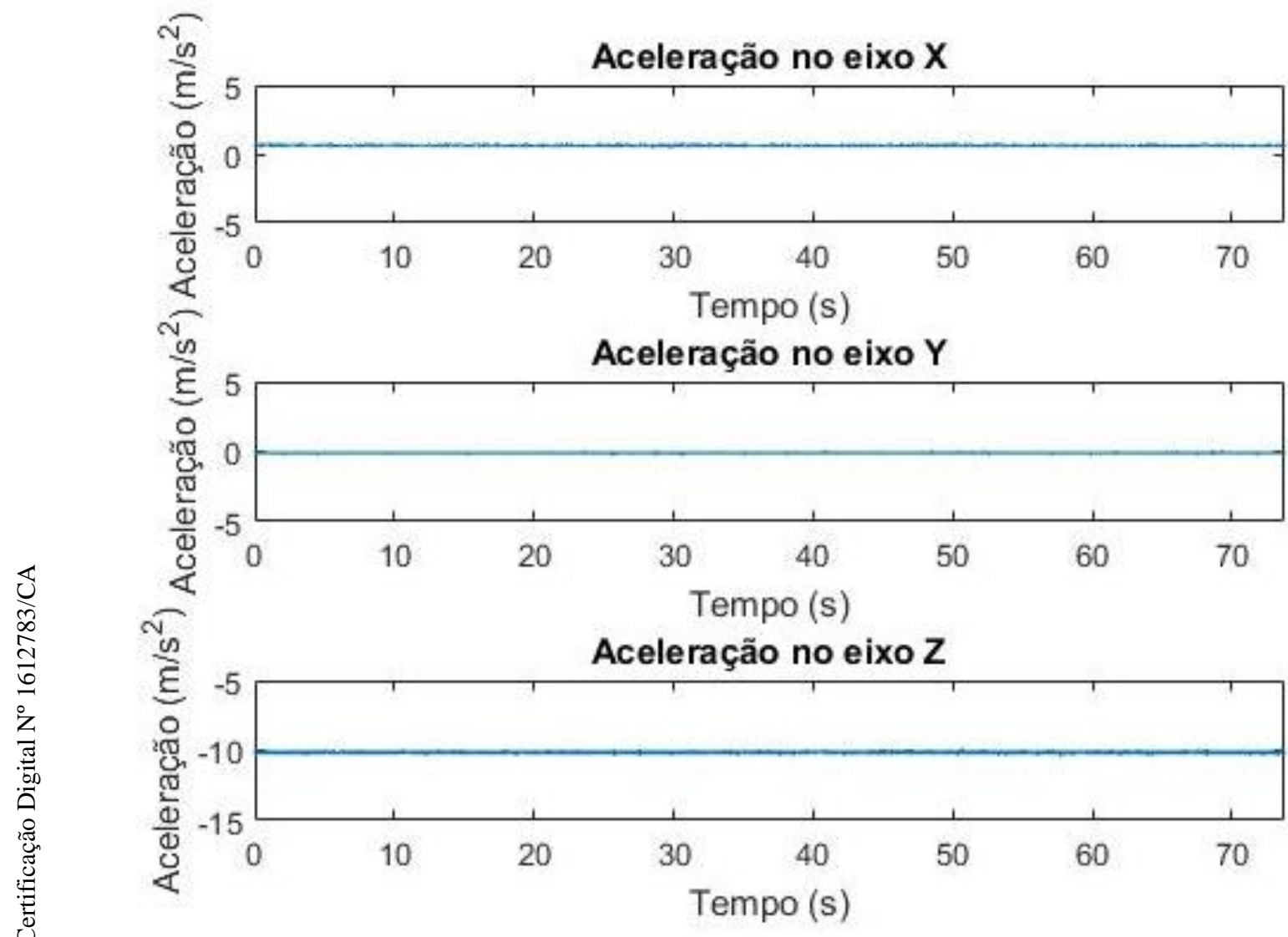

Figura 29 -- Medidas do acelerômetro sem vibração

A hipótese formulada para a origem destas perturbações é que estas seriam em maior parte devido à vibração no veículo; problemas como desalinhamento e desbalanceamento são causas comuns de vibrações indesejadas em sistemas mecânicos rotativos. (Garcia, M. S., 2005). Em problemas de vibração, é útil realizar uma análise das frequências atuantes no sistema. Para isso, foi realizada a Transformada Rápida de Fourier com a função "fft" disponível nas bibliotecas do MATLAB. Na Figura 31 estão representados os resultados obtidos da aplicação da transformada de Fourier no sinal do acelerômetro sem vibração, e a Figura 32 apresenta os resultados com vibração. 


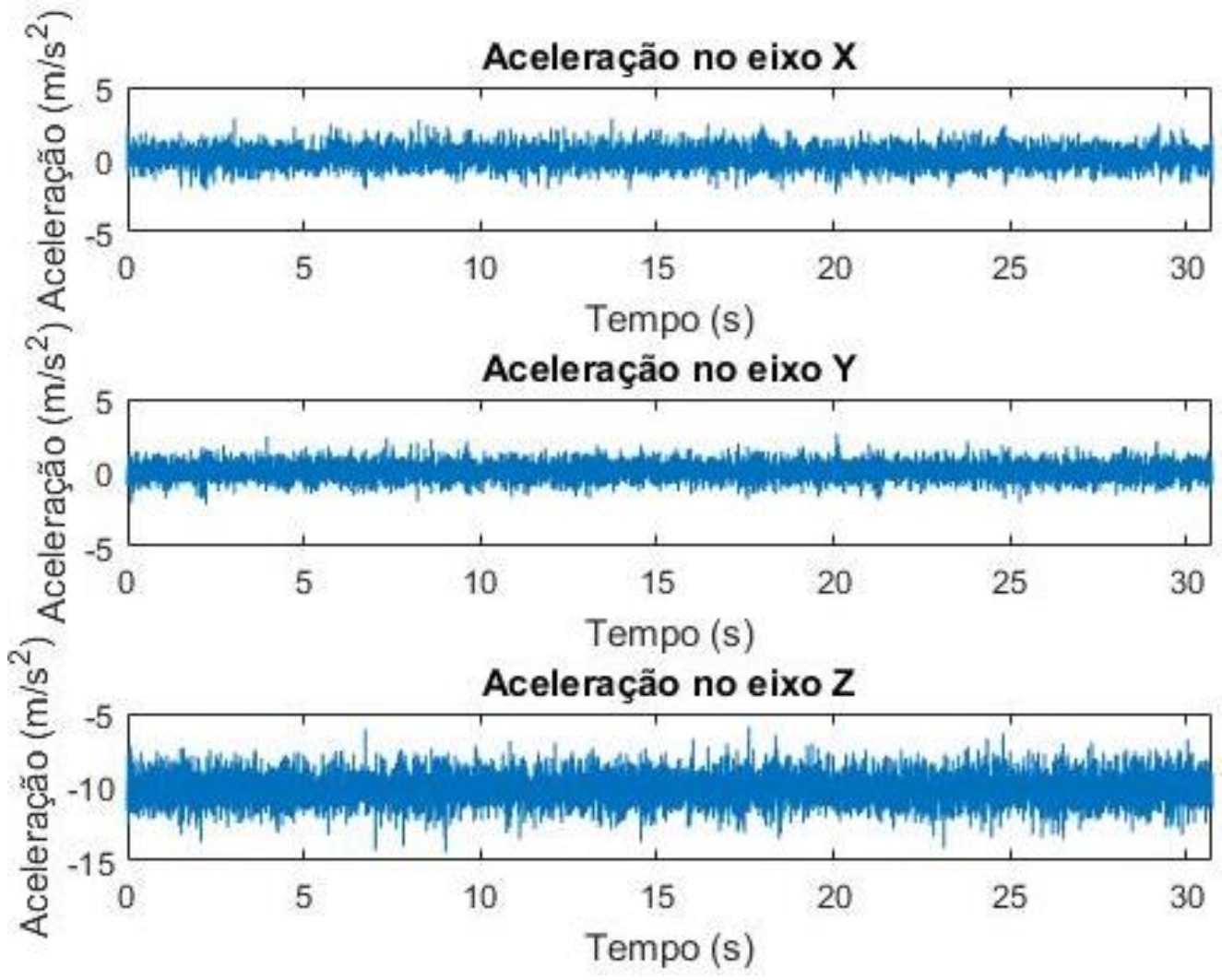

Figura 30 - Medidas do acelerômetro com vibração
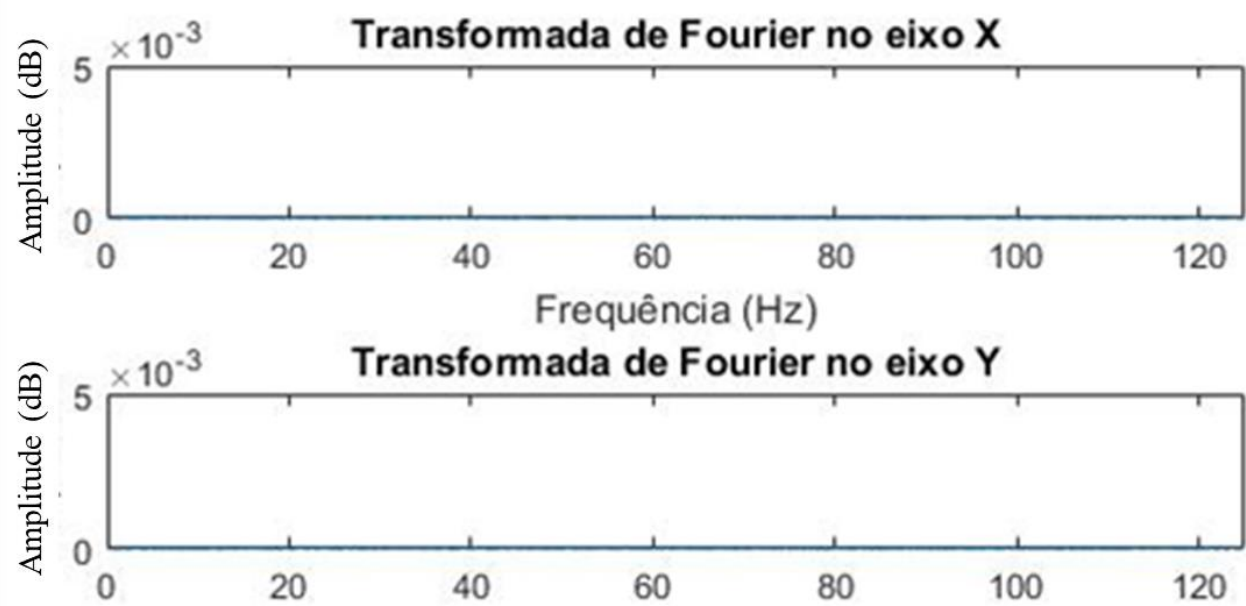

Frequência $(\mathrm{Hz})$

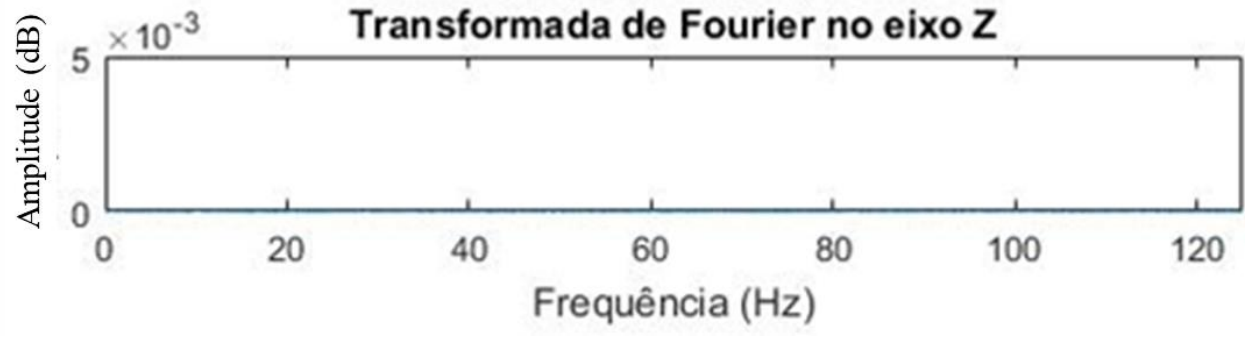

Figura 31 - Transformada de Fourier das medidas sem vibração 

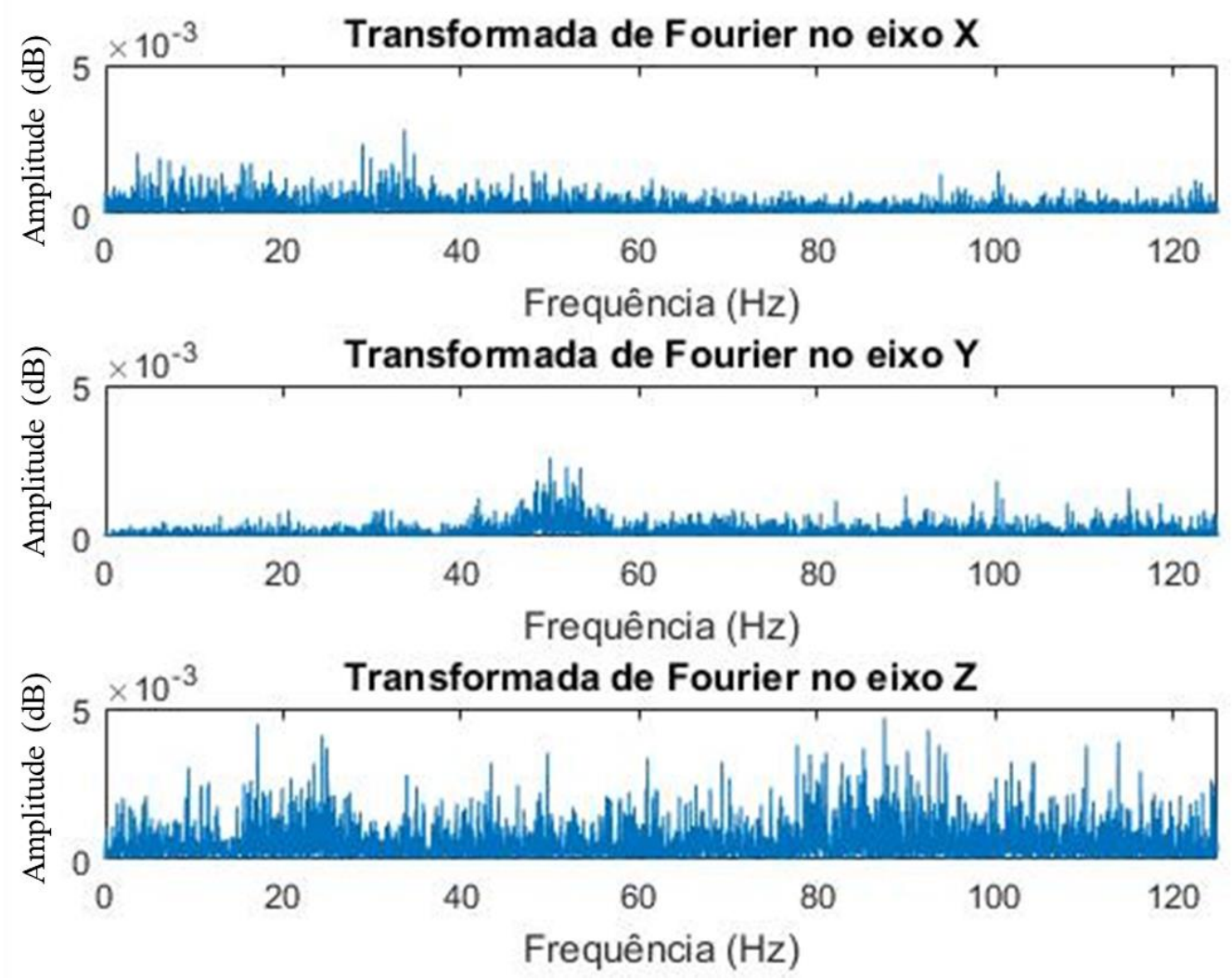

Figura 32 - Transformada de Fourier das medidas com vibração

O resultado obtido na Figura 32 demonstra que a frequência da perturbação não estava concentrada em nenhuma faixa de frequência mesurável. Considerando que transformada de Fourier só pode identificar frequências até metade da frequência de aquisição que no caso da IMU é de $250 \mathrm{~Hz}$, os resultados obtidos indicam que a frequência da perturbação possui componentes significativas acima de $125 \mathrm{~Hz}$.

Para diminuir os efeitos da vibração na IMU, o seu peso foi aumentado prendendo-o em suportes de metal. Desse modo, sua massa original de 28,8g foi aumentada (com sua base) para 303,7g (Figura 33.b). Além deste aumento de peso significativo para o conjunto, ele foi colocado dentro de uma estrutura de espuma pouco densa (Figura 33.a). Estas modificações foram feitas considerando que a espuma funcionaria como amortecedor, mas também diminuindo a rigidez do conjunto, o que com o aumento de peso do conjunto (base e IMU) diminuiria a frequência natural de vibração. 


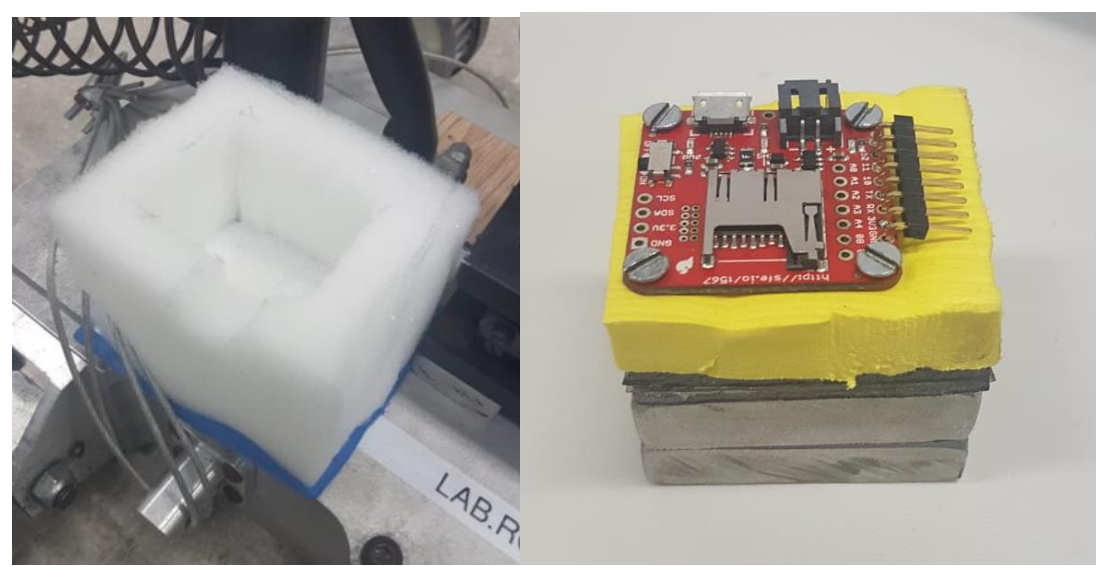

Figura 33 - a) caixa de espuma (esquerda) b) IMU+base+pesos (direita)

São realizados novamente testes com o veículo parado no topo de um pedestal, para verificar o efeito do sistema proposto. Na Figura 34 estão as medidas realizadas pelo acelerômetro com as rodas em movimento.

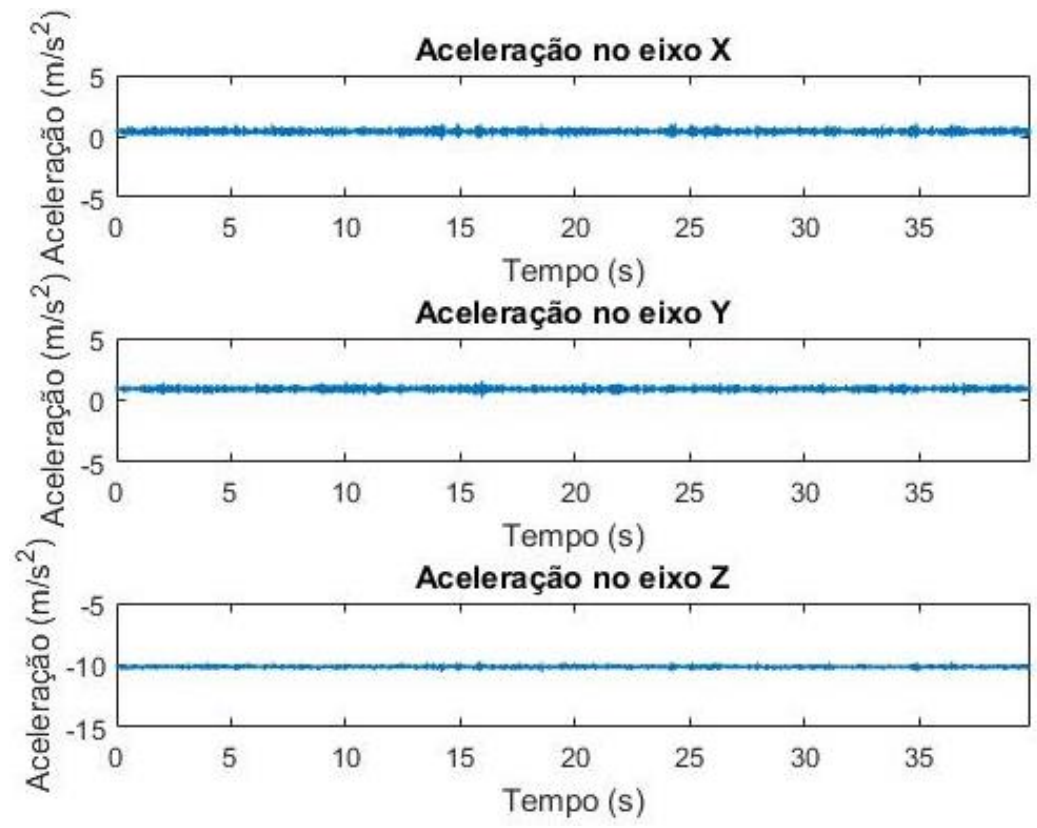

Figura 34 - Medidas do acelerômetro com sistema de atenuação

O sistema para a redução da vibração diminuiu consideravelmente a amplitude da perturbação. Outra vantagem do sistema aplicado foi posicionar os efeitos da perturbação nas medidas dos sensores numa região que pode ser mais facilmente filtrada. Na Figura 35 estão as transformadas de Fourier das medidas dos acelerômetros com o sistema utilizado. Utilizando a função "fdesign" das bibliotecas do MATLAB, é desenvolvido um filtro para atenuar o sinal nas frequências onde ainda há perturbações nas medidas, em uma faixa de 11 a $60 \mathrm{~Hz}$. A Figura 36 ilustra o sinal depois da aplicação do filtro. 


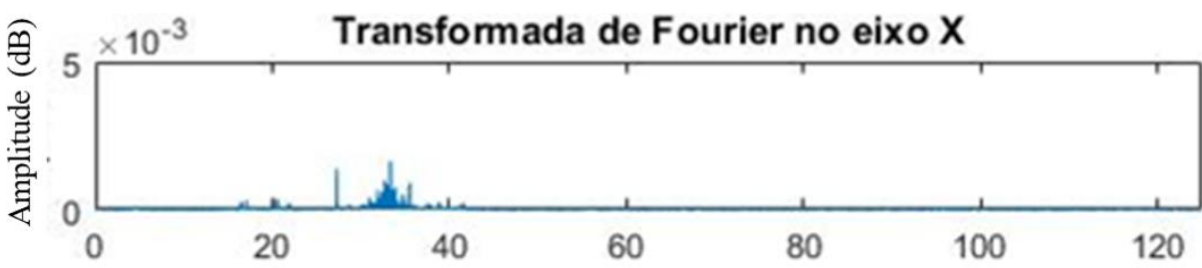

Frequência $(\mathrm{Hz})$

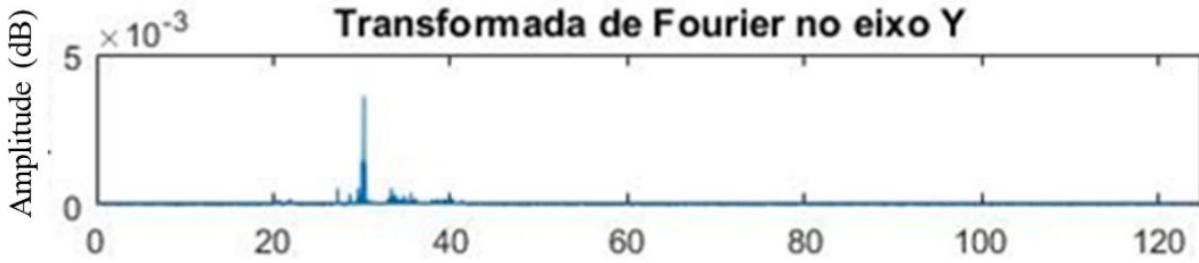

Frequência $(\mathrm{Hz})$

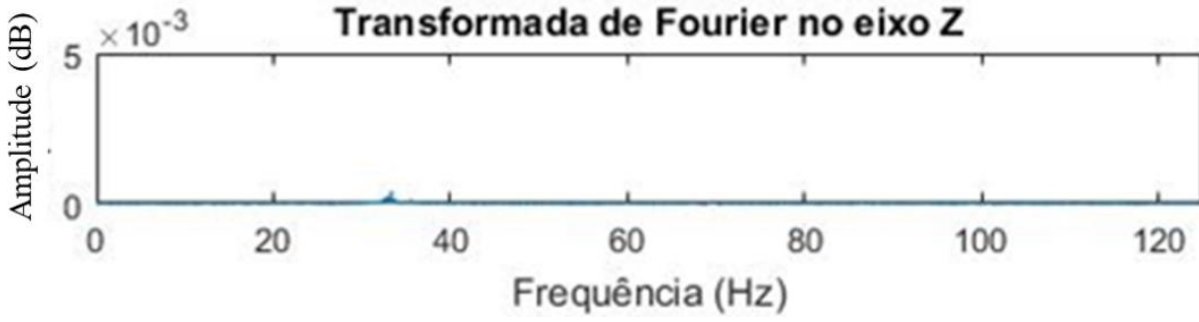

Figura 35 - Transformada de Fourier com sistema de atenuação

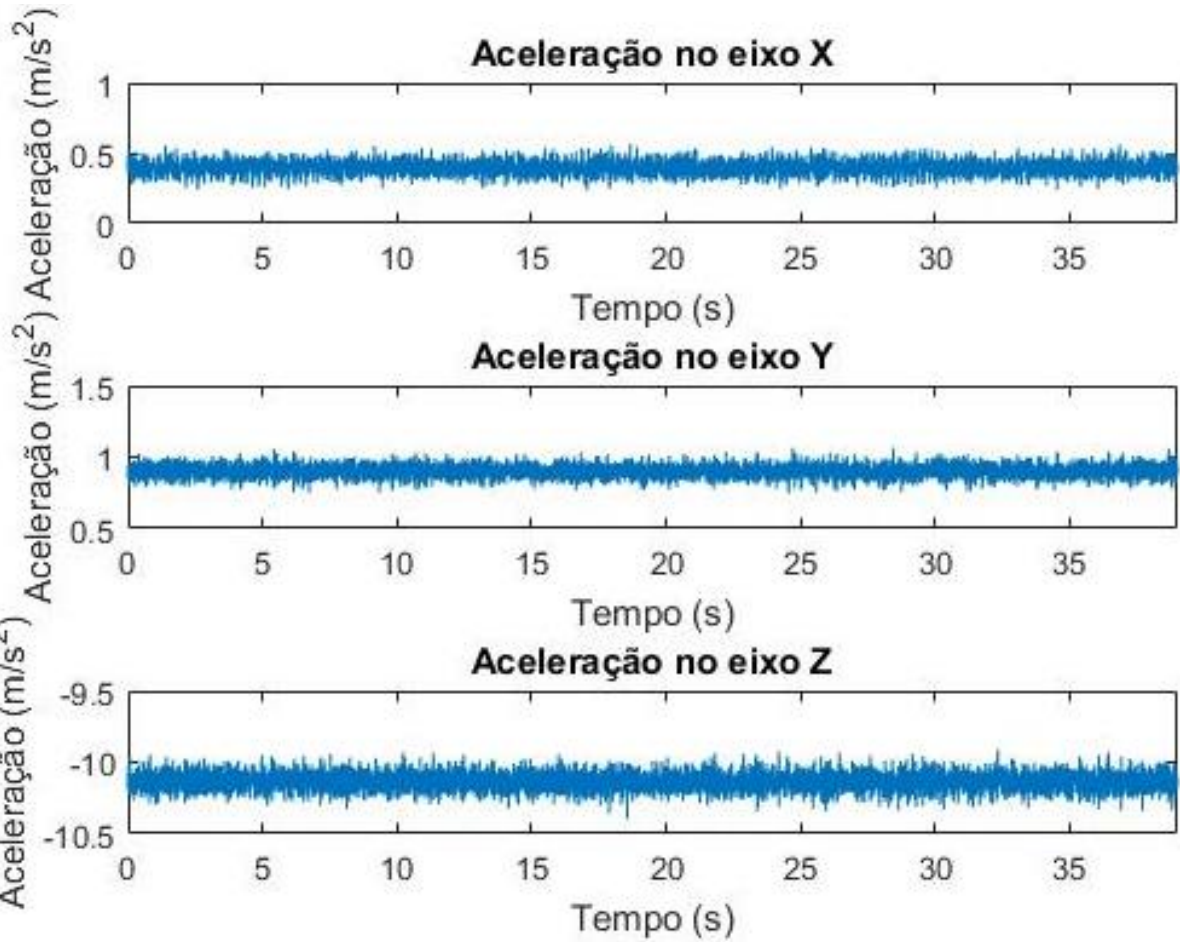

Figura 36 - Sinal do acelerômetro após filtragem 
Com o objetivo de quantificar a qualidade da solução proposta, é calculada a variância dos sinais de aceleração no eixo Y em 4 condições: para o sinal sem perturbação, com perturbação sem o sistema atenuação de vibração, com o sistema de atenuação, e com ambos a filtragem e o sistema de atenuação. Os resultados obtidos estão descritos na Tabela 5.

Tabela 5 - Variâncias dos sinais do acelerômetro para cada caso

\begin{tabular}{|c|c|c|c|c|}
\hline & Sem perturbação & $\begin{array}{c}\text { Com } \\
\text { perturbação }\end{array}$ & $\begin{array}{c}\text { Sistema de } \\
\text { atenuação }\end{array}$ & $\begin{array}{c}\text { Atenuação + } \\
\text { Filtro }\end{array}$ \\
\hline Variância $\left(\frac{m^{2}}{s^{4}}\right)$ & 0,0031 & 0,3497 & 0,0266 & 0,0019 \\
\hline
\end{tabular}

As técnicas descritas neste capítulo são utilizadas nos testes experimentais, descritos no capitulo 6, permitindo o correto uso dos sensores embarcados no veículo. Os parâmetros medidos neste capítulo também são utilizados para simular o sistema experimental, como é descrito no capitulo a seguir. 


\section{Simulações}

Neste capítulo, a teoria desenvolvida no capítulo 2 é utilizada para desenvolver uma simulação em Simulink do sistema experimental, ajustada baseada em dados experimentais. Os resultados obtidos são comparados com os resultados de uma simulação utilizando a cinemática de um robô de acionamento diferencial, ressaltando a importância de modelar adequadamente o veículo utilizado.

O diagrama na Figura 37 ilustra o modelo utilizado na simulação. Nele são imple1mentadas as equações governantes do sistema. As saídas dos sistemas são as medidas que podem ser usadas para comparar com as medições realizadas durante os testes. Essas são:

- Aceleração linear do veículo, que pode ser comparada com os resultados obtidos do acelerômetro;

- Velocidade angular do veículo, sendo comparada com os valores do girômetro;

- Velocidade angulares das rodas, que podem ser comparadas com as obtidas dos encoders;

- As posições X e Y ao longo do tempo, que podem ser utilizadas para uma análise qualitativa do movimento durante os testes;

- A posição final do robô, que pode ser comparada com a posição final real do veículo durante os testes.

\subsection{Parametrização do modelo do motor}

Com o objetivo do desenvolvimento de um modelo dinâmico que represente adequadamente o sistema experimental utilizado, é proposto um modelo dinâmico simples para modelar o torque fornecido pelos atuadores em função das velocidades de rotação do eixo do motor. O modelo proposto segue a equação:

$$
T_{m}=K_{V} u-K_{\omega} \omega_{m}
$$


onde:

- $T_{m}$, torque exercido pelo motor;

- $u$, comando recebido pelo motor (valor adimensional);

- $\omega_{m}$, velocidade de rotação do motor.

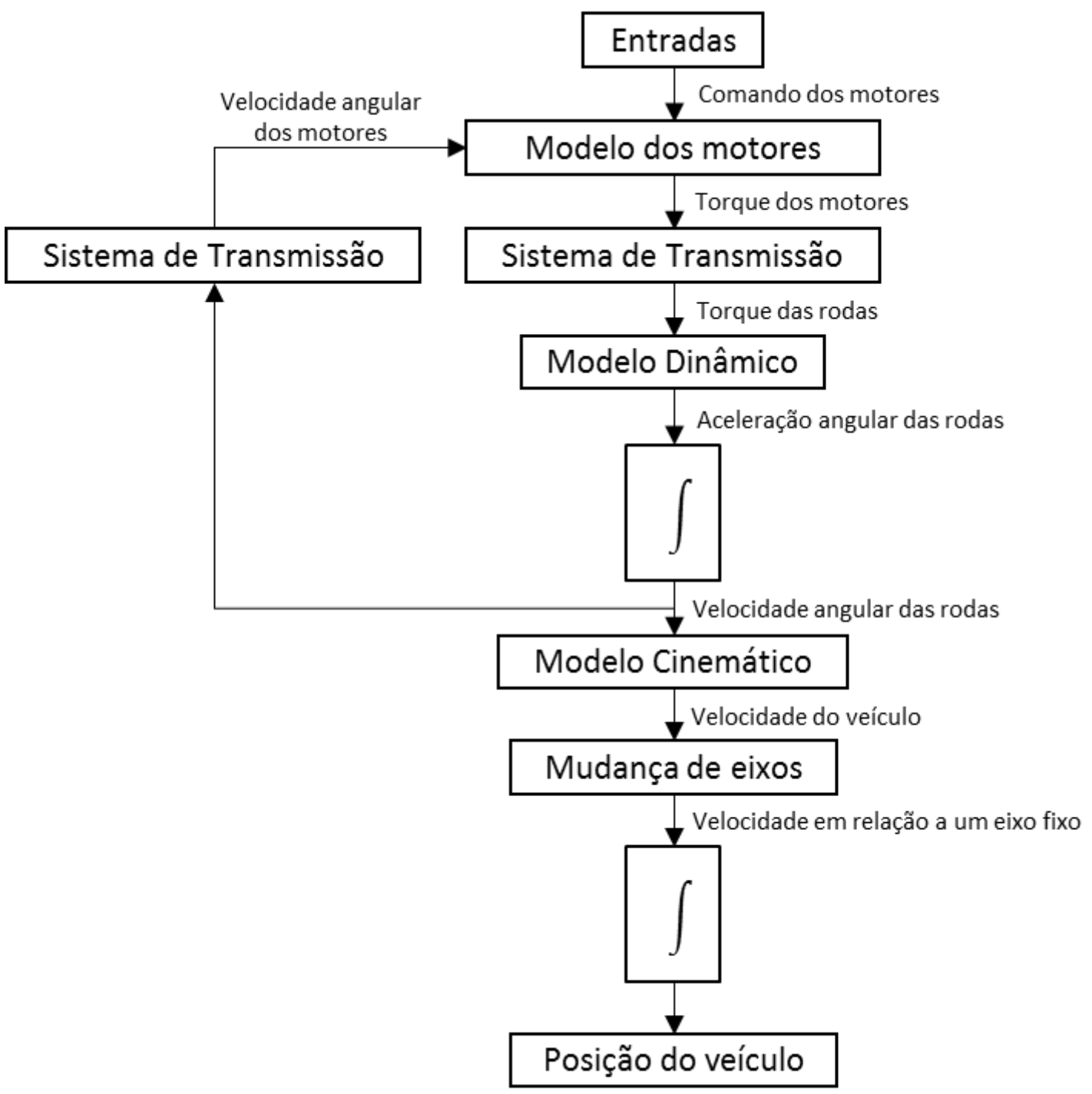

Figura 37 - Diagrama da simulação

Os parâmetros $K_{\omega}$ e $K_{V}$ devem ser escolhidos de forma a representar adequadamente o funcionamento do veículo em operação. Com esse objetivo são utilizadas medições experimentais na determinação destes parâmetros.

As leituras obtidas dos sensores de efeito Hall dos testes em linha reta, descritos na secção 6.2, são utilizadas como representação do funcionamento do veículo. Este tipo de teste é utilizado devido à simplicidade na análise dos resultados 
e simples verificação experimental, uma vez que não há curvas: em virtude de seu movimento retilíneo, os efeitos do deslizamento podem ser considerados desprezíveis.

Para realizar uma boa comparação entre os resultados, durante os testes são gravados os comandos enviados aos motores pelo joystick. Estas entradas são fornecidas ao modelo garantindo que o sinal utilizado na simulação reflete os utilizados nos testes.

Como pode ser observado na Figura 38, as entradas nos motores são constantes e iguais. Considerando os motores como sendo idênticos e simétricos isso garante um movimento retilíneo.

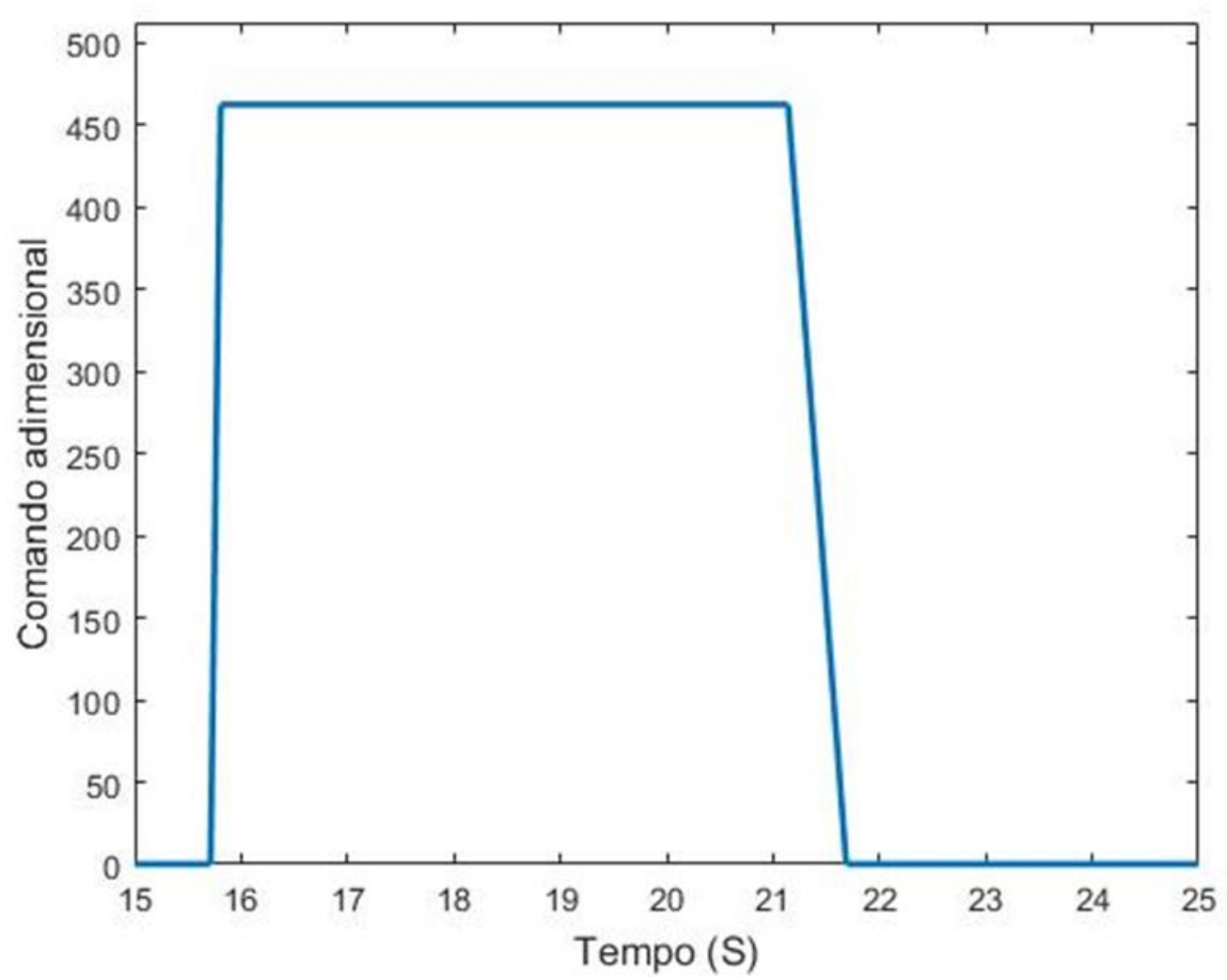

Figura 38 - Comandos enviados aos motores esquerdo e direito

Os resultados obtidos diretamente das medições dos encoders (Figura 39) demonstram comportamento parecido para ambos os motores. Assume-se que a diferença entre as velocidades medidas e teóricas sejam dadas devido aos erros associados aos encoders utilizados. O movimento do veículo observado no 
laboratório ao longo do teste também apoia a hipótese de movimento retilíneo durante o teste, com eventuais desvios desprezíveis não detectados.

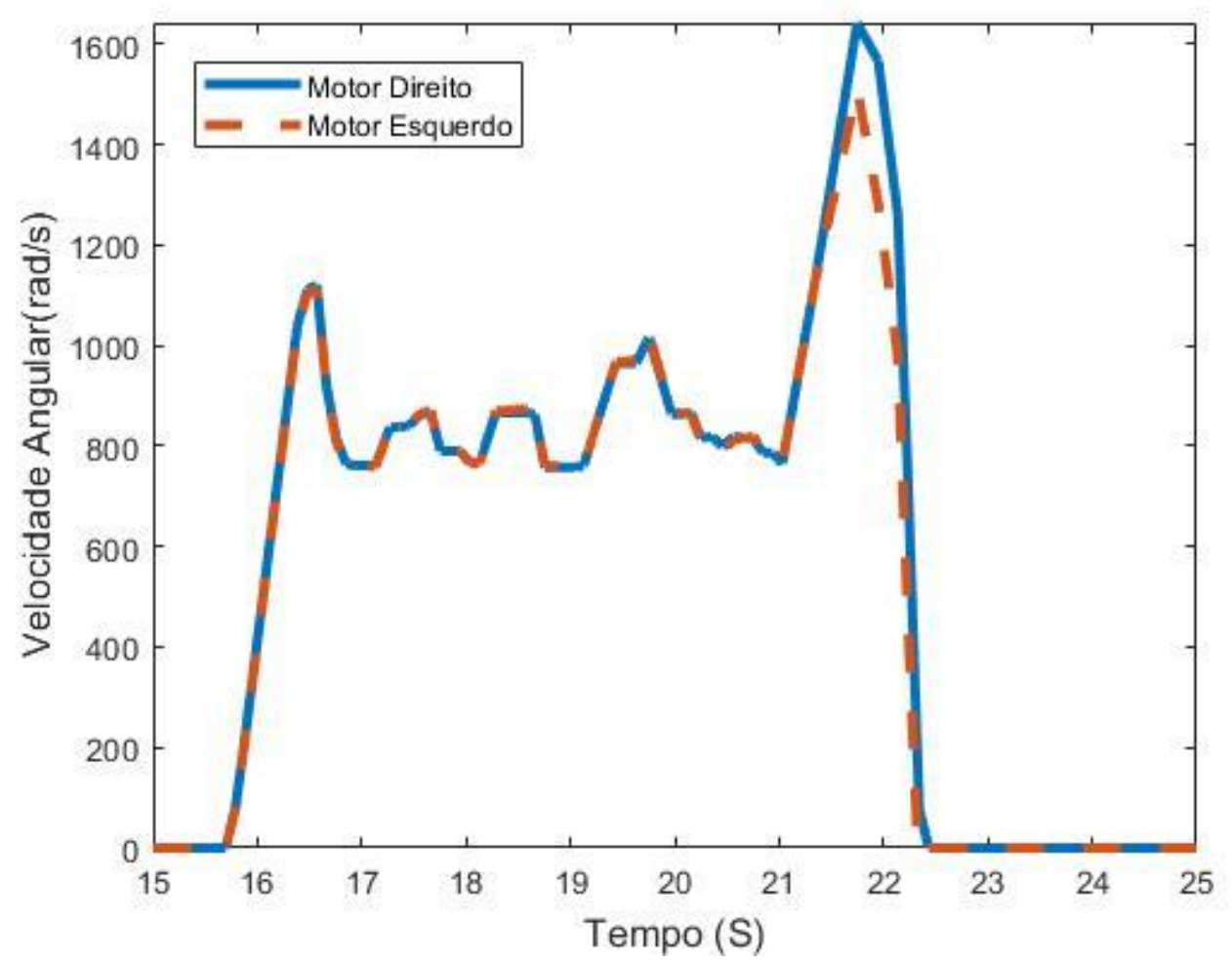

Figura 39 - Estimativas a partir dos encoders esquerdo e direito

Utilizando os parâmetros do veículo, listados no capitulo 4, é possível ajustar os parâmetros $K_{\omega}$ e $K_{V}$ (Tabela 6) de modo a refletir o comportamento do veículo nos testes realizados.

Tabela 6 - Parâmetros do modelo do motor

\begin{tabular}{|l|l|}
\hline$K_{V}$ & $2,389410^{-5}$ \\
\hline$K_{\omega}$ & $8,762510^{-6}$ \\
\hline
\end{tabular}

Na Figura 40 está ilustrada a curva de velocidade simulada utilizando os parâmetros determinados. A maior diferença entre o modelo desenvolvido e os dados obtidos experimentalmente é que no modelo a velocidade converge para um determinado comando enviado. Nos experimentos, os resultados oscilam um pouco em torno de um valor, sendo a razão deste comportamento atípico associada ao controlador originalmente implementado pelos desenvolvedores do sistema, que 
não faz parte do escopo deste trabalho, e a eventuais perturbações por atrito. Não obstante, o modelo utilizado ao longo deste trabalho é considerado satisfatório.

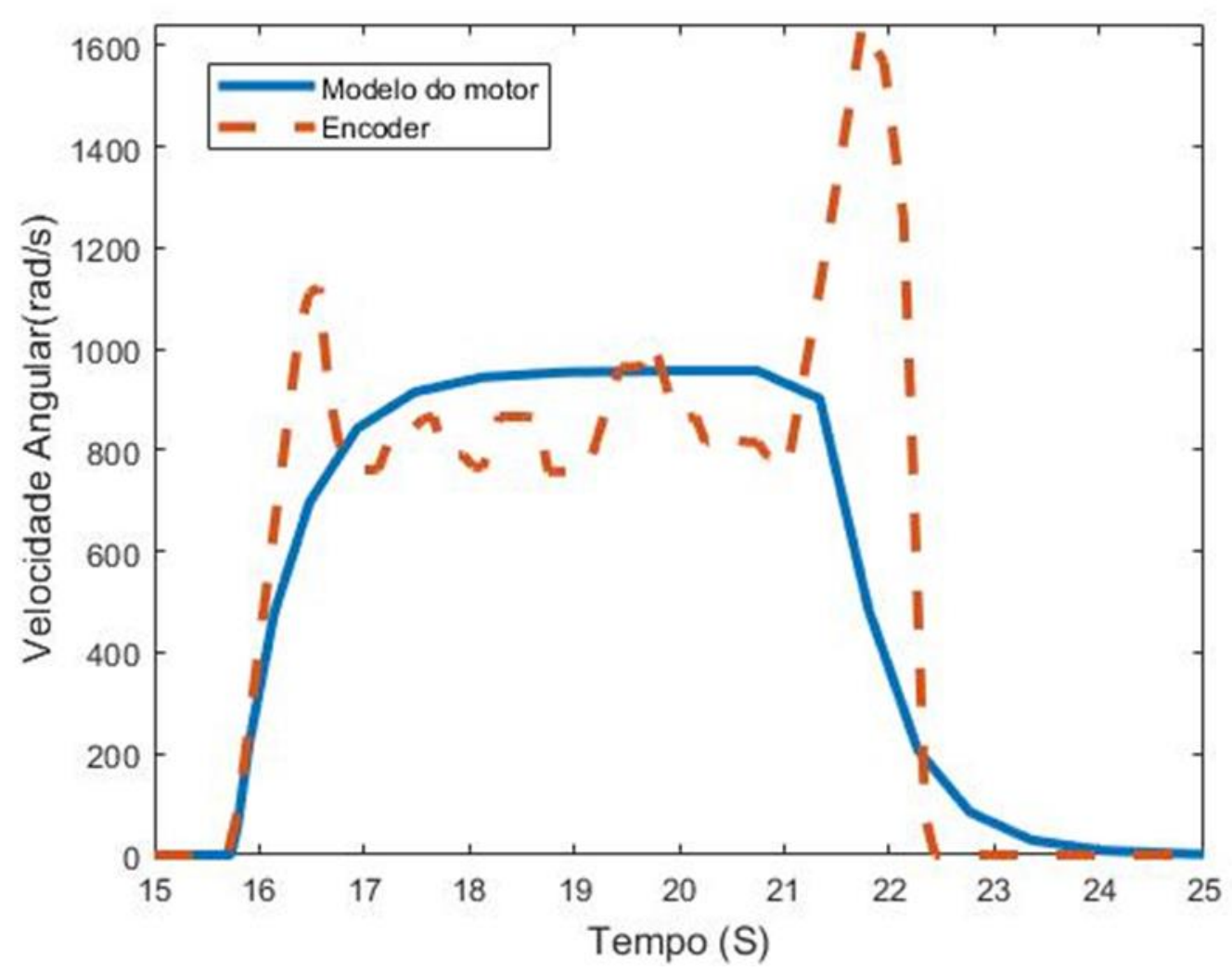

Figura 40 - Velocidade angular do modelo do motor

\subsection{Parametrização do modelo cinemático}

No capítulo 2 foi decidido utilizar o modelo do centro instantâneo de rotação. Neste método, é necessária a determinação experimental do parâmetro $\varphi$, crucial para o funcionamento do modelo.

Utilizando os comandos do joystick do robô aplicados nos testes de manobra, descritos no capítulo 6, é possível estimar o valor de $\varphi$ que melhor representa o movimento do veículo.

Depois de uma determinação qualitativa da ordem de grandeza de valores que melhor ajustam os dados às medidas realizadas, três diferentes valores de $\varphi$ são testados: 1,1, 1,25, 1,5, (Figura 41). A posição final obtida em cada uma das simulações é comparada com a posição real do veículo no fim do teste. 


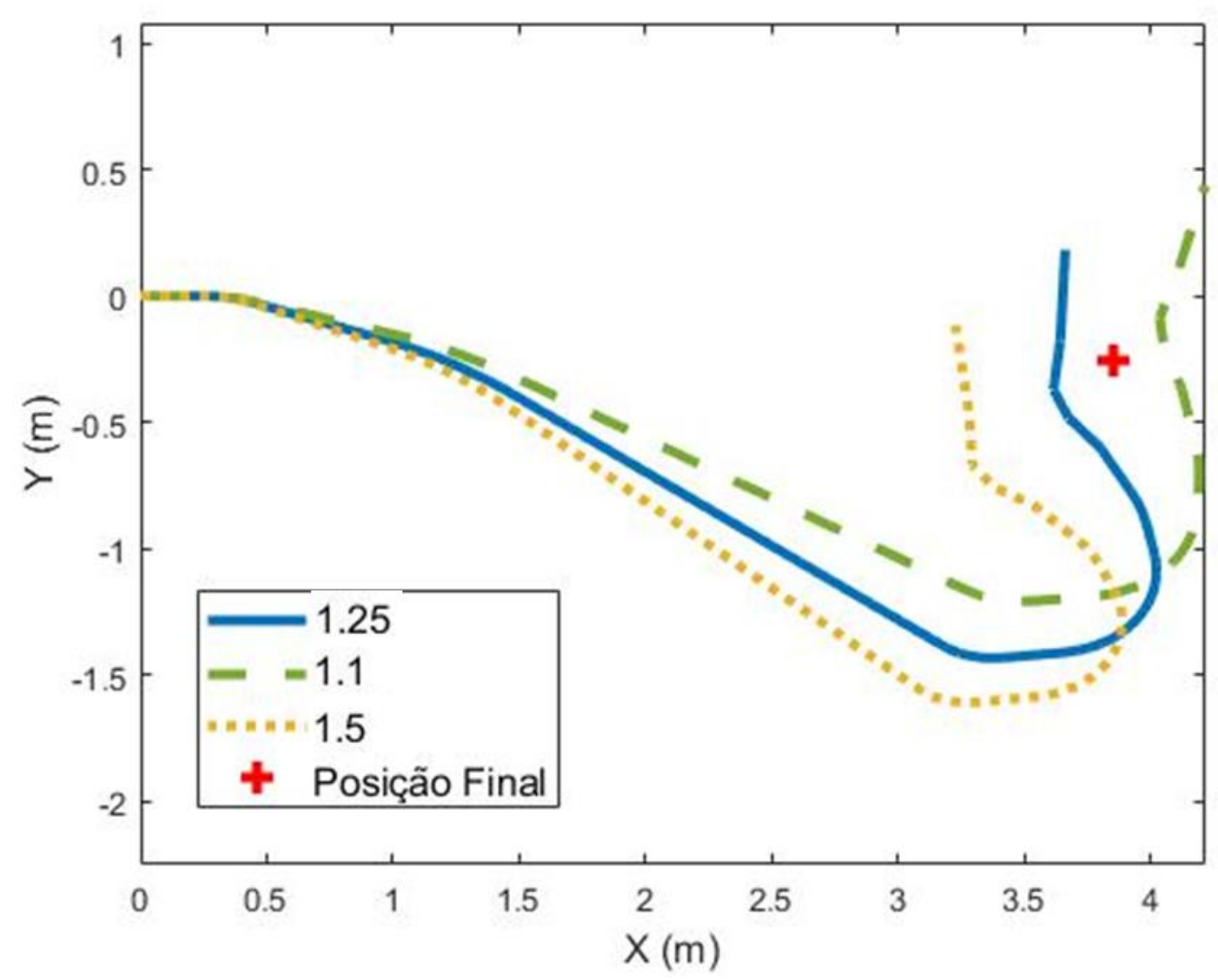

Figura 41 - Comparação entre valores de $\varphi$

A simulação é repetida para todos os testes realizados. O parâmetro com o menor erro em relação à posição final medida fisicamente é $\varphi=1,25$. Desta forma este é o parâmetro utilizado nas simulações e no filtro de Kalman.

\subsection{Comparação com o modelo de acionamento diferencial}

Também utilizando os dados do teste de manobra, é realizada uma comparação entre os resultados da simulação e os que seriam obtidos caso fosse assumido que o comportamento do veículo pode ser modelado adequadamente pelo modelo de acionamento diferencial, vide Figura 42. 


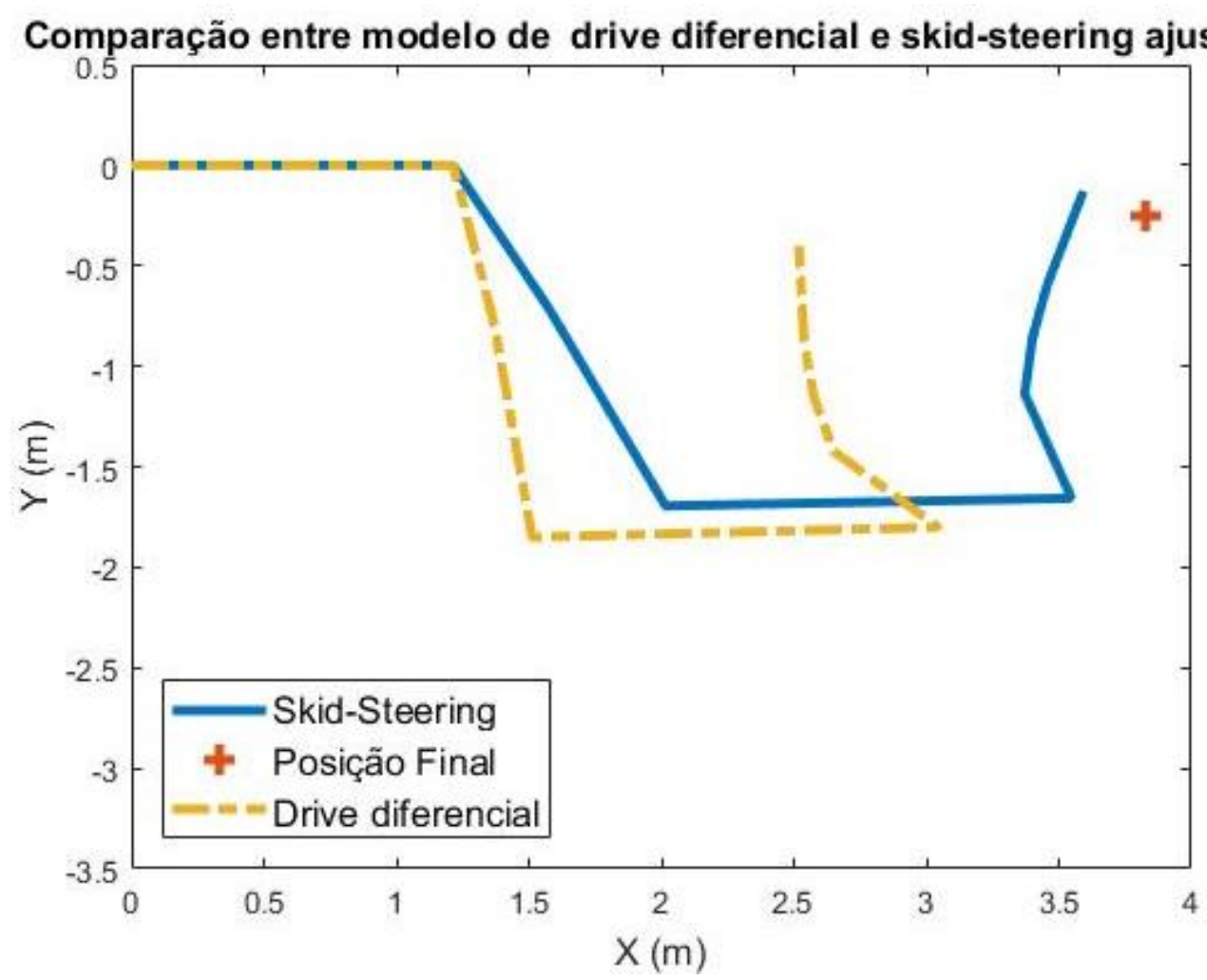

Figura 42 - Comparação entre as rotas previstas pelos modelos

No gráfico é visível a grande diferença entre os resultados obtidos. O modelo de acionamento diferencial (drive diferencial) apresenta uma trajetória muito diferente da observada experimentalmente e medida utilizando seus sensores ( $s k i d$ steering), e seu ponto final está em uma posição que dista muito da posição final medida em laboratório a partir de distâncias das paredes (o ponto + no gráfico).

A grande diferença dos modelos está no cálculo da velocidade angular do veículo. No modelo da cinemática experimental utilizado na simulação, as rotações que seriam obtidas são divididas pelo fator $\varphi$, determinado experimentalmente, resultando em valores menores de velocidade angular para uma mesma combinação de velocidades das rodas.

Com o objetivo de validar o uso do modelo, foram comparadas as velocidades angulares simuladas dos dois modelos e as velocidades angulares medidas diretamente pelo girômetro. Na Figura 43 está uma vista detalhada das velocidades angulares simuladas e a medida pelo giroscópio, durante cinco segundos de teste. Pode ser observado visualmente que o modelo utilizado se assemelha mais aos resultados medidos pelo girômetro que o modelo de drive diferencial. 


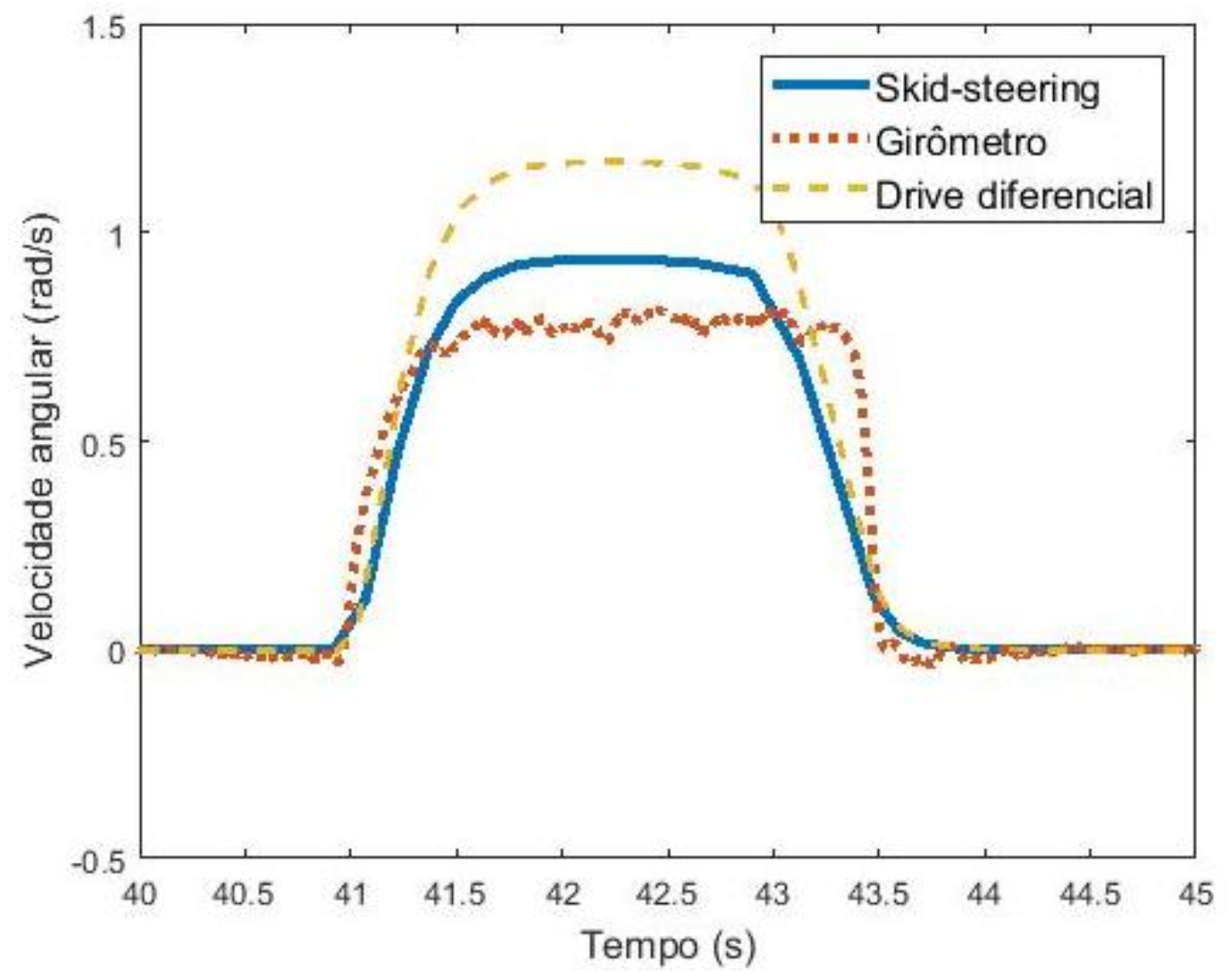

Figura 43 - Comparação das velocidades angulares dos modelos e medida

Com o objetivo de garantir que o modelo utilizado representa melhor a realidade, o processo foi repetido para todos os testes realizados. Na Tabela 7 estão os erros quadráticos médios para ambos os modelos.

Tabela 7- Erro quadrático médio entre modelos e girômetro

\begin{tabular}{|c|c|c|}
\hline & Skid-Steering & Drive diferencial \\
\hline Teste $1\left(\frac{r a d^{2}}{s^{2}}\right)$ & 0,0403 & 0,0301 \\
\hline Teste $2\left(\frac{r a d^{2}}{s^{2}}\right)$ & 0,0311 & 0,0381 \\
\hline Teste $3\left(\frac{r a d^{2}}{s^{2}}\right)$ & 0,0281 & 0,0368 \\
\hline Teste $4\left(\frac{r a d^{2}}{s^{2}}\right)$ & 0,0793 & 0,0977 \\
\hline Teste $5\left(\frac{r a d^{2}}{s^{2}}\right)$ & 0,0208 & 0,1182 \\
\hline Teste $6\left(\frac{r a d^{2}}{s^{2}}\right)$ & 0,0969 & 0,1049 \\
\hline Teste $7\left(\frac{r a d^{2}}{s^{2}}\right)$ & 0,0836 & \\
\hline
\end{tabular}


Os resultados obtidos na comparação entre os modelos demonstraram que o modelo cinemático experimental, devidamente ajustado, representa melhor o sistema real. As evidências demonstradas nesta seção são consideradas suficientes para justificar o uso do modelo cinemático experimental ao longo deste trabalho.

\subsection{Simulação do sistema de localização}

Além de permitir a determinação de parâmetros, a simulação desenvolvida pode ser utilizada para avaliar o funcionamento do sistema de localização em um ambiente controlado, permitindo ajuste de parâmetros e teste das técnicas utilizadas.

Os sensores utilizados têm uma grande importância no desempenho num sistema de localização, por isso é importante realizar a modelagem destes equipamentos de modo a refletir o funcionamento de maneira realística. A estrutura da simulação utilizada nesta seção está ilustrada na Figura 44.

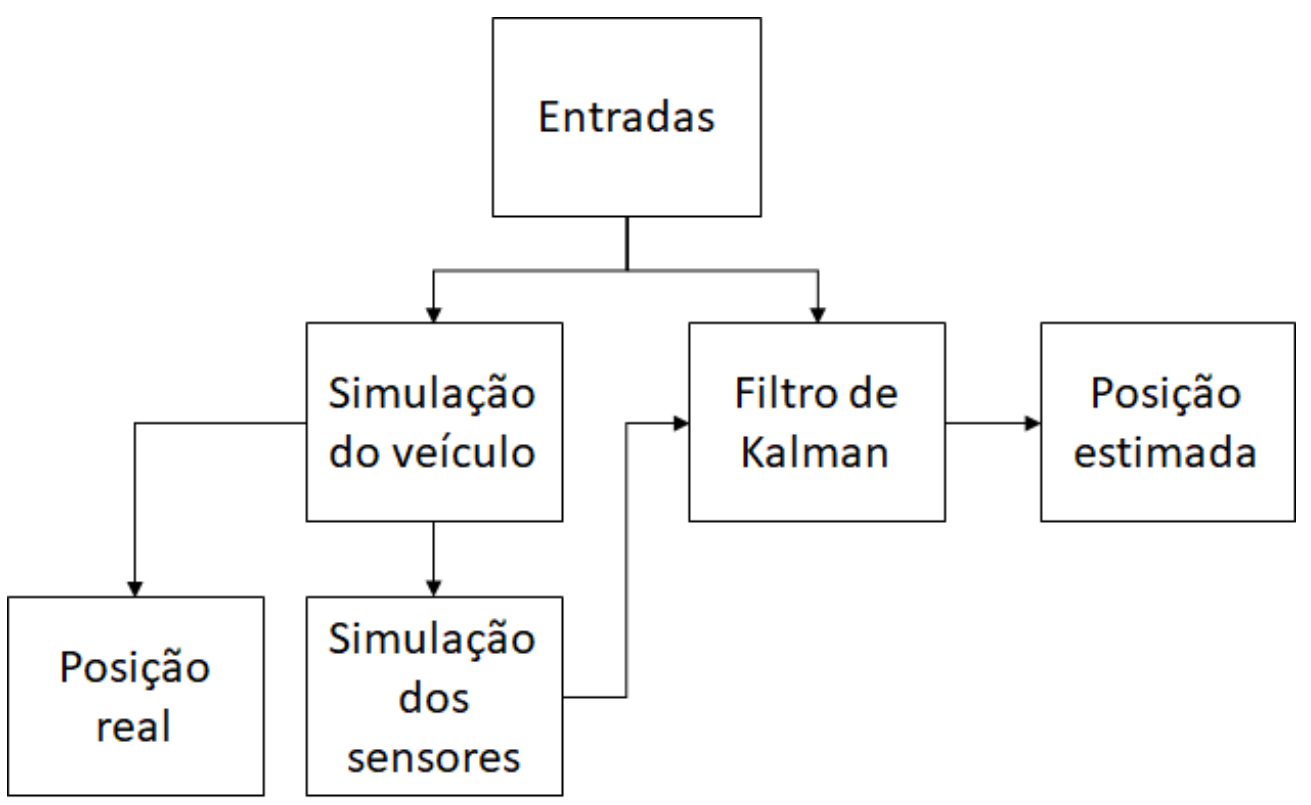

Figura 44 - Diagrama da simulação do sistema de localização

No bloco "Simulação dos Sensores", no diagrama, os valores das grandezas obtidas através da simulação dos sistemas são alterados de forma a representar os valores que seriam medidos pelos sensores. Neste trabalho, a única alteração realizada, para este fim, é a adição de um ruído com distribuição normal de mesma 
variância que a medida para o sensor. Para isso, é utilizada a função "Random Number", disponível no Simulink. As variâncias de todos os sensores se encontram na Tabela 8 .

Tabela 8 - Variâncias utilizadas na simulação

\begin{tabular}{|c|c|}
\hline Variância do encoder esquerdo $\left(\sigma_{e L}\right)$ & $0,0426\left(\frac{\mathrm{m}^{2}}{\mathrm{~s}^{2}}\right)$ \\
\hline Variância do encoder direito $\left(\sigma_{e R}\right)$ & $0,0426\left(\frac{\mathrm{m}^{2}}{\mathrm{~s}^{2}}\right)$ \\
\hline Variância do acelerômetro $\left(\sigma_{a y}\right)$ & $0,0348\left(\frac{\mathrm{m}^{2}}{\mathrm{~s}^{4}}\right)$ \\
\hline Variância do girômetro $\left(\sigma_{\omega z}\right)$ & $0,000162\left(\frac{\mathrm{rad}^{2}}{\mathrm{~s}^{2}}\right)$ \\
\hline
\end{tabular}

O funcionamento do veículo é simulado durante 200 segundos. As entradas utilizadas (valores adimensionais V) são rampas crescentes de acionamento até o valor 300, seguidas de rampas decrescentes até zero. Estes comandos foram repetidos de maneira periódica até 120 segundos, com uma defasagem de 10 segundos entre os motores. Os valores dos comandos são mantidos constantes e iguais durante 20 segundos. Após isso, é aplicada uma rampa decrescente até alcançar o zero em 150 segundos. No restante do tempo o comando enviado é zero (Figura 45).
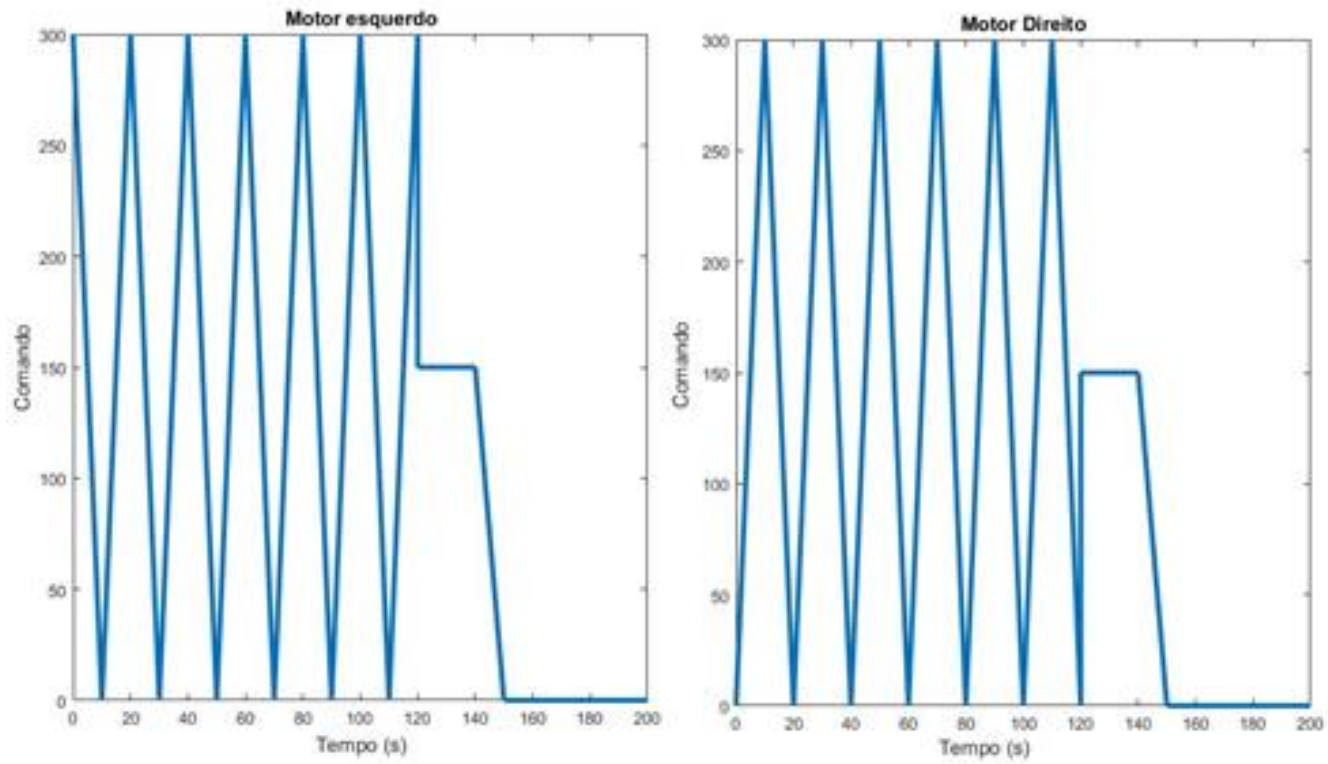

Figura 45 - Comandos utilizados na simulação do filtro de Kalman 
As entradas escolhidas têm como objetivo a realização de um caminho curvilíneo, sendo realizadas curvas para ambos os lados. Ao final, uma trajetória retilínea é comandada com orientação igual à inicial, e finalmente a parada do veículo sem mudança de orientação. Na Figura 46 está ilustrado o caminho simulado. Na imagem é possível observar que a trajetória está de acordo com o comportamento esperado. As medições simuladas e as entradas ilustradas na Figura 45 foram utilizadas no filtro de Kalman, e a trajetória obtida pode ser observada na Figura 46.

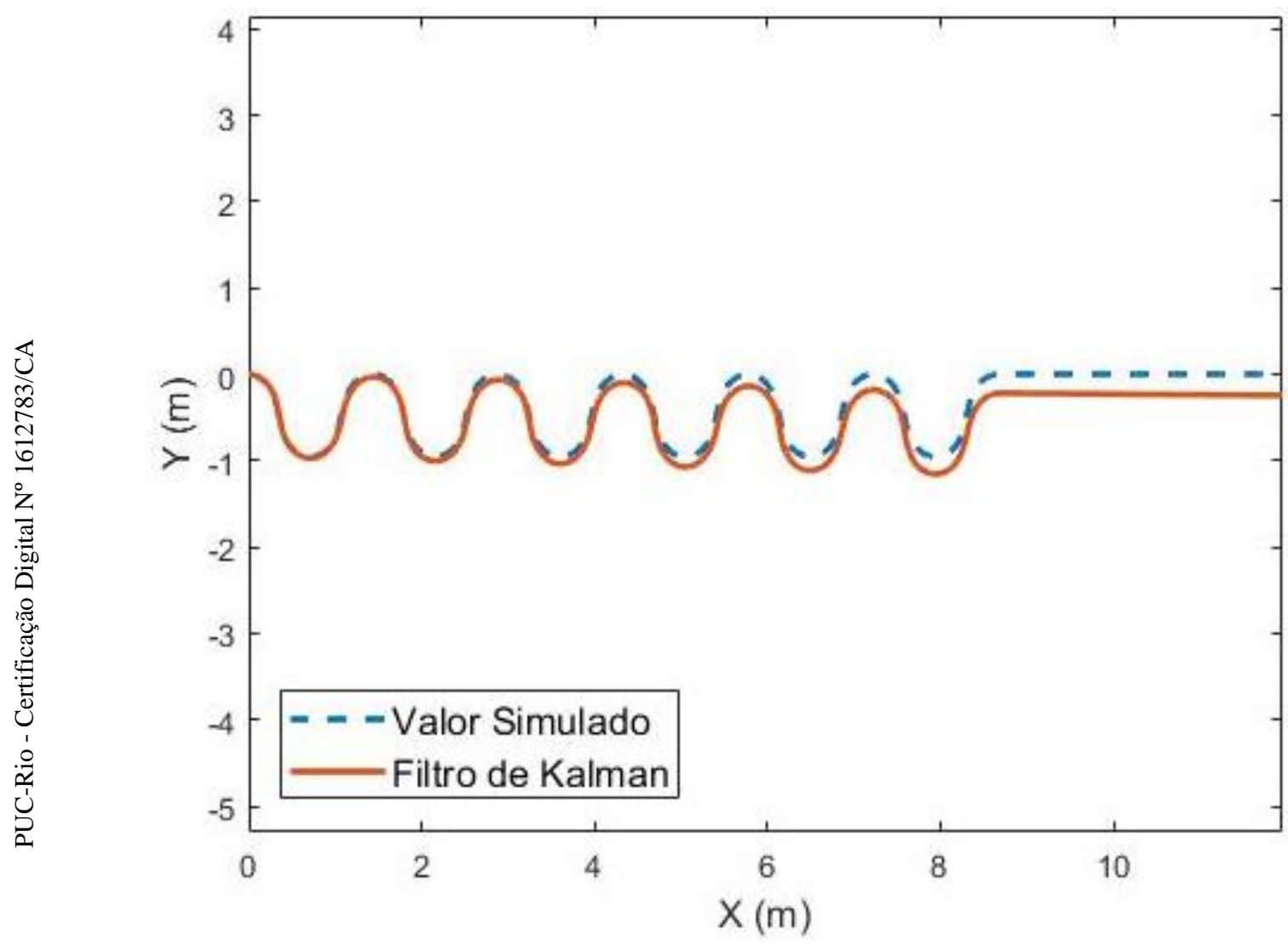

Figura 46 - Trajetória simulada e filtro de Kalman

O resultado demonstra que o caminho estimado pelo filtro de Kalman se distancia do valor real simulado ao longo do tempo. De modo a quantificar o erro do filtro na simulação, é calculada a distância entre a posição simulada e a estimada pelo filtro ao longo do tempo (Figura 47). 


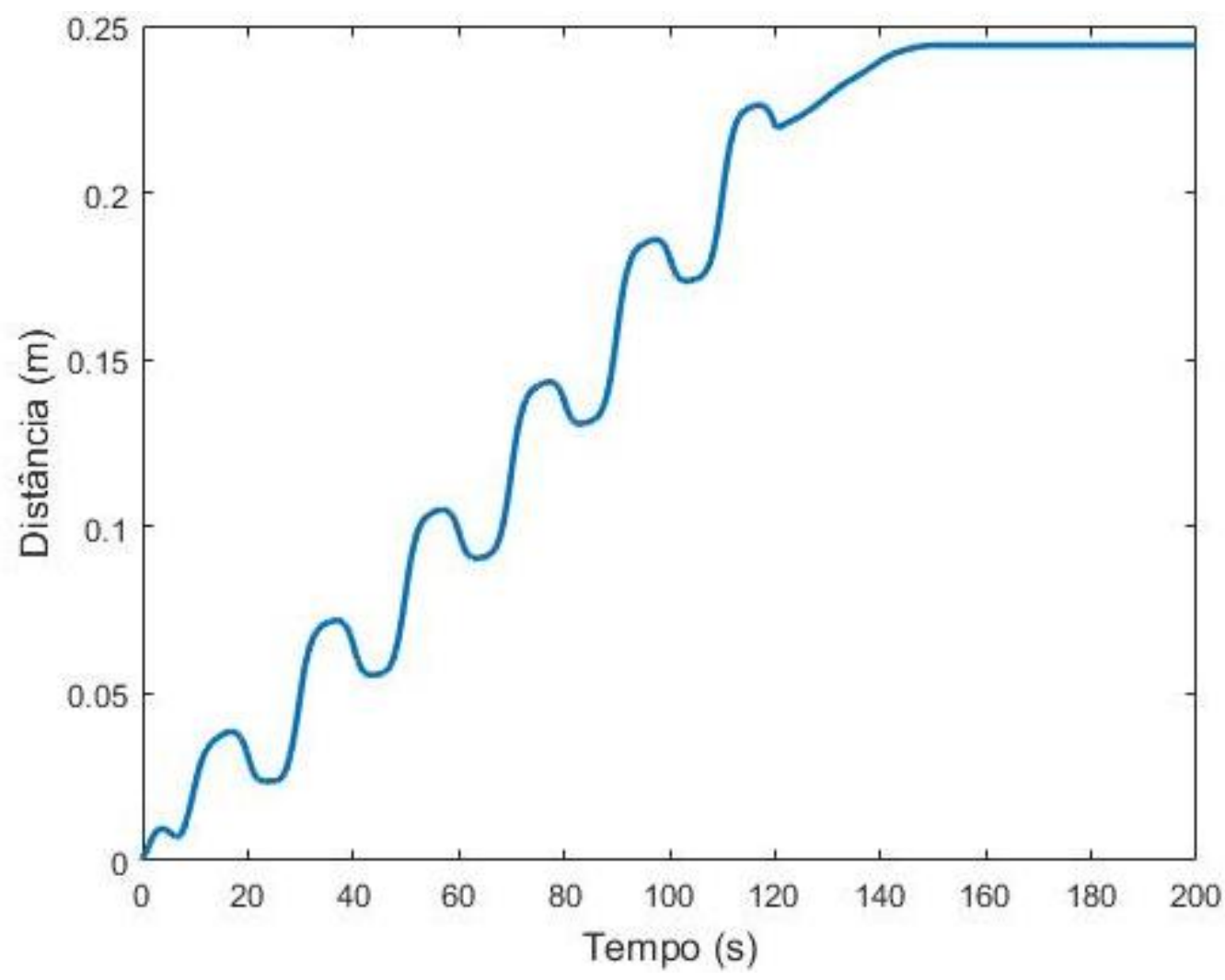

Figura 47 - Erro entre a simulação e o filtro de Kalman

Os erros de distância ilustrados na Figura 47 demonstraram um crescimento geral ao longo do tempo, um resultado esperado devido ao uso do sistema para a localização que não contém nenhum sensor capaz de oferecer uma medição absoluta da posição do veículo, sendo assim necessário o uso de cálculos integrais. Este processo está sujeito a grande quantidade de drift, causando assim um aumento do erro ao longo do tempo.

Para comparar as grandezas estimadas pelo filtro de Kalman com os resultados obtidos, é calculado o erro quadrático médio entre a velocidade estimada pelo filtro de Kalman, a medida através dos encoders simulados, e a integração das medidas simuladas para o acelerômetro (Tabela 9). O mesmo é feito para a velocidade angular, sendo comparados o girômetro, os encoders e o filtro de Kalman (Tabela 10). 
Tabela 9 - Erro quadrático médio da velocidade na simulação

\begin{tabular}{|c|c|}
\hline & Erro quadrático médio $\left(\frac{m^{2}}{s^{2}}\right)$ \\
\hline Encoders simulados & $9,4810^{-6}$ \\
\hline Acelerômetro Simulado & 0,3409 \\
\hline Filtro de Kalman & $2,5410^{-7}$ \\
\hline
\end{tabular}

Tabela 10 - Erro quadrático médio da velocidade angular na simulação

\begin{tabular}{|c|c|}
\hline & Erro quadrático médio $\left(\frac{\mathrm{rad}^{2}}{\mathrm{~s}^{2}}\right)$ \\
\hline Encoders simulados & $1,7310^{-4}$ \\
\hline Girômetro simulado & $1,6910^{-4}$ \\
\hline Filtro de Kalman & $1,3110^{-5}$ \\
\hline
\end{tabular}

É possível observar que o filtro foi capaz de estimar a velocidade linear e a angular reais do veículo com maior precisão que seria possível utilizando os outros sensores, justificando assim o uso da fusão de sensores.

Os resultados das simulações validaram as técnicas desenvolvidas, porém é necessário verificar se a simulação desenvolvida adequadamente representa o sistema experimental sendo utilizado. No capítulo seguinte são descritos os testes para validação experimental dos métodos desenvolvido durante este trabalho. 


\section{Resultados experimentais}

Neste capitulo, são descritos os experimentos realizados no veículo RITA (Figura 48) com o objetivo de comparar e validar o sistema de localização proposto. Três testes são realizados: em linha reta, para avalição do filtro de Kalman em condições de pouco deslizamento; de manobra, para análise do comportamento em caso geral; e com magnetômetro, para comparar o sistema de localização com e sem o uso do sensor.

Todos os testes foram realizados no Laboratório de Robótica da PUC-Rio. Devido à existência de parâmetros dependentes do terreno (i.e. $\varphi$ ) deve ser levado em conta que, em uma eventual reprodução dos testes realizados, tal parâmetro deve ser calibrado para o ambiente utilizado.

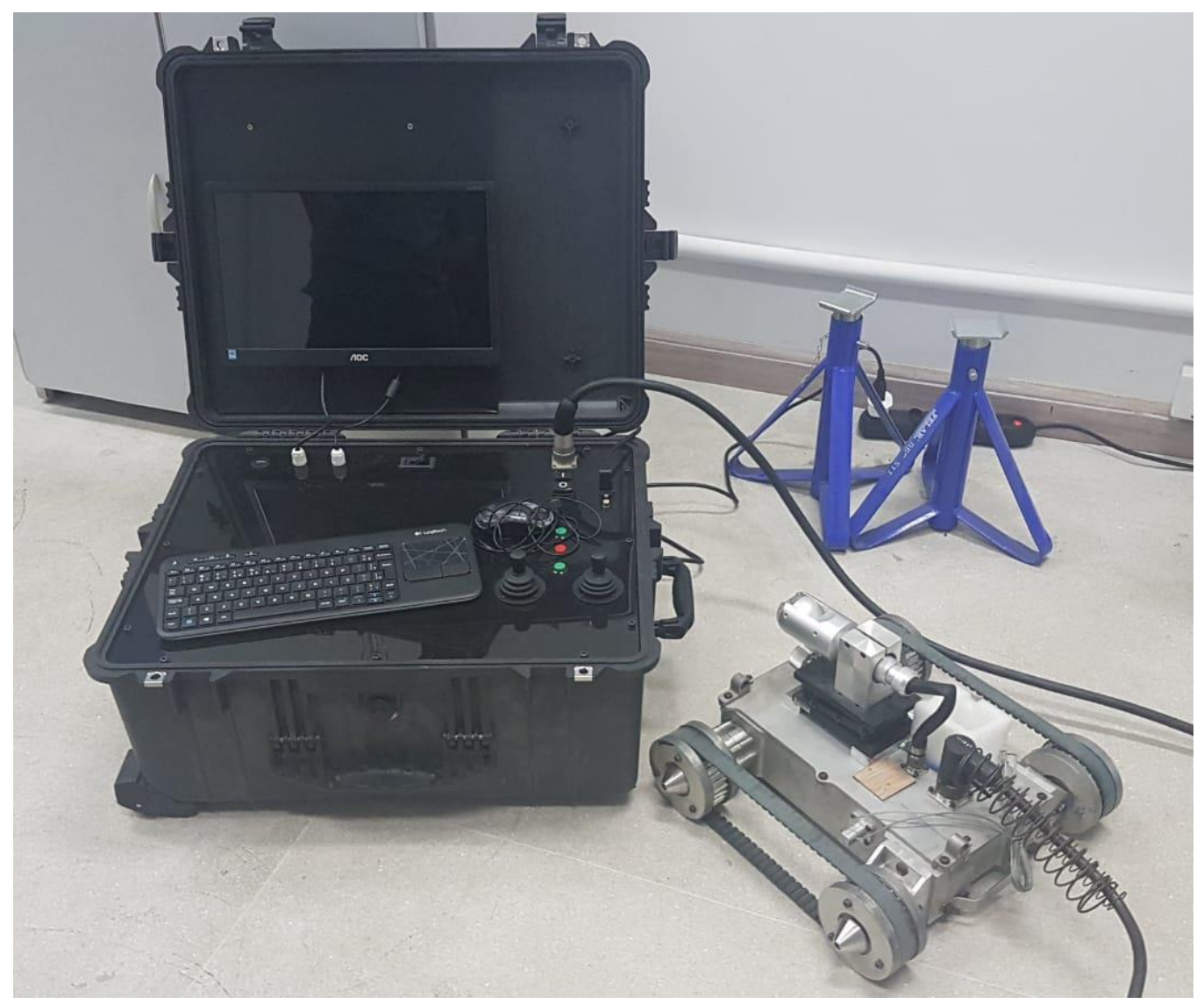

Figura 48 - Computador e o robô RITA conectados pelo umbilical 
O veículo é conectado ao computador por meio de um cabo umbilical, como ilustrado na Figura 48. O peso e tração neste fio não foram considerados na modelagem realizada, por isso ao longo dos testes este cabo é mantido fora do chão e sem tração, de modo a minimizar os efeitos da sua presença na dinâmica do veículo. Isto também permitiu que o veículo realizasse manobras sem a interferência da presença do cabo, facilitando a realização dos testes.

\subsection{Estrutura do sistema de localização}

Foi desenvolvido um sistema de localização permitindo analisar a eficiência dos métodos descritos neste trabalho. O sistema consiste na aquisição das medidas dos sensores e das entradas enviadas aos motores. Em seguida, as medidas da IMU são filtradas pelo filtro de banda, discutido no capitulo 4. Estas informações são introduzidas no filtro de Kalman, desenvolvido de acordo com a teoria exposta no capítulo 3, determinando as estimativas de velocidade e velocidade angulare do veículo. A partir de cálculos simples de integração é possível determinar a posição do veículo em relação a um eixo fixo de coordenadas. O sistema completo está ilustrado esquematicamente na Figura 49.

Para a utilização do sistema, é necessário determinar as variâncias dos sensores e das previsões realizadas pelo modelo. As variâncias dos sensores foram medidas na seção 4.3. Devido à dificuldade em calcular analiticamente as variâncias das estimativas fornecidas pelo modelo de previsão, os valores foram estimados de forma a oferecer um melhor desempenho ao filtro. Na Tabela 11 estão agregados todos os valores de variância utilizados no sistema de localização.

O sistema de localização descrito é utilizado nos testes a seguir, de forma a validar e avaliar as teorias, métodos e técnicas desenvolvidas ao longo deste trabalho. 


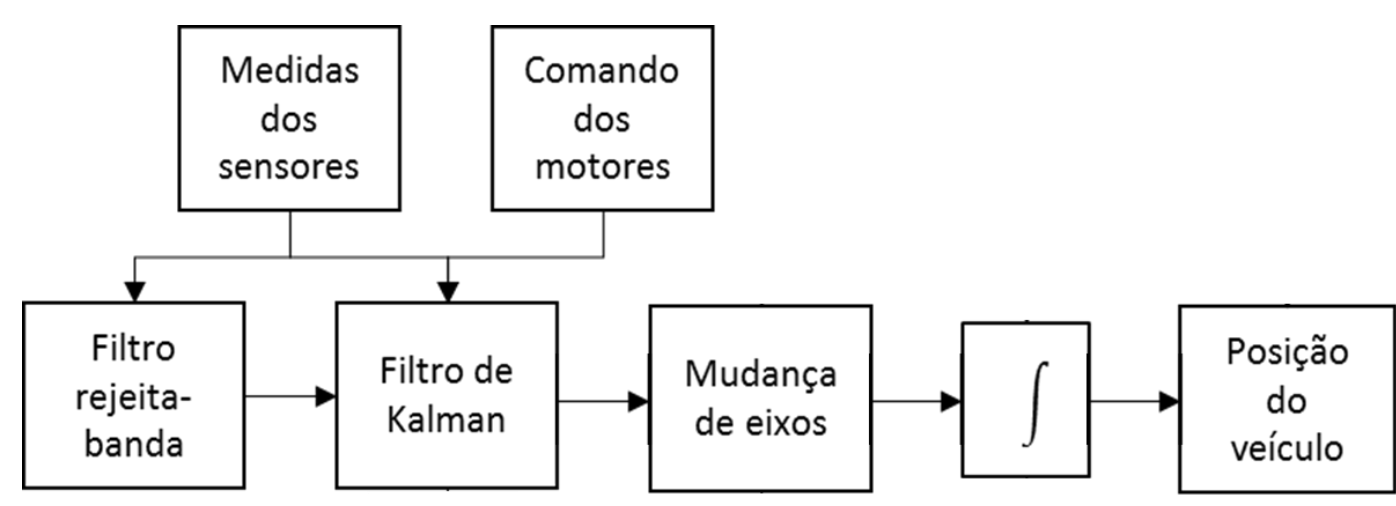

Figura 49 - Diagrama do sistema de localização

Tabela 11- Variâncias utilizadas no filtro de Kalman

\begin{tabular}{|c|c|}
\hline Variância do encoder esquerdo $\left(\sigma_{e L}\right)$ & $0,0426\left(\frac{m^{2}}{s^{2}}\right)$ \\
\hline Variância do encoder direito $\left(\sigma_{e R}\right)$ & $0,0426\left(\frac{m^{2}}{s^{2}}\right)$ \\
\hline Variância do acelerômetro $\left(\sigma_{a y}\right)$ & $0,0348\left(\frac{m^{2}}{s^{4}}\right)$ \\
\hline Variância do girômetro $\left(\sigma_{\omega z}\right)$ & $0,000162\left(\frac{r^{2 a d}}{s^{2}}\right.$ \\
\hline Variância da previsão de $v_{y}\left(\sigma_{v_{y}}\right)$ & $0,0001\left(\frac{m^{2}}{s^{2}}\right)$ \\
\hline Variância da previsão de $\omega_{z}\left(\sigma_{\omega_{z}}\right)$ & $0,0001\left(\frac{\mathrm{rad}^{2}}{s^{2}}\right)$ \\
\hline
\end{tabular}

\subsection{Testes em linha reta}

O primeiro tipo de teste realizado é o deslocamento em linha reta (Figura 50). Neste teste é enviado, durante um determinado período, um comando constante e igual aos motores direito e esquerdo. Isto deve, de acordo com o modelo proposto, garantir movimento retilíneo ao longo da operação. Ao final do movimento, a distância percorrida é medida utilizando uma trena.

O objetivo deste teste é verificar a eficiência do sistema de localização proposto, sem bússola, em uma condição onde o efeito do deslizamento é mínimo. 


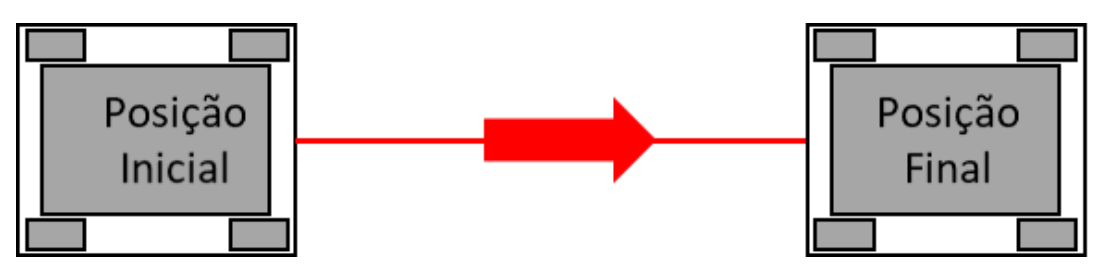

Figura 50 - Teste 1 de localização

São realizadas cinco repetições deste experimento, para um conjunto de quatro velocidades diferentes, resultando em vinte diferentes grupos de dados. Os grupos são chamados de: Teste 1 , Teste 2 , Teste 3 , Teste 4 . A numeração é realizada de forma decrescente com relação à velocidade: no Teste 1 é utilizada a uma velocidade próxima da máxima do veículo, aproximadamente $0,4 \mathrm{~m} / \mathrm{s}$, enquanto no Teste 4 a velocidade utilizada é próxima da mínima disponível, por volta 0,13 $\mathrm{m} / \mathrm{s}$.

Para permitir uma análise mais simples dos resultados obtidos, é calculado o erro quadrático médio $\left(\mathrm{em}^{2}\right.$ ) entre a posição final estimada por cada um dos métodos sendo comparados neste trabalho.

Tabela 12 - Erro quadrático médio da posição final

\begin{tabular}{|l|c|c|c|c|c|}
\hline & $\begin{array}{c}\text { Teste 1 } \\
(0,4 \mathrm{~m} / \mathrm{s})\end{array}$ & $\begin{array}{c}\text { Teste 2 } \\
(0,3 \mathrm{~m} / \mathrm{s})\end{array}$ & $\begin{array}{c}\text { Teste 3 } \\
(0,22 \mathrm{~m} / \mathrm{s})\end{array}$ & $\begin{array}{c}\text { Teste 4 } \\
(0,13 \mathrm{~m} / \mathrm{s})\end{array}$ & Média \\
\hline Encoders $\left(m^{2}\right)$ & 0,0126 & 0,0240 & 0,0063 & 0,0049 & 0,0120 \\
\hline Simulação $\left(m^{2}\right)$ & 0,0479 & 0,0211 & 0,0062 & 0,0060 & 0,0203 \\
\hline $\begin{array}{l}\text { Filtro de Kalman } \\
\left(m^{2}\right)\end{array}$ & 0,0041 & 0,0099 & 0,0046 & 0,0027 & 0,0053 \\
\hline
\end{tabular}

Os resultados demonstram que a fusão de sensores por meio do filtro de Kalman fornece melhores estimativas de velocidade que os outros métodos analisados, justificando este método para as condições testadas.

\subsection{Teste de manobra}

Para o segundo teste são definidas uma posição inicial e uma final conhecidas e constantes. Utilizando os joysticks instalados no computador de controle do veículo, o robô é dirigido até a posição final. No caminho são realizados diferentes tipos de curvas antes de se alcançar o objetivo, como mostrado na Figura 51. As 
posições finais e iniciais do veículo em cada teste são conferidas por meio de medições diretas e marcações no ambiente.

São realizados múltiplos caminhos diferentes, de forma a analisar a resposta do sistema em diversas condições. Desta forma, é possível realizar uma análise mais abrangente do sistema proposto, excitando as diversas fontes de erro, em especial relacionadas ao deslizamento nas curvas. As posições inicial e final (Tabela 13), porém, são as mesmas em todos os testes, simplificando sua realização.
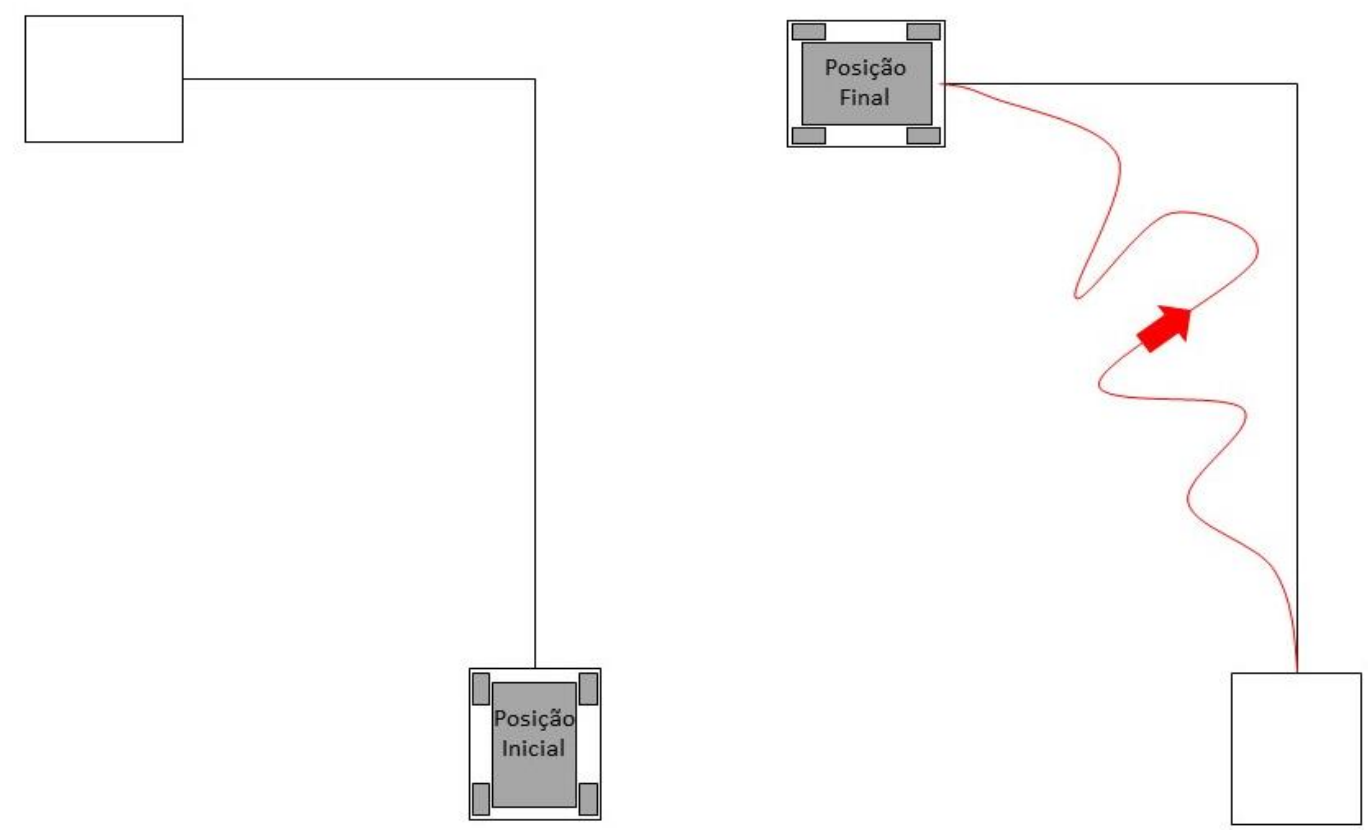

Figura 51 - Teste de manobra

Tabela 13 - Posições inicias e finais dos testes de manobra

\begin{tabular}{|c|c|c|c|}
\hline & $\mathrm{X}(\mathrm{m})$ & $\mathrm{Y}(\mathrm{m})$ & $\theta(\mathrm{rad})$ \\
\hline Posição Inicial & 0 & 0 & 0 \\
\hline Posição Final & 3,8275 & 0,2525 & $\frac{\pi}{2} \cong 1,57$ \\
\hline
\end{tabular}

O objetivo deste teste é analisar o movimento do veículo em uma condição de movimento geral, por isto os caminhos realizados foram propositalmente diferentes entre testes. Desse modo não é possível ajustar o sistema para funcionar melhor numa dada condição, o que acarretaria numa avaliação tendenciosa dos resultados. 
São realizados sete vezes este teste, com o objetivo de analisar se o sistema de localização está funcionado adequadamente incluindo a interferência por deslizamento.

O sistema de localização proposto neste trabalho é utilizado para estimar a posição final do veículo a partir dos comandos enviados aos motores pelos joysticks e as medidas realizadas pelos sensores presentes no veículo, sendo estes a IMU e os encoders dos motores.

Para que seja possível comparar a qualidade da solução com outras estimativas de posição, também foram calculados os resultados utilizando sistemas de localização mais simples, estes sendo: localização por odometria pura a partir do mesmo modelo cinemático utilizado no equacionamento do filtro, e simulação pura com as entradas reais utilizadas durante o teste (mas sem uso de dados de sensores).

A Figura 52 ilustra as trajetórias estimadas obtidas para um dos testes realizados. Na imagem estão representados os resultados do filtro e dos outros métodos sendo comparados.

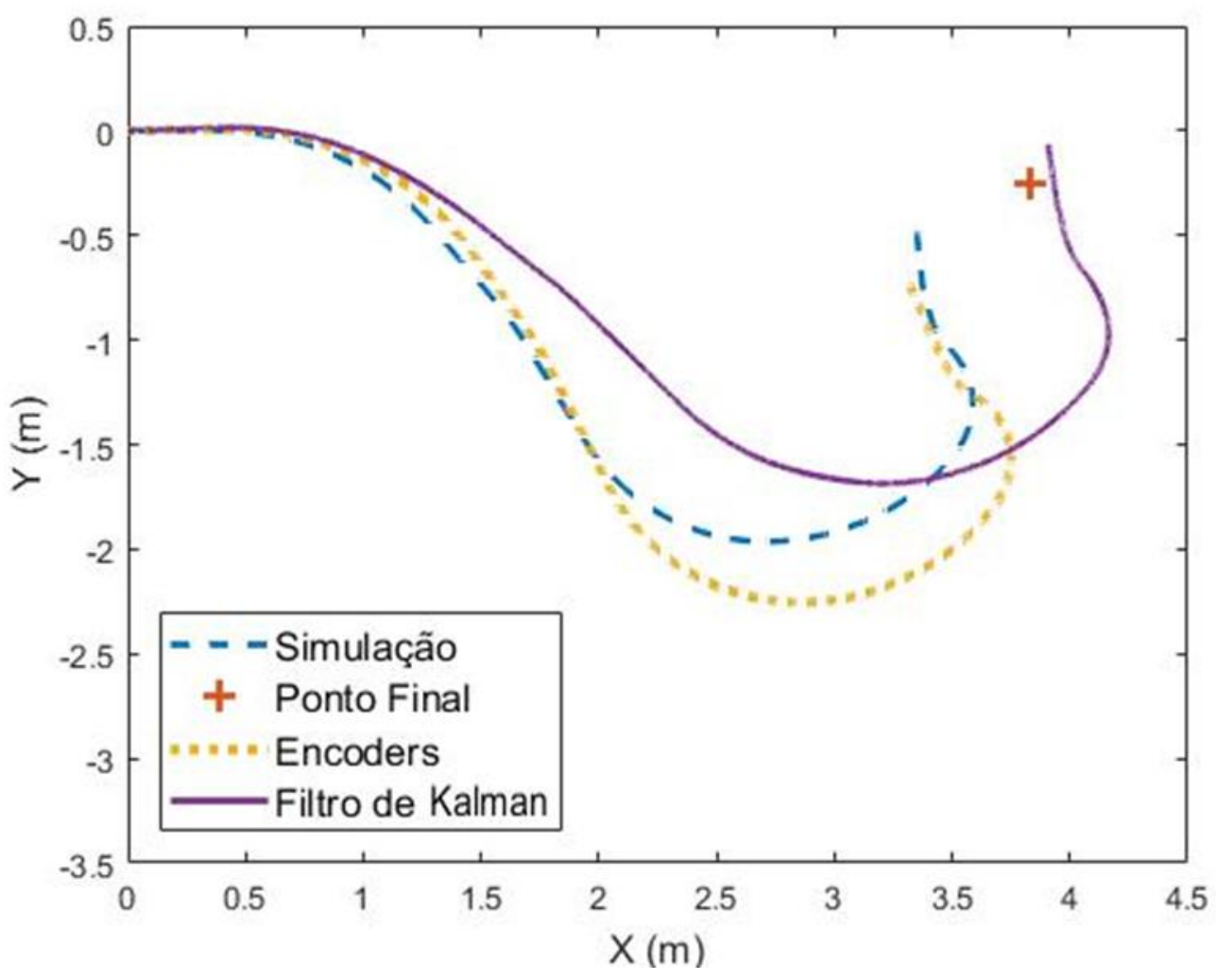

Figura 52 - Comparação entre trajetórias estimadas 
Os resultados obtidos a partir do sistema de localização baseado no filtro de Kalman apresentaram melhor desempenho que as outras opções, oferecendo estimativas mais próximas da posição real do veículo. Na Figura 53 está ilustrado, de forma agregada, as posições finais obtidas em todos os sete testes de manobra realizados.

Com o objetivo de oferecer dados quantitativos para avaliar o desempenho do sistema descrito, foram calculadas a distância entre os pontos finais previstos pelos diversos métodos ilustrados na Figura 53 e a posição real medida diretamente em laboratório a partir de distâncias de suas paredes (Tabela 14).

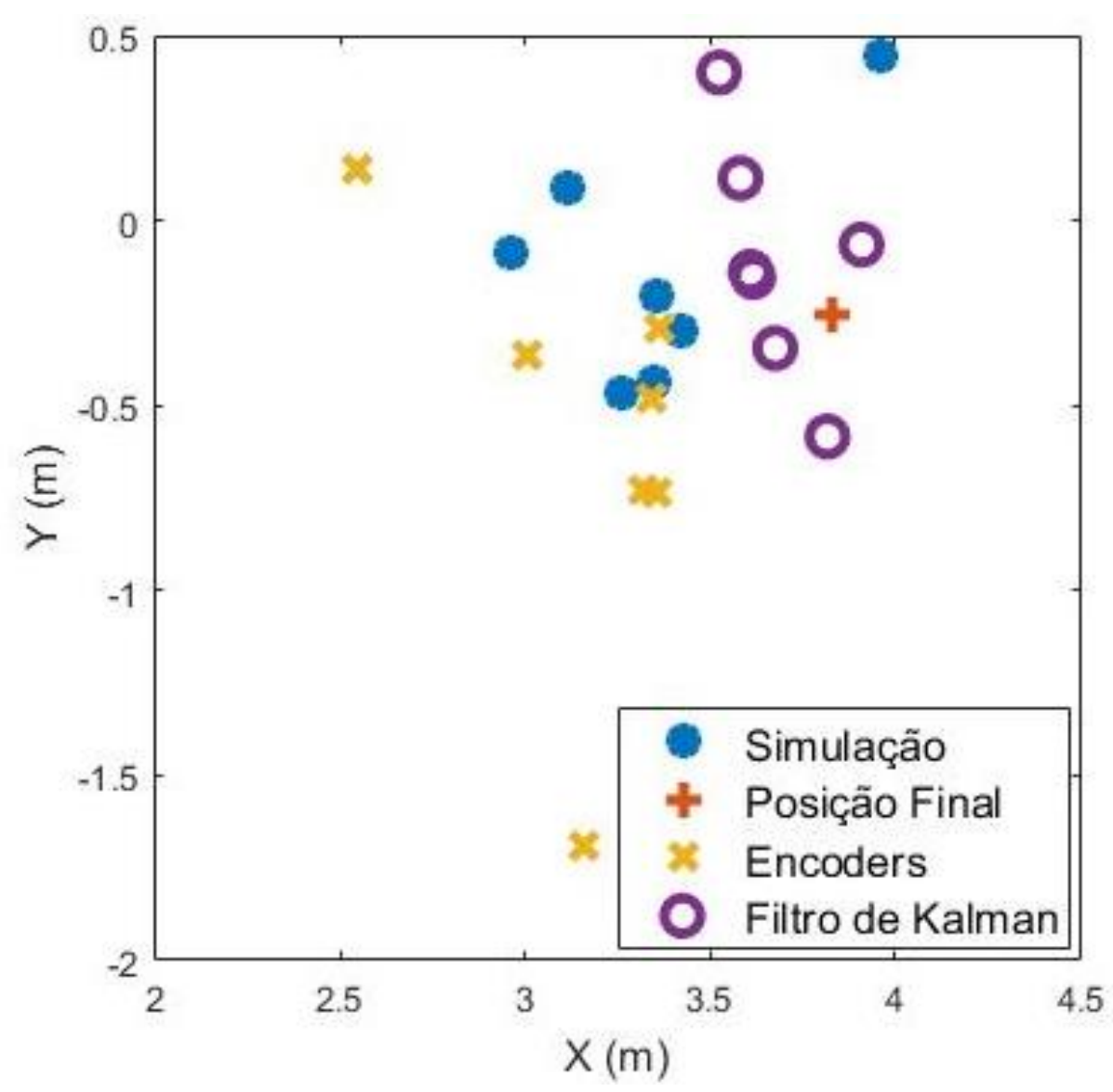

Figura 53 - Comparação entre posições finais estimadas 
Tabela 14 - Erro entre a posição final e previsões

\begin{tabular}{|l|c|c|}
\hline & $\begin{array}{c}\text { Distância média até o } \\
\text { ponto real }(\mathrm{m})\end{array}$ & $\begin{array}{c}\text { Erro no ângulo de } \\
\text { orientação }\left(\mathrm{rad}^{2}\right)\end{array}$ \\
\hline Encoders & 0,8765 & 1,5871 \\
\hline Simulação pura & 0,6252 & 0,1235 \\
\hline Filtro de Kalman & 0,3762 & 0,0383 \\
\hline
\end{tabular}

\subsection{Testes com o sistema de bússola}

No desenvolvimento do sistema de localização, foi decidido não utilizar as medições da direção do campo magnético realizadas pelo magnetômetro, devido à interferência causada pelo uso de rodas magnéticas. Com o objetivo de justificar a decisão tomada, são realizados outros testes similares aos testes de manobra descritos na seção 6.3.

Para a realização destes testes, foi necessária a modificação do firmware personalizado desenvolvido para a IMU, de modo a permitir a leitura do magnetômetro. Esta mudança diminuiu a frequência de aquisição dos dados da central inercial, de $250 \mathrm{~Hz}$ para aproximadamente $166.67 \mathrm{~Hz}$.

$\mathrm{O}$ valor utilizado para $\sigma_{\theta}$, assim como as variâncias de outros parâmetros previstos, são estimados. O valor $\sigma_{m a g}$ é medido na seção 4.3.3. A Tabela 15 apresenta os valores de variância utilizados para fácil consulta.

Tabela 15 - Parametros para o sistema de localização com magnetômetro

\begin{tabular}{|c|c|}
\hline Variância da previsão de $\theta\left(\sigma_{\theta}\right)$ & $0,0001\left(\mathrm{rad}^{2}\right)$ \\
\hline Variância do ângulo medido $\left(\sigma_{m a g}\right)$ & $0,0016\left(\mathrm{rad}^{2}\right)$ \\
\hline
\end{tabular}

Utilizando o sistema de localização descrito na seção 3.3, são realizados testes experimentais para que seja possível comparar os resultados com os do sistema de localização proposto. Os testes realizados são similares aos testes de manobra descritos na seção 6.3. A única diferença foi a nova posição final do veículo (Tabela 16). 
Tabela 16 - Posições iniciais e finais para os testes com o magnetômetro

\begin{tabular}{|c|c|c|c|}
\hline & $\mathrm{X}(\mathrm{m})$ & $\mathrm{Y}(\mathrm{m})$ & $\theta(\mathrm{rad})$ \\
\hline Posição Inicial & 0 & 0 & 0 \\
\hline Posição Final & 2,2475 & 0,2525 & $\frac{\pi}{2} \cong 1,57$ \\
\hline
\end{tabular}

Nestes testes, além de todas as informações extraídas do sistema, também são lidas as medições realizadas pelo magnetômetro. A defasagem entre o norte magnético e o eixo fixo da área de teste foi definida de modo que o ângulo de orientação medido coincide com ângulo de orientação real no início do teste. Utilizando essas informações, é possível estimar a localização do sistema com e sem o uso do magnetômetro. Os resultados obtidos para um dos testes estão ilustrados na Figura 54.

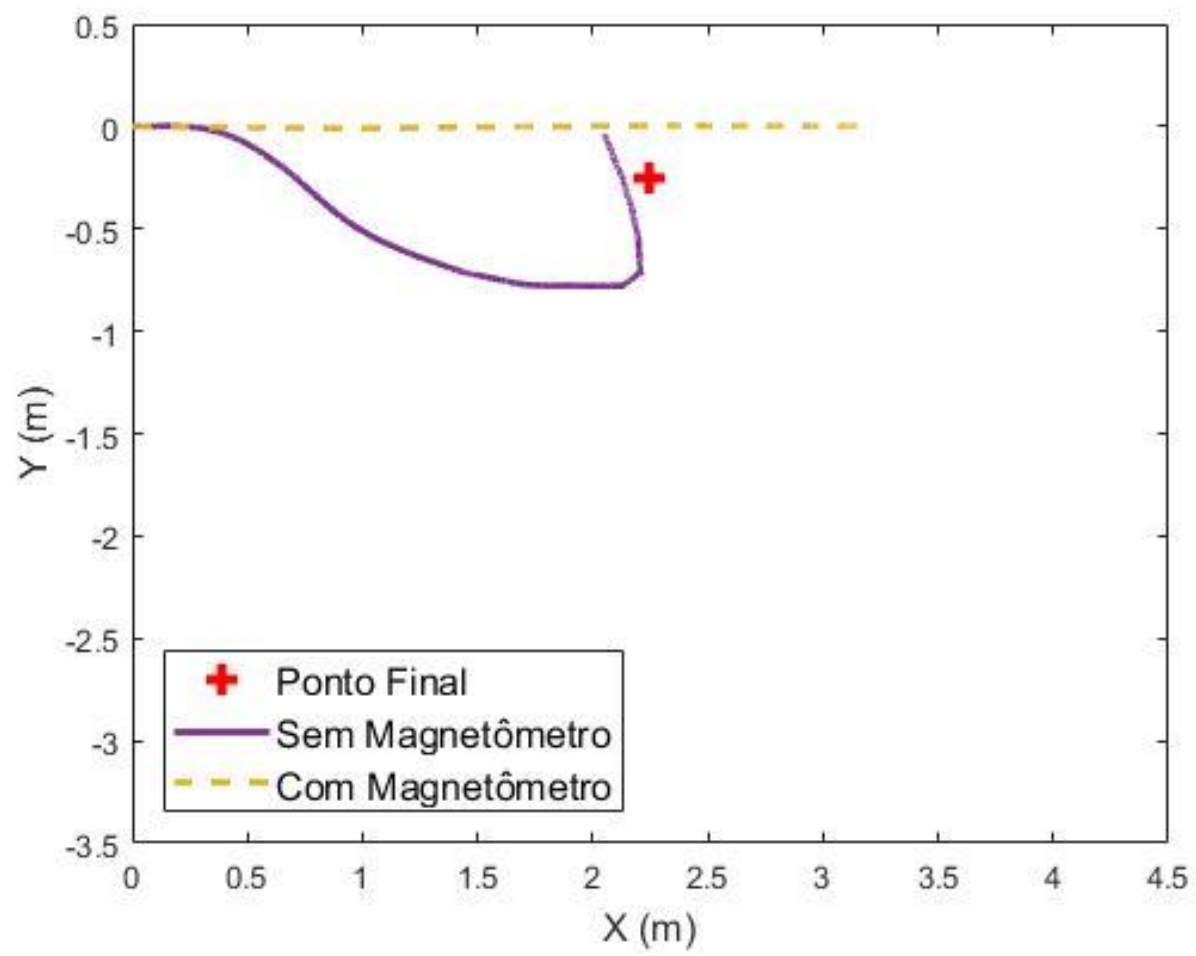

Figura 54 - Caminho estimado com e sem magnetômetro

$\mathrm{Na}$ Figura 54, a trajetória obtida pelo sistema de localização utilizando o magnetômetro foi aproximadamente retilínea. Isto ocorre pois as medições realizadas pela bússola (Figura 55) indicam uma orientação aproximadamente constante que não é compatível com o teste realizado, influenciada fortemente pelo campo magnético das rodas. 
Os ângulos medidos, ilustrados na Figura 55, obtiveram pouca variação, no máximo de 0,03 rad, durante o teste. Este erro foi causado pela presença do campo magnético gerado pelas rodas do veículo. A grande intensidade do campo produzido pelas rodas magnéticas faz com que este seja o campo com o maior efeito nas medições do magnetômetro. Como as posições das rodas são constantes em relação ao veículo, o campo tem pouca variação, resultando no mesmo ângulo medido.

Num esforço de reduzir o efeito do campo magnético das rodas nas medições do ângulo de orientação do veículo, é repetido o processo de calibração do magnetômetro, descrito na seção 4.3.3. Com a IMU posicionada no veículo, este foi rotacionado manualmente duas vezes. Os resultados do campo magnético estão ilustrados na Figura 56.

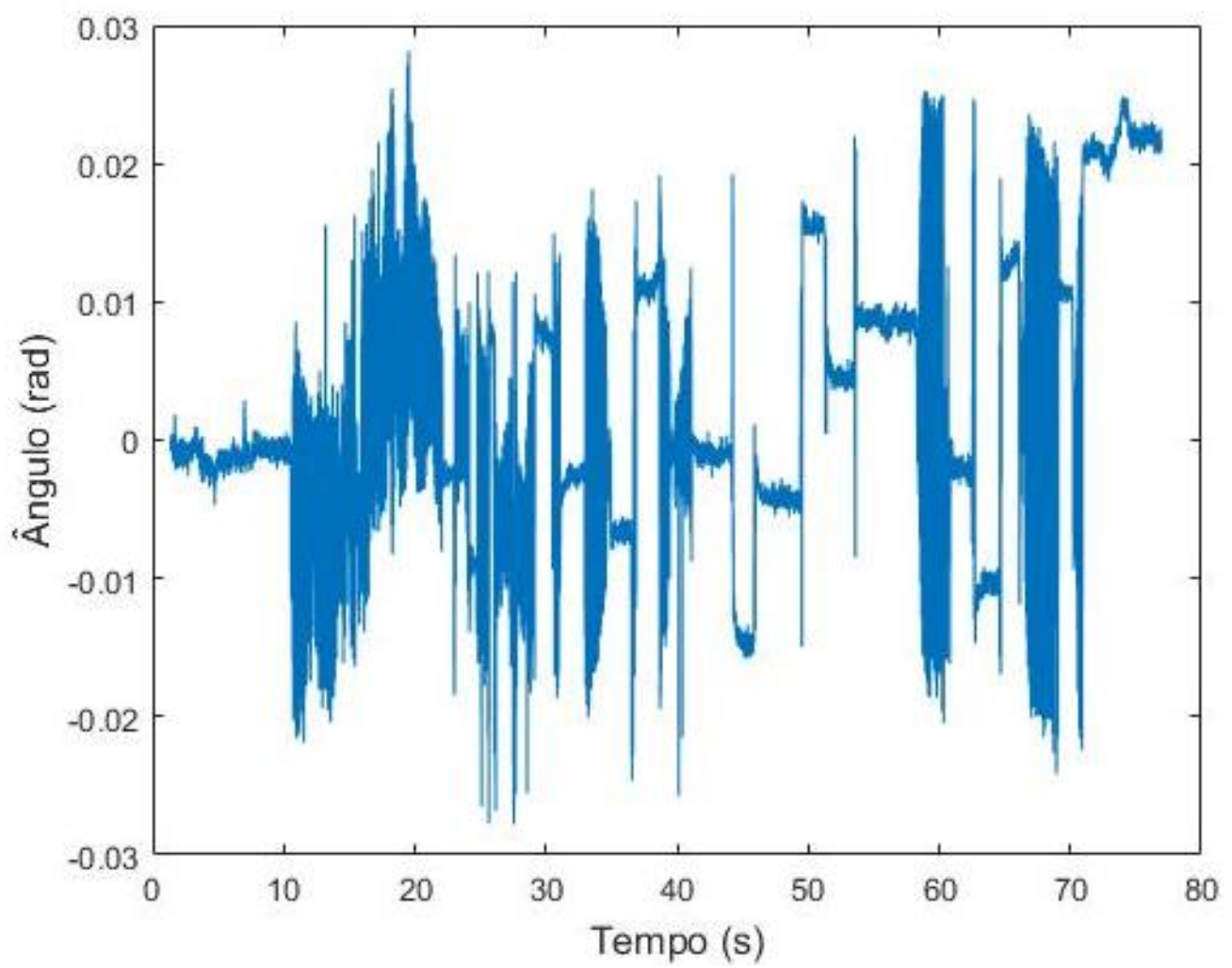

Figura 55 - Ângulo medido pelo magnetômetro durante o teste 


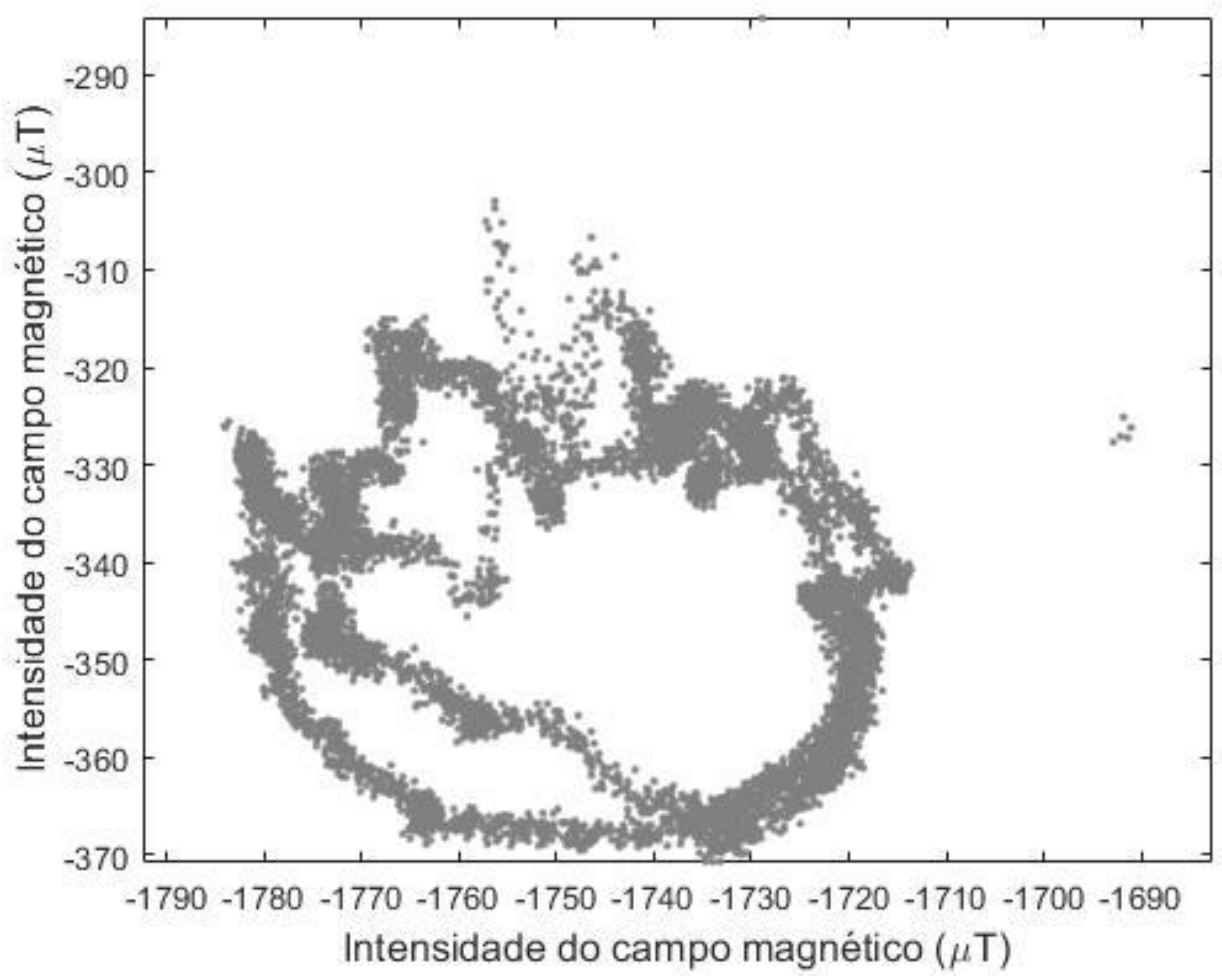

Figura 56 - Campo magnético com rodas magnéticas

O resultado do campo magnético demonstrou alto nível de distorção do campo graças às rodas magnéticas do veículo. A maior parte sendo uma grande distorção do tipo hard-iron, como havia sido antecipado. O processo de calibração é então realizado sendo determinados os parâmetros descritos na Tabela 17.

Tabela 17 - Parâmetros de Calibração para as rodas magnéticas

\begin{tabular}{|c|c|}
\hline$S_{x}$ & 1 \\
\hline$S_{y}$ & 1,05 \\
\hline$C_{x}$ & 1747,6 \\
\hline$C_{y}$ & 347,455 \\
\hline
\end{tabular}

Os resultados da calibração estão ilustrados graficamente na Figura 57. Observando a imagem é fácil perceber a ordem de magnitude das perturbações causadas pelo campo magnético das rodas e, consequentemente, o grande valor das correções necessárias. 


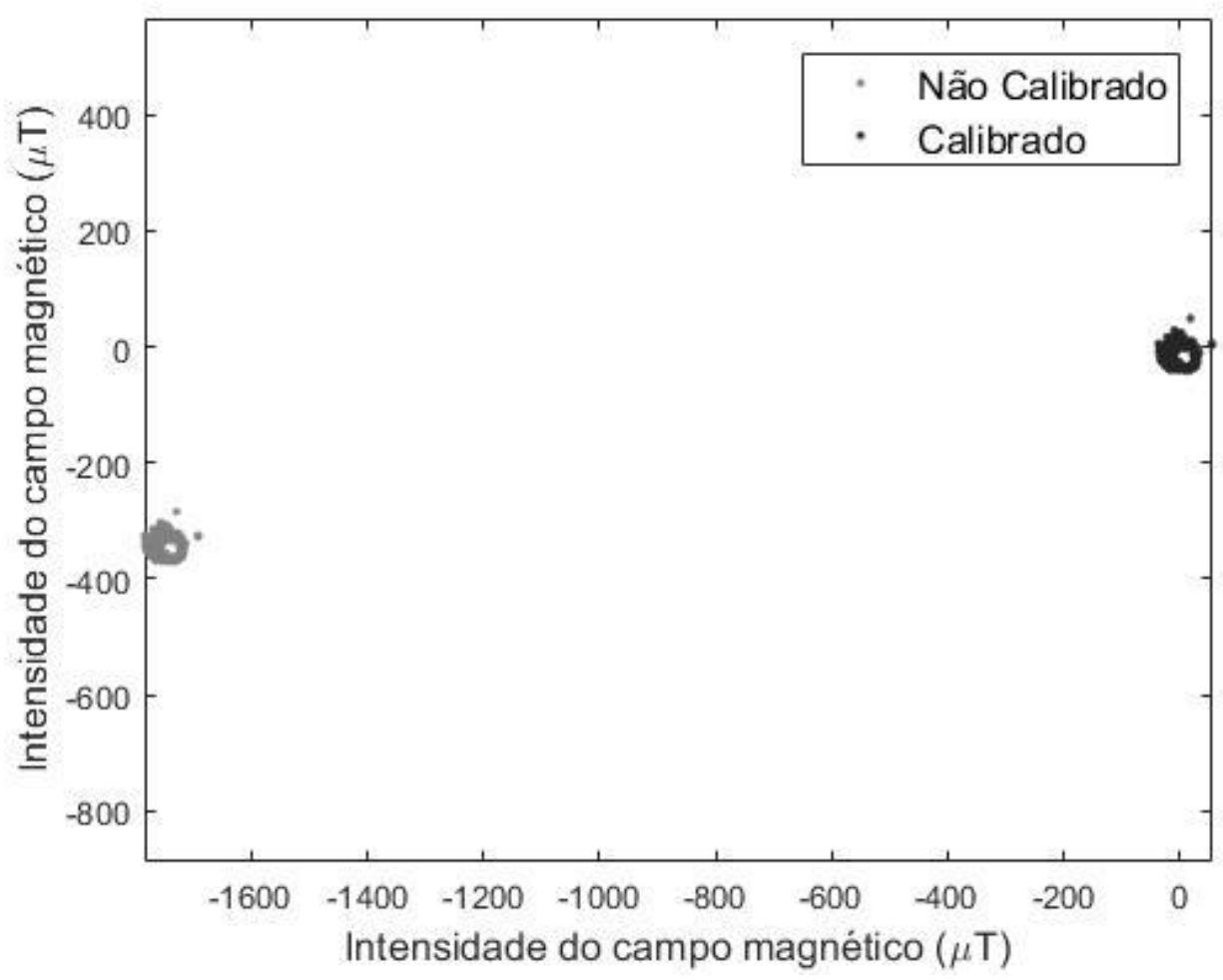

Figura 57 - Campo magnético calibrado com rodas magnéticas

Utilizando esta nova calibração, as medições realizadas pelo magnetômetro são utilizadas novamente para medir a orientação do veículo. Os resultados obtidos apresentaram um melhor desempenho, demonstrando que foi possível reduzir os efeitos do campo magnético das rodas nas medições.

No entanto, apesar das correções realizadas, os resultados do sistema com uso do magnetômetro não foram tão bons quanto os do sistema proposto sem ele (Figura $58)$. 


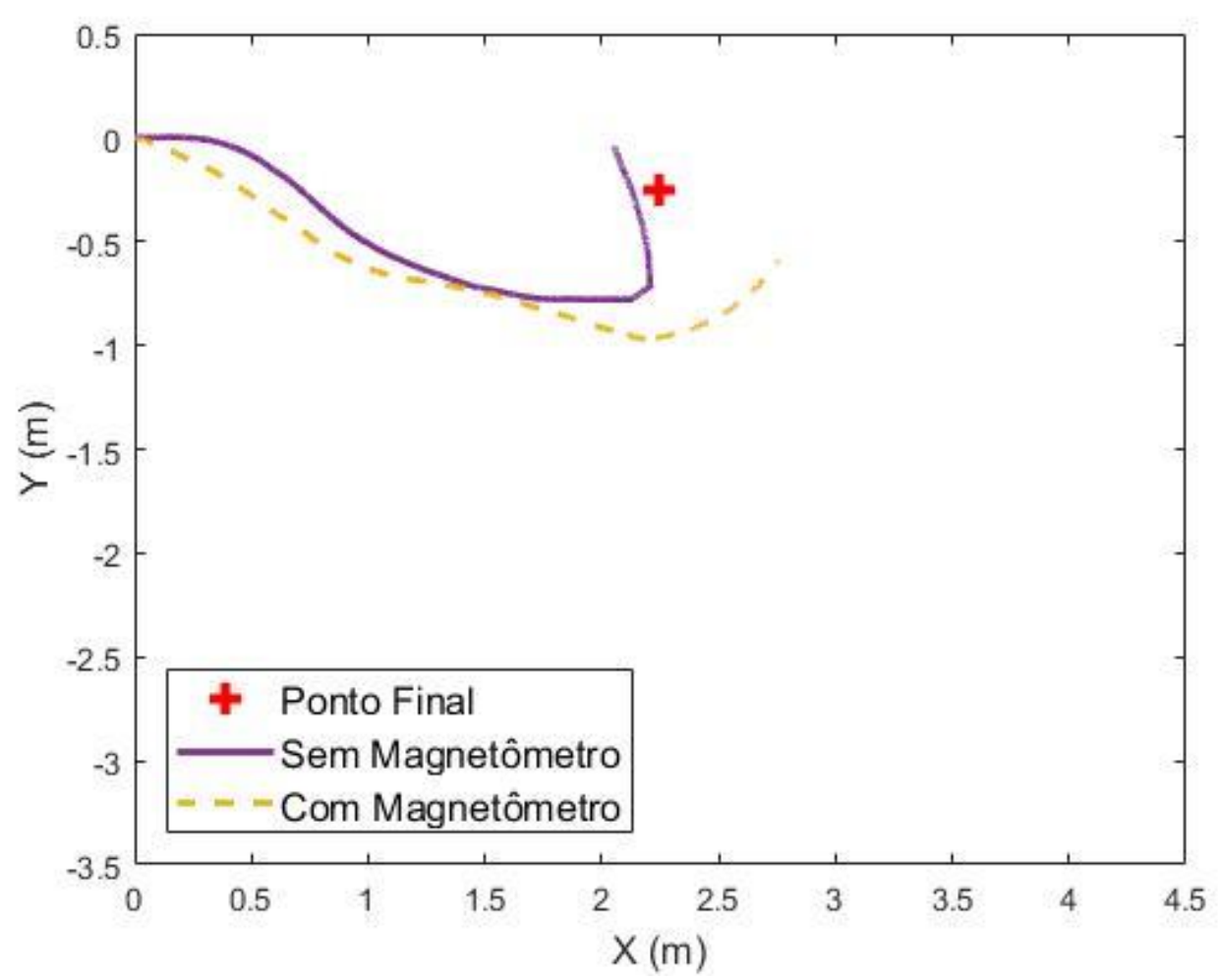

Figura 58 - Caminho estimados após a calibração

Com o objetivo oferecer dados quantitativos para a avaliação de ambos os sistemas testados, é calculada a distância média entre os pontos finais estimados por ambos o sistemas de localização e o real. Também é calculado o erro quadrático médio entre o ângulo de orientação final previsto e o real.

Tabela 18 - Erros das posições finais e do sistema de localização

\begin{tabular}{|l|c|c|}
\hline & $\begin{array}{c}\text { Distância média até o } \\
\text { ponto real }(\mathrm{m})\end{array}$ & $\begin{array}{c}\text { Erro no ângulo de } \\
\text { orientação }\left(\mathrm{rad}^{2}\right)\end{array}$ \\
\hline Com magnetômetro & 1,2088 & 0,8919 \\
\hline Sem magnetômetro & 0,4257 & 0,1101 \\
\hline
\end{tabular}

O sistema proposto, sem o magnetômetro, apresentou melhores resultados nos testes realizados. Isso mostra que, para o veículo testado, a interferência do campo magnético resulta em uma perda de desempenho significativa do filtro. Mesmo com a calibragem do magnetômetro, conclui-se que a decisão de não incluílo no sistema de localização proposto neste trabalho foi sensata.

Em suma, os testes apresentados neste capítulo comprovam a eficiência das técnicas utilizadas. Os testes de linha reta e manobra, nas seções 6.2 e 6.3 
respectivamente, compararam o sistema proposto com medição direta pelos encoders e previsão pela simulação. O melhor resultado oferecido pelo sistema comprova experimentalmente que a fusão de sensores através de filtro de Kalman, sem o uso do magnetômetro, oferece melhor desempenho que os métodos de previsão e medição empregados, validando seu uso. Os testes comparativos realizados com o magnetômetro e o sistema proposto confirmaram experimentalmente que as perturbações devidas às rodas magnéticas do veículo afetam negativamente as estimativas da orientação do veículo. 


\section{Conclusões}

Neste trabalho foi apresentada a teoria do modelo cinemático experimental para veículos tipo skid-steering. Foram desenvolvidas as equações e hipóteses utilizadas pelo modelo. Este modelo também foi comparado com uma dedução mais rigorosa da cinemática deste tipo de veículo. Foi explicada a dificuldade de implementação deste modelo analítico, justificando o uso do modelo utilizado neste trabalho.

Um modelo dinâmico foi elaborado a partir do modelo cinemático, e foi base de uma simulação desenvolvida em Simulink. Esta simulação foi calibrada a partir de evidências experimentais. A simulação foi comparada ao modelo de veículo de acionamento diferencial, comprovando que o modelo cinemático experimental melhor representa o sistema utilizado.

A partir do modelo dinâmico, foi equacionado o filtro de Kalman para a localização do veículo utilizando os sensores inerciais e odometria. Foi testado o funcionamento do filtro de Kalman na simulação, onde foi possível verificar que o filtro ofereceu melhores resultados de localização do que seria obtido utilizando os sensores do veículo separadamente, validando assim o uso da fusão de sensores.

Os sensores foram devidamente calibrados e suas variâncias medidas, permitindo o uso destas no filtro do Kalman. As medições dos sensores inerciais demonstraram grandes perturbações devido à vibração. O problema foi contornado pelo uso de um sistema de atenuação da vibração e o uso de um filtro de banda, diminuindo a variância dos erros de medição de $0,3497 \frac{\mathrm{m}^{2}}{\mathrm{~s}^{4}}$ para $0,0019 \frac{\mathrm{m}^{2}}{\mathrm{~s}^{4}}$. A atenuação da vibração foi imprescindível para permitir a utilização da IMU, possibilitando assim o uso do sistema proposto.

Finalmente, experimentos foram realizados para analisar o funcionamento do sistema proposto na prática. O primeiro conjunto de testes apresentados foram movimentos retilíneos com o objetivo de analisar o sistema de localização em condições de pouco deslizamento. No segundo conjunto de testes, o veículo se locomoveu de uma posição conhecida a outra, realizando diversas curvas ao longo 
do caminho; neste caso, existe influência significativa de deslizamento no funcionamento do veículo. Este teste permitiu analisar a qualidade da localização em condições de movimento geral.

Os resultados obtidos a partir do uso do filtro de Kalman foram comparados com a simulação desenvolvida e localização realizada apenas pelos encoders. Em todos os casos estudados o sistema proposto se demonstrou mais preciso que as alternativas investigadas. Para justificar a ausência do magnetômetro no sistema de localização, foram realizados testes de manobra utilizando-o. Estes testes demonstraram que, devido ao campo magnético das rodas, o sistema de bússola magnética tem um efeito negativo no funcionamento do filtro, apesar das suas calibrações realizadas. Os erros médios na distância $(1,2088 \mathrm{~m})$ e médio quadrático na orientação $\left(0,8919 \mathrm{rad}^{2}\right)$ com o uso do magnetômetro foram consideravelmente maiores que os obtidos pelo sistema proposto $\left(0,4257 \mathrm{~m} \mathrm{e} 0,1101 \mathrm{rad}^{2}\right)$, justificando assim não utilizar o magnetômetro.

\subsection{Trabalhos Futuros}

As principais contribuições deste trabalho foram o equacionamento, simulação e teste de um sistema de localização baseado no filtro de Kalman para a fusão de sensores inerciais (acelerômetro e girômetro), e odometria, para robôs de inspeção de quatro rodas magnéticas fixas. Este sistema proposto não usa dados de magnetômetros (muito ruidosos nesses sistemas), mas em compensação incorpora um modelo para considerar eventuais deslizamentos nas estimativas de posição e orientação.

Esta dissertação pode ser utilizada como base de trabalhos futuros. A possibilidade mais direta envolve repetir os testes experimentais realizados neste trabalho utilizando sistemas de medição de posição absoluta (e.g. motion tracking). Com a informação da posição ao longo da trajetória, e não apenas da posição inicial e final medidas diretamente no ambiente, é possível uma avaliação mais rigorosa do sistema proposto.

Parte característica do funcionamento do robô RITA, e da maioria dos robôs de inspeção de tanques de armazenamento, é o uso de rodas magnéticas. Estudar as interações entre o veículo e o solo nestas condições é muito importante para o 
projeto de um sistema de localização que possa ser utilizado no campo, melhorando os modelos de deslizamento ao considerar este magnetismo.

Devido à natureza do filtro de Kalman, é possível realizar a fusão de um grande número de sensores em um mesmo sistema. O estudo sobre a implementação de outros sensores no veículo, assim como sua integração com o sistema desenvolvido, pode ser útil para melhorar a precisão do sistema. Foco especial pode ser dado à possibilidade de uso de sensores capazes de realizar medições absolutas de posição, o que contribuiria para diminuição de efeitos de drift comuns em cálculos integrais. Cabe notar que no robô utilizado não seria possível a fusão com sensores GPS, uma vez que esse sinal não está disponível no interior de tanques de armazenamento metálicos, em especial no caso do robô submerso em combustível. 


\section{Referências Bibliográficas}

Garcia, M. S. Análise de defeitos em sistemas mecânicos rotativos a partir da monitoração de vibrações. Rio de Janeiro, 2005. 119p. Dissertação de Mestrado - Engenharia Mecânica, Universidade Federal do Rio de Janeiro (UFRJ).

Grewal, M. S.; Andrews, A. P. Kalman filtering: theory and practice using MATLAB, 2 2a Edição, John Wiley \& Sons, 2001.

Hartsell, D. R, Putting the maverick fuel-tank inspection robot to the test, IEEE Robotics \& Automation Magazine, vol. 6, no.3, Feb. pp. 54-64, 1999.

Jaulin, L. Mobile Robotics. 1st. ed. Londres: Elsevier, 2015

Junior, S. L. S. Aplicação de filtro de Kalman para filtragem de sinais da rede elétrica. Londrina, 2016. 75p. Trabalho de conclusão de curso - Engenharia Elétrica. Universidade Estadual de Londrina.

Kalman R. E. A New Approach to Linear Filtering and Prediction Problems. Transactions of the ASME - Journal of Basic Engineering, 82 (Series D): 3545,1960 .

KIozlowsk, K., Pazderski, D. Modeling and control of a 4-wheel skid-steering mobile robot. International Journal of Applied Mathematics and Computer Science. Vol. 14, No. 4, 477-496, 2004.

Kluga, J., Kluga, A., Vecvagars, V. Magnetometer Error Models of Low-Cost Land Vehicle Navigation System. Elektronika ir Elektrotechnika, ISSN13921215, VOL.22, NO.6, 2016

Kubelka, V., Oswald, L., Pormeleau, F. , Colas, F., Svoboda, T., Reinstein, M. Robust Data Fusion of Multimodal Sensory Information for Mobile Robots. Journal of Field Robotics 32(4), pp.447-473, 2015.

Malagon-Soldara, S. M., Toledano-Ayala, M. , Soto-Zarazua, G., Roberto V. Carrillo-Serrano, Edgar A. Rivas-Araiza. Mobile Robot Localization: A Review of Probabilistic Map-Based Techniques. International Journal of Robotics and Automation, Vol. 4, No. 1, pp. 73 81, 2015.

Mandow, A., Martínez, J. L., Morales, J., Blanco, J. L. Experimental kinematics for wheeled skid-steer mobile robots. In Proceedings of the International Conference on Intelligent Robots and Systems, pp. 1222-1227, 2007. 
Martínez, J. L., Mandow, A., Morales, J., Pedraza, S., García-Cerezo, A. Approximating Kinematics for Tracked Mobile Robots. The International Journal of Robotics Research Vol. 24, No. 10, pp. 867-878, 2005.

Negenborn, R. Robot Localization and Kalman Filters: On finding your position in a noisy world. Copenhaga, 2003. 157p. Dissertação de mestrado em ciência, Utrecht University

Paranhos, P. M., Localização em Ambientes Externos através da Fusão de Sensores GPS e Inercial por um Filtro de Kalman. Rio de Janeiro, 2009. 179p. - Departamento de Engenharia Mecânica, Dissertação de Mestrado, Pontifícia Universidade Católica do Rio de Janeiro.

Panta, P. E. G., Monitoramento de robô de inspeção interna de oleodutos GIRINO. Rio de Janeiro, 2005. 111 p. - Departamento de engenharia Mecânica, Dissertação de mestrado, Universidade Federal do Rio de Janeiro (UFRJ).

Sato A. K., Projeto de um tanque de armazenamento atmosférico com teto flutuante para estocagem de gasolina. Guaratinguetá, 2015. 69p. - Departamento de Engenharia Mecânica Trabalha de conclusão de curso, Universidade Estadual Paulista Júlio de Mesquita Filho.

Schempf H., Chemel B, Everett N. Neptune: Above-Ground Storage Tank Inspection Robot System. IEEE Robotics \& Automation, Society Magazine, Issue: June 1995

Shamah, B., Experimental Comparison of Skid Steering Vs. Explicit Steering for a Wheeled Mobile Robot. Pittsburgh, 1999. 66p. - Dissertação de Mestrado em ciência, Universidade Carnegie Mellon.

Shukla A., Karki H. Application of Robotics in onshore oil and gas industry - A review Part I. Robotics and Autonomous Systems 75 490-507, 2016.

Sogi, T., Kawaguchi, Y., Morisaki, H., Ohkawa, K., Kai, N., Hayakawa H. INSPECTION ROBOT FOR SPHERICAL STORAGE TANKS. 26th International Conference on Industrial Electronics Control and Instrumentation (IECON'2000), Nagoya, Japan, pp. 393-398, 2000

Thrun, S., Burgard, W., Fox, D. Probabilistic Robotics. Cambridge, The MIT Press 2005, 646, pp.

Wang, T., Wu, Y., Liang, J., Han, C., Chen, J., Zhao, Q. (2015). Analysis and Experimental Kinematics of a Skid-Steering Wheeled Robot Based on a Laser Scanner Sensor. Sensors, vol 15, no. 5, pp. 9681-9702, 2015.

Welch, G., Bishop, G. (2006). An Introduction to the Kalman Filter. Department of Computer Science, University of North Carolina, UNC-Chapel Hill, TR 95-04, 2006. 
Won, D., Ahn, J., Sung, S., Heo, M., Im, S., Lee, Y. J., Performance Improvement of Inertial Navigation System by Using Magnetometer with Vehicle Dynamic Constraints. Journal of Sensors, Volume 2015, 11 pp. 2015.

Wong, J. Y. Theory of ground vehicles. New York, John Wiley \& Sons, INC, $3^{\text {a }}$ edição, 2001.

Xavier J. E. S. C. Aplicação do Filtro de Kalman na correção de dados provenientes de um sistema de Localização baseado em RFID. Porto, 2011. 83p. - Engenharia Electrotécnica e de Computadores, Dissertação de mestrado, Faculdade de Engenharia da Universidade do Porto.

Yi, J., Zhang, J., Song, D., Jayasuriya, S. IMU-based localization and slip estimation for skid-steered mobile robots. IEEE/RSJ International Conference on Intelligent Robots and Systems, IEEE, São Diego, CA, pp. 2845-2850, 2007.

Yu, W., Chuy Jr, O., Colins Jr., E. G., Hollis, P. Dynamic Modeling of a SkidSteered Wheeled Vehicle with Experimental Verification. The 2009 IEEE/RSJ International Conference on Intelligent Robots and Systems, pp. 4212-4219, 2009. 